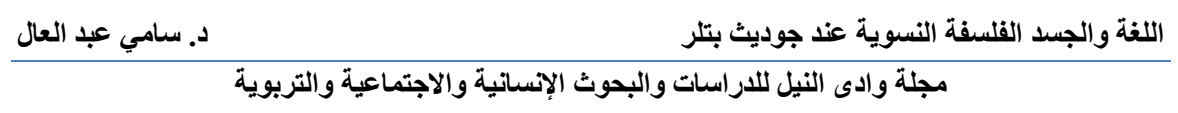

\title{
اللغة والبسد
}

\section{الفلسفة النسوية عند جوديث بتلر}

\section{د. داهي عبد المعال}

أستاذ مساعد- قسم الفلسفة- كلية الآداب- جامعة الزقازيق

ليست العلاقة بين اللغة والجسد مجرد إحالةٍ، لأنَّ واو العطف بين الكلمتين تعني

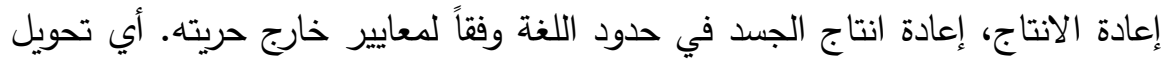

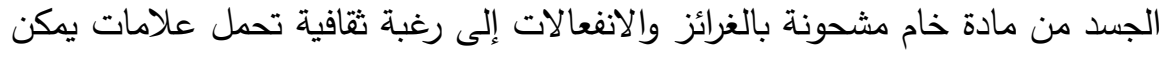

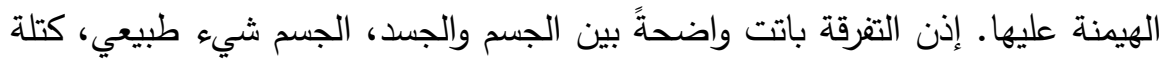

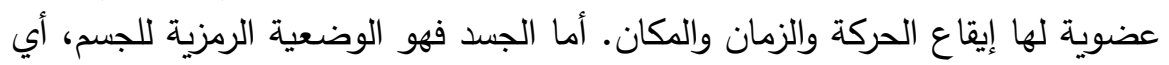

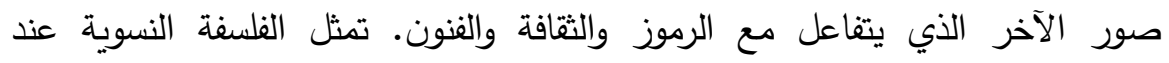
الفيلسوفة الأمريكية العاصرة جوديث بتلر تفكيراً حراً في خطورة الجسد الأنثوي داخل

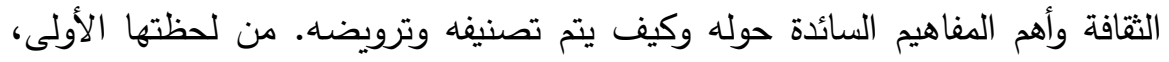

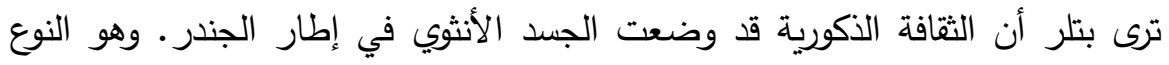

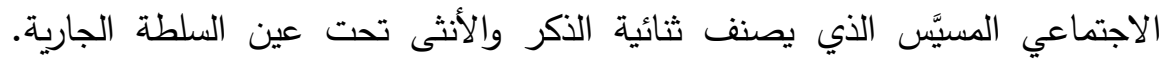

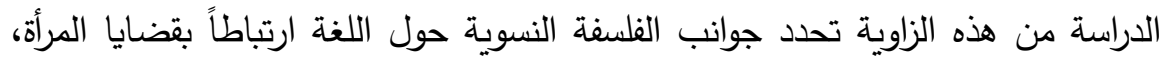

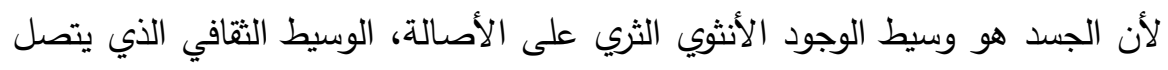

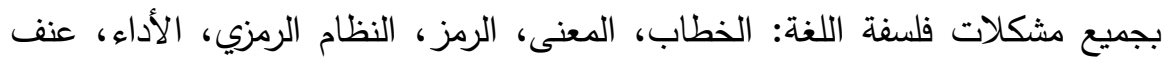

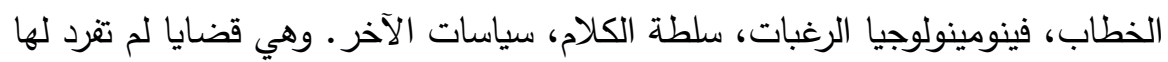

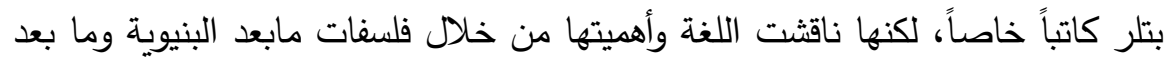

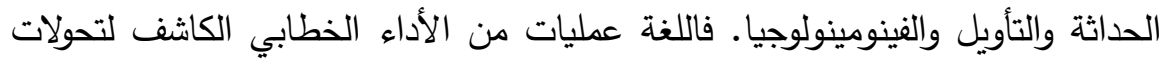

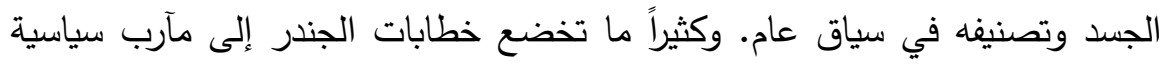

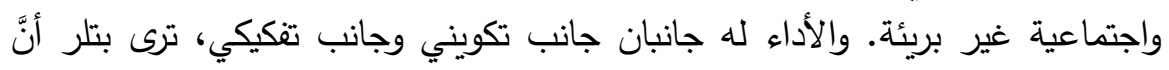

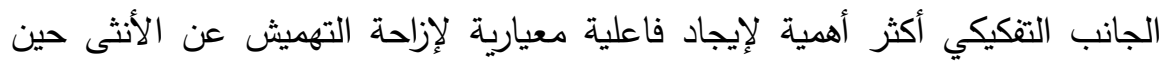

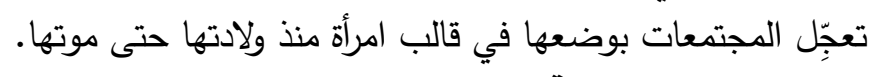

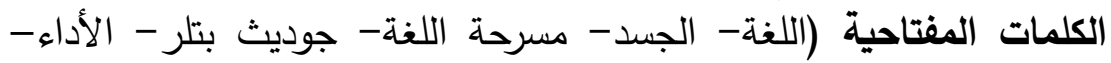

الجندر - الفاعلية المعيارية). (لماتية 


\title{
مجلة وادي النيل للاراسات والبحوث الإنسانية والاجتماعية ـ مجلة علمية محكمة
}

(ISSN: 2536 - 9555)

The Language and the Body: The feminist philosophy of Judith Butler

\begin{abstract}
:
The relationship between language and the body is not a mere reference, because the relationship between the two words means reproduction, the reproduction of the body within the limits of language according to criteria outside of its freedom. In other words, the transformation of the body from a raw material charged with instincts and emotions into a cultural desire that carries signs that can be dominated. So the distinction has become clear between the corpus and the body, the corpus is a natural thing, an organic mass that has a rhythm of movement, time and space. As for the body, it is the symbolic position of the body, that is, the images of the other that interact with symbols, culture and the arts. Feminist philosophy of the contemporary American philosopher Judith Butler represents a free reflection on the danger of the female body within culture and the most important concepts prevailing around it and how it is classified and tamed. From her first moment, Butler sees the male culture as framing the female body in terms of gender. It is the politicized gender that classifies the duality of male and female under the eye of the current power. From this angle, the study seeks to analyze aspects of feminist philosophy about language in connection with the essence of women's issues, because the body is the mediator of the rich feminine existence on originality, the cultural mediator that relates to all the problems of language philosophy: discourse, meaning, symbol, symbolic system, performance, violence of discourse, Phenomenology Desires, power of speech, politics of others. These issues were not singled out by Butler as a private writer, but she discussed language and its importance through philosophies of poststructuralism, postmodernism, hermeneutics, and phenomenology. Language is a process of discursive performance revealing the transformations of the body and its classification in the general context. Consequently, gender discourses are often subjected to innocent political and social goals. And performance has two aspects: a formative aspect and a deconstructive aspect. Butler believes that the deconstructive aspect is more important to create a normative effect to displace the marginalization of the female, who societies hasten to place in the form of a woman from birth until her death.
\end{abstract}

Key word (language- body- theorization of language- Judith Butler- performance- gender- normative agency).

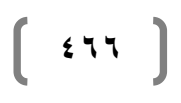




\section{تقديم}

الجسد علاقة انطولوجية حميمة بالعالم، أو العكس هو حضور خاص لماهية الحياة داخلنا. هذا الحضور المُعبر عن كيان الإنسان بمله الكلمة، لأنَّه بمثابة

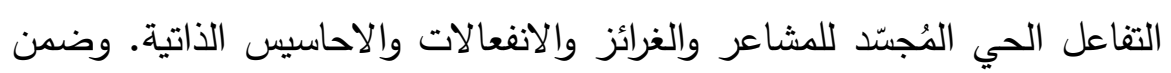

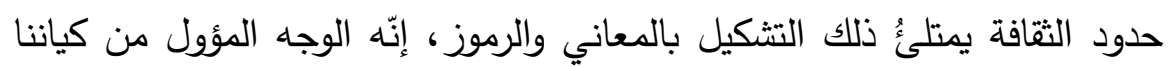

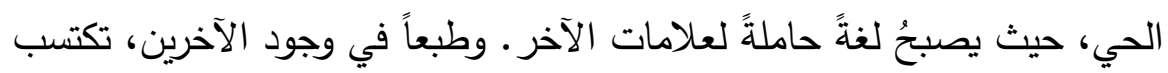

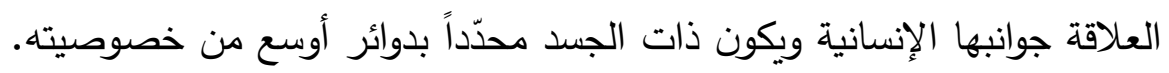

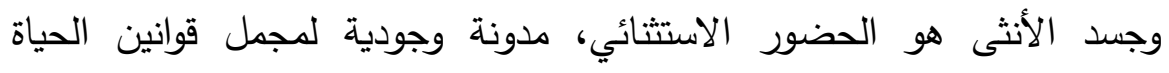

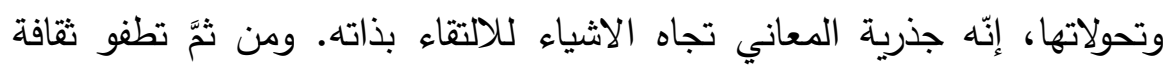

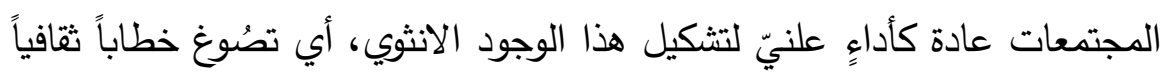
يضع الانثى في فضاءٍ لغوي مؤولِّا تكوين الواقع وممارساته.

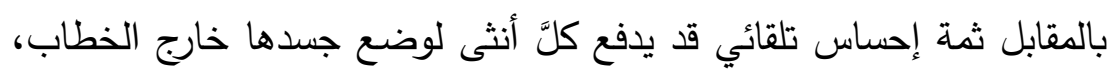

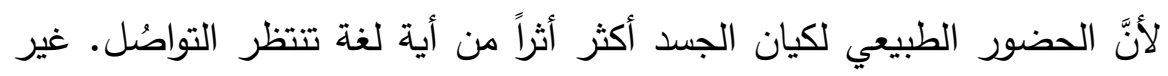

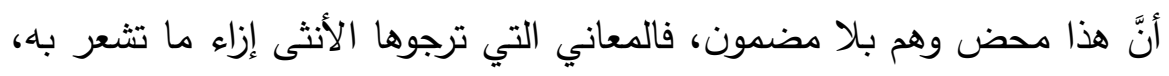

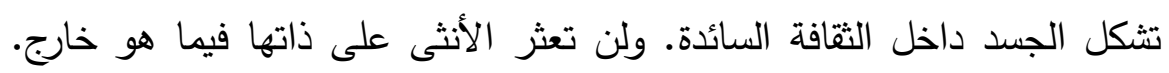

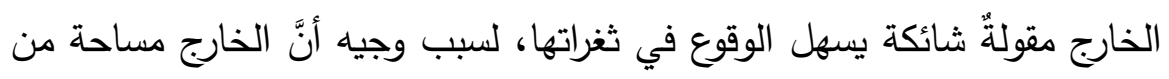

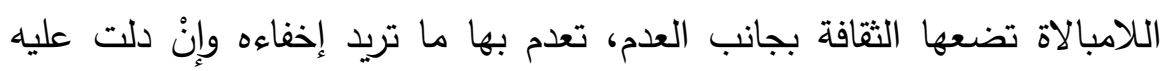

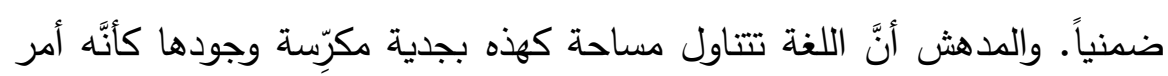

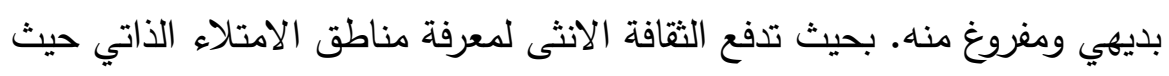
تشعر بكيانها العام. دوماً تُوجد- في جميع الثقافات- ممارسة منجزة سلفاً لدخول الأنثى ثنائية

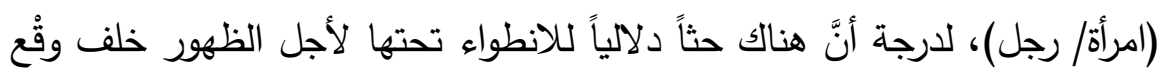

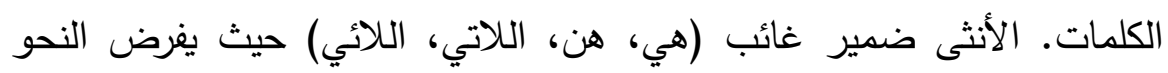


والجندر استعمال اللغة. والجسد ليس موازياً لمادته الأولى ولن يكون وإلاًّ لوقفت

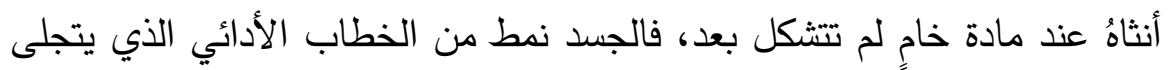

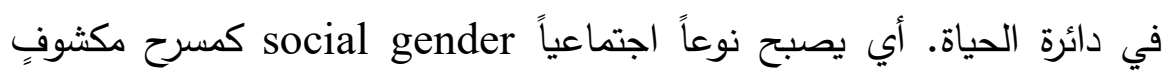
للآخرين، يُؤدي دلالات الاجساد مكسوّة بما تمارس المجتمعات.

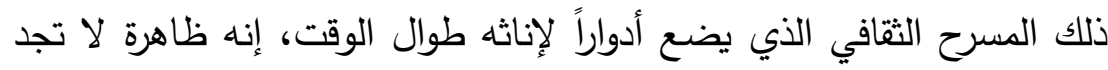

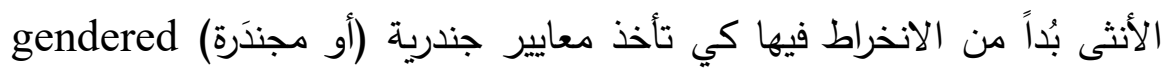
Norms

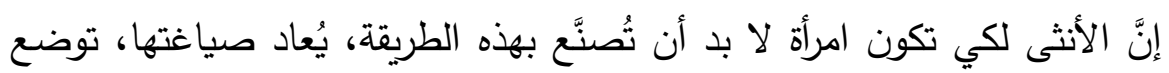

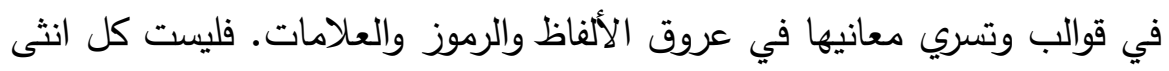

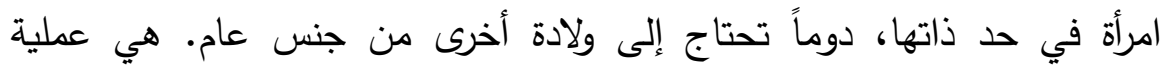
استنساخ Cloning process كما تقول الفيلسوفة الأمريكية المعاصرة جوديث داديث بتلر Judith Butler صاحبة الاسهامات الأبرز في"الفلسفة النسوية" والتي ستُقرد لها الدراسة مجالاً لمعرفة تلك الجوانب الخاصة بالجسد الأنثوي، مع تحليل أفكارها

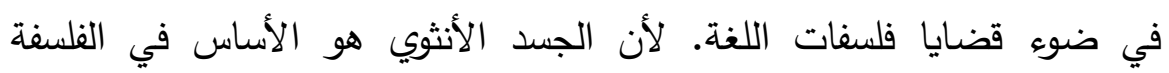
النسوية وهو الحامل للجندر كما أنه خطاب تأويلي قابل للقراءة. وفي هذا الإطار، ثمة نقاط مفصلية ترتبط فلسفياً بنقاط أخرى تخص اللغلة:

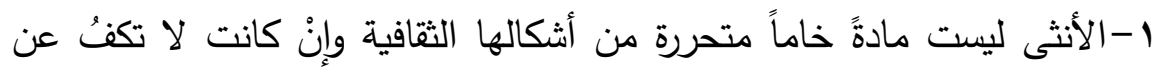
التطلع إلى ذلك. - مالك. r-مواقع الأنثى مرسومة من قَبْل كامرأةً في حركة الكلمات والخطابات. ب- السلطة المعيارية للجندر تعطي الأنثى هويتها الرمزية بحجم الثقافة فئة الجارية.

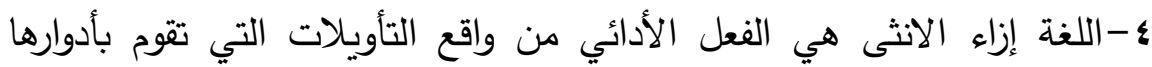
خطابياً. 


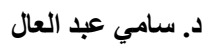
اللغة والجسد الفلسفة النسوية عند جوديث بتلر مجلة وادى النيل للاراسات والبحوث الإنسانية والاجتماعية و التربوية

ه-ثمة عنف قابع في عمليات التعبير عن المرأة، عنف قد تقبله الأنثى كأنَّه "الطبيعة الطابعة" natura naturans بلغة سبينوزا.

צ-الجسد الأنثوي محط استعارات وعلامات يفترضها نظام اللغة، ولا يتوانى natura "الواقع الاجتماعي عن إعادة خلقه، هذه "الطبيعة المطبوعة naturata V-معاني الجسد بالنسبة للمرأة هو كيان الأنثى القابع فيها ويحدد آفاق وجودها بالنسبة للآخرين.

حينئذ، ماذا يكمُن في اللغة من إمكانيات لتحليل جوانبها فلسفياً؟ - اللغة أداء، أي فعل انكثاف وتجلٍ وعرض يُمسرِح المعاني والمدلولات. - اللغة جسد استعاري بديل يُحوّل الأنثى إلى امرأةٍ عبر مفهوم النساء. - اللغة قوة تترك آثارها وبصماتها على الموضوعات، وتتورط مع القوى المهيمنة على أنظمة المجتمعات الإنسانية. - اللغة علامات تتقش سلطةً معياريةً تمارس دورها في خفاءٍ، حتى فيما لم يعلنه الفاعلون صراحةً طوال الوقت. - اللغة تكوِّن صوراً فكرية وسميائية كتفاعلات على مسارح الخطاب الاجتماعي- الثقافي.

- اللغة إغواء قابل للاتساع نحن دوماً داخل حدوده. ويصعب السيطرة عليه (رغبات الكلام والتكرار والتتميط والمُودات الخطابية والأساليب المختلفة

$$
\text { والعبارات والمقولات غير المألوفة). }
$$

- اللغة تجعل فضاء الثقافة سياق معانٍ (رأسياً وأفقياً) لا مجرد وصف أو تعبير • - اللغة تتفلت بكل تلك المعالم من المركزية (الجانب العكسي)، وتتقض أسسن الخطابات وتعري أيديولوجيتها. 
ولربط النقاط البينية inter points بين اللغة والجسد، سأطرح منهجياً فكرة

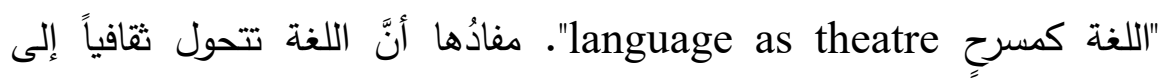
"مسرح مفتوح" يحوي كافة الخطابات التي تؤدي المعاني. والفكرة بالصياغة اللغوية

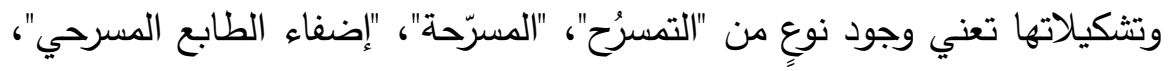

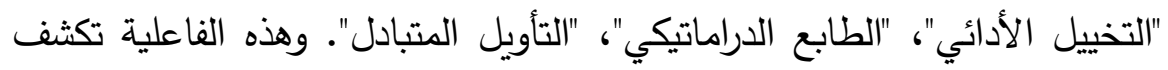
عمل اللغة إزاء صور الجسد كما يلي:

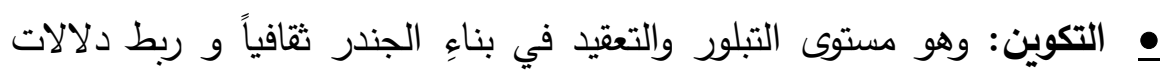

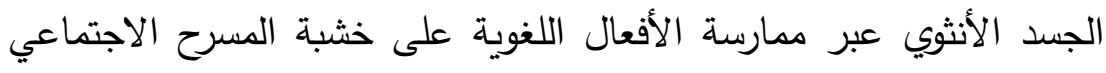
.social stage • الوظيفة: حيث تتوزع الدلالات والمعاني الناتجة عن التمييز الجنسي في اتجاهات مقَرَرة جندرياً، وتحدد لها مكانة بحسب التكوين السابق.

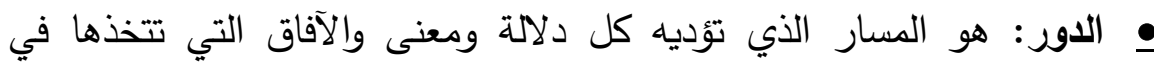
عمليات الانجاز لمبررات الجندر وأهمية وجود سلطته داخل كل ثثافة.

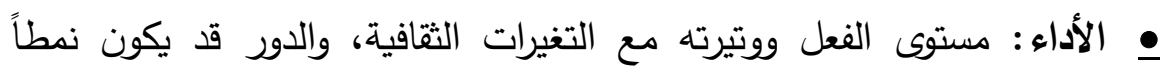
معيّاً نتيجة ارتباط الدور والوظيفة بناء على تكوين المعاني.

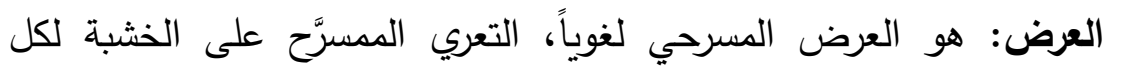

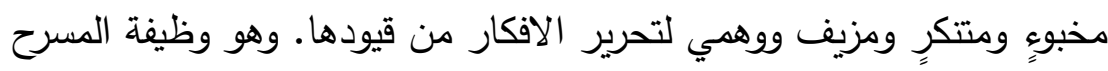

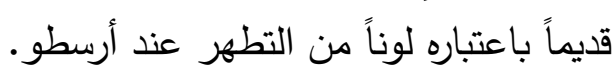

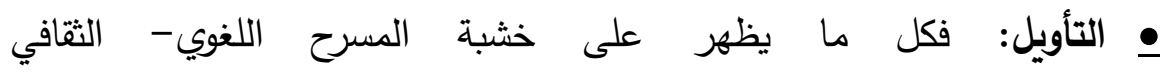
مؤول interpreted، صور مؤولة أمام صور تأولية تتواتر في الأفق العام. فالجسد صورة مؤولة والجندر أسلوب ومفاهيم مؤولة بالمثل.

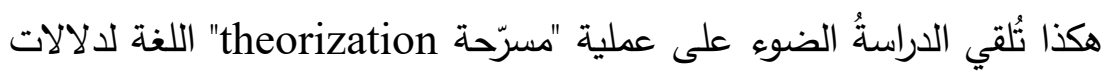
الأنوثة والأفكار النسوية إزاء الجسد والجندر والمعاني المتداولة حولهما، فاللغة

$$
\text { ( } \mathrm{k} \cdot \text {. })
$$


تُخرج المسرحيّات، تمسرّح theorize المعاني في إطار الخطابات على خلفية

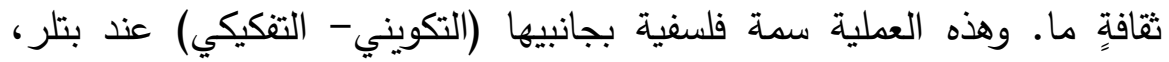
وتطرح مفاهيم مدهثة حول اللغة والجسد، لدرجة أنَّ طرائق عرضها لقضايا النسوية تعد قراءةَ تساؤل وتحرير للممارسات والتاريخ الثقافي القامع للمرأة. إنَّ

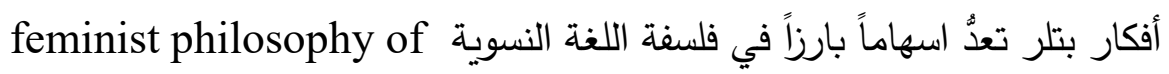
language المعتمدة على اسئلة اللغة حول الأنثى كخطاب وتحليل للعنف الرمزي وتصنيفات الجندر وسياسات الخطاب النسوي كياناً وإبداعاً وتتوعاً داخل

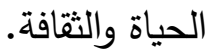

\section{تحديد مشكلة}

بين اللغة والجسد الأنثوي، يقف الجندر حائلاً دون التقائهما. الحيلولة تأتي بكلّ التاريخ الذي يراكم معاني الأنثى، وتستحضر مجتمعاً بكامل مكوناته الثقافية وترسم الواقع المتثكل من ثنائية الذكر والأنثى. فالجسد عنوان للقول بالكيان

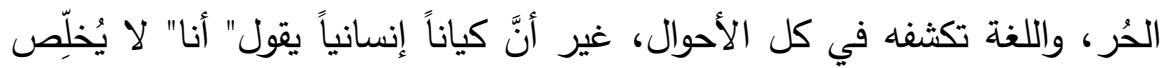
ذاته مما يشكله. وبالتالي فليس الجندر غير آلةٍ من المعايير التي تقرر: كيف التهائ يكون الجسد، وما هي رمزيته، وإيلام سيؤول عبر أنساق الثقافية؟! بالمقابل تبدو

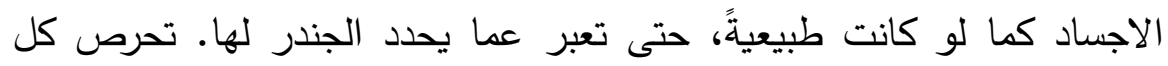

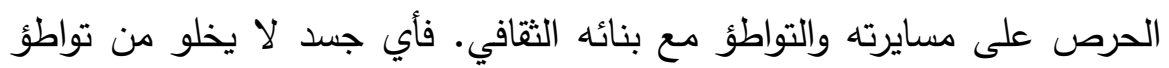

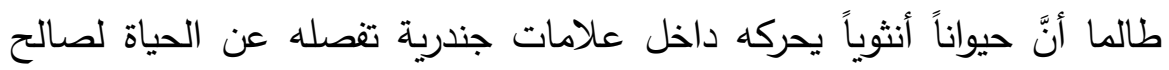
الواقع التاريخي الذي يصوره.

ومن ثَّ، يرتبط الخطاب الاجتماعي بهيكل السلطة الذكورية، ويعيد انتاجها

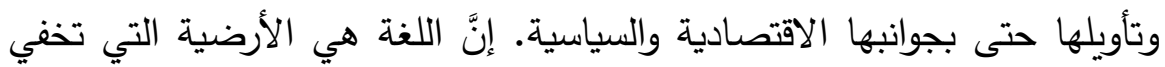

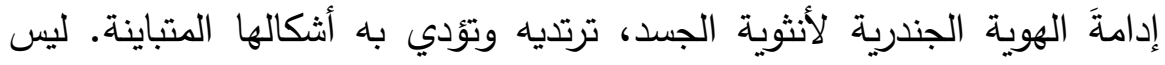

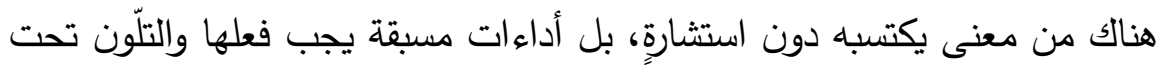


مرجعيتها. ذلك أنَّ الجندر مبنيّ خطابياً discursively على نحو أدائي performatively.

مشكلة التكوين الجندري أنَّه يحكم علاقات الأفراد وتصوراتهم، هو ليس مجرد معطى مباشر يخطف انتباهنا، لكننا نعي به صورة العالم دون السيطرة عليه،

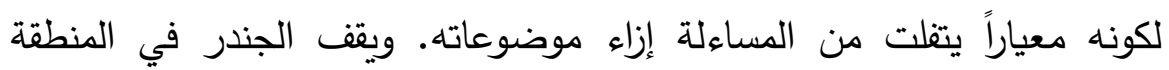

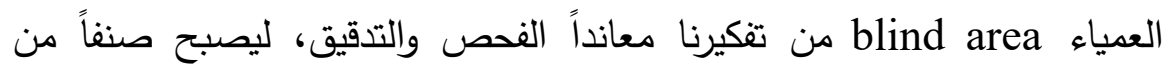
الإيمان القابل للتكرار. وترى بتلر أنَّ المشكلة فلسفياً في كون الهوية الجندرية performative accomplishment انجازاً أدائياً عقوبات وتابوهات اجتماعية Social sanction and taboo، وأنَّ إمكانية تنكيك

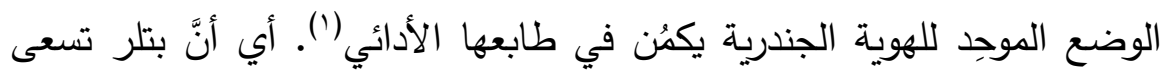

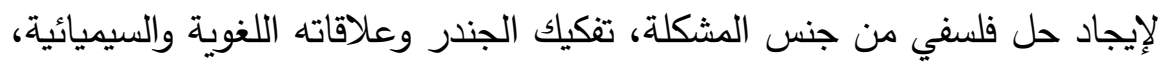
لا بقفزة من الخارج كنوعٍ من معاندة التماسك بتماسك آخر ، كأننا أمام آليتين

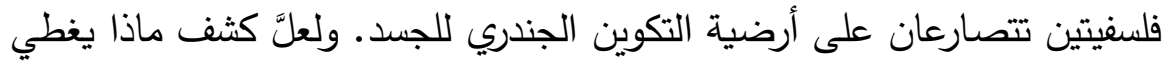

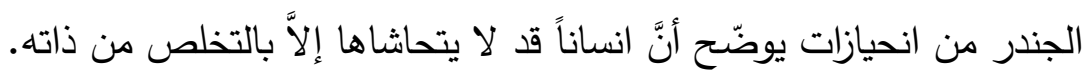

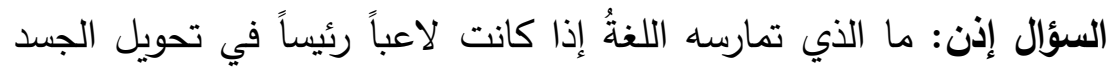

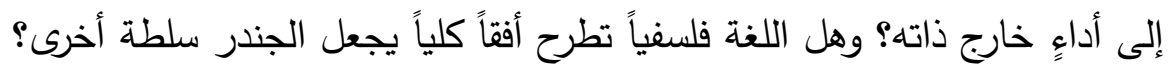

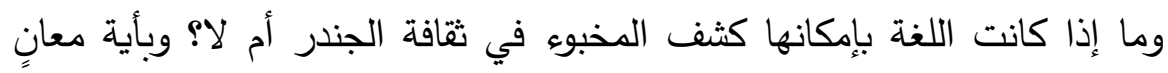
تترك اللغة بصمات على مسرح الجسد؟ يبدو أنَّ القواعد النحوية للغة (أنثى، مذكر - نوع) هي لحظة تماهِ مع حياتنا ولا نراها، النحو بمثابة نحو الثقافة grammar of culture- كما سنطرح-

(1) - Judith Butler, Performative Acts and Gender Constitution: An Essay in Phenomenology and Feminist Theory, Theatre Journal, Volume, 40, Number 4 (December, 1988), The Johns Hopkins University Press, 1988, P 520.

$$
\text { ( } v^{*} \text { ) }
$$


يستعمل ذواتتا قبل أنْ نستعمله، يحدد طريقة النطق الفكري واللغوي معاً وما يترتب

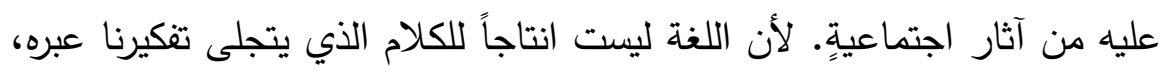

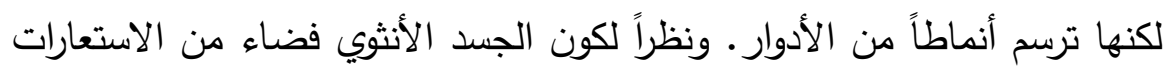
والعلامات، فاللغة تجده مادة لتمثيل الأدوار التي يكتبها الجندر وسلطته. ولاسيما

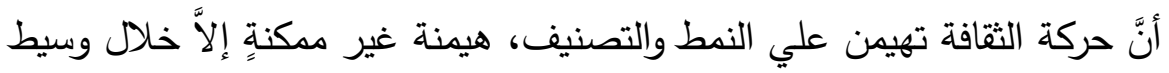
يعطيها حضوراً متنوعاً.

الفكرة العصية على التحديد أنَّ قواعد النحو في اللغة نأخذها بعين الاعتبار

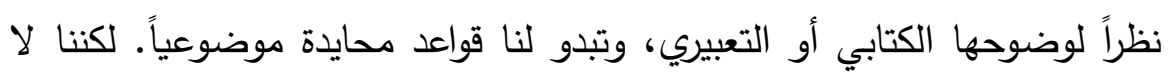

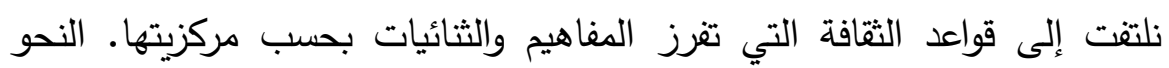
(إثارة) والثقافة (عبارة) هكذا بهذا التكوين المتبادل، وبفضل أن العبارة لها قواعد،

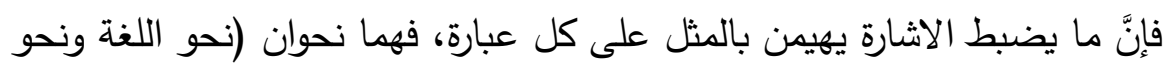
الثقافة) متزامنان. ويبدو هذا جلياً خلال تداول الخطاب، وهو ما يجعل مشكلة الفلسفات النسوية كالتمييز الجنسي والجسد والأنوثة ومكانة المرأة مشكلة لغوية النائ

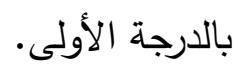

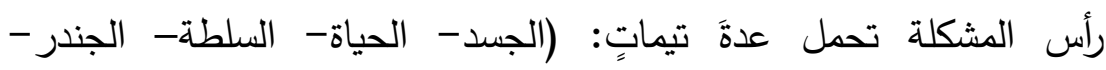
العلامة- اللغة)، فالجندر أداء لغوي يحدد طبيعة الجسد ويقبض على لهئ زمام حياته

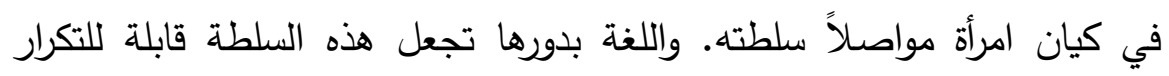
مراراً، وبأسلوب يكاد يكون خارج التحكم من قبل المنخرطين فيها، أي يكررون

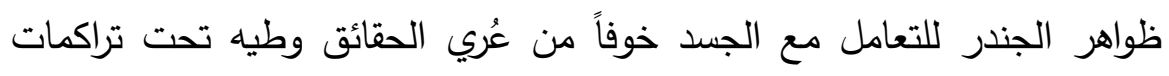
سلطةٍ مهيمنة على الثنائيات. فلا يكون الجسد الأنثوي حراً، لكونه ينحاز سلفاً

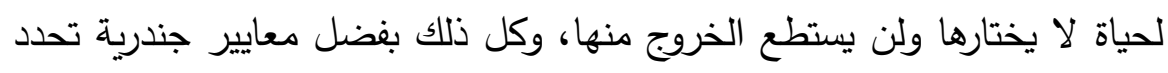

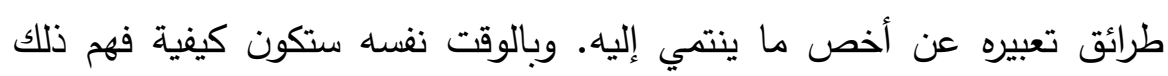

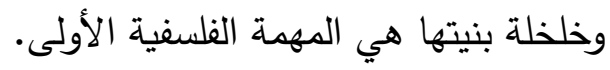




\section{الأنثى في اللغةة}

إذا كانت الأنثى تظنُ أنها تتنمي إلى ذاتها خالصة من التصنيف الجندري،

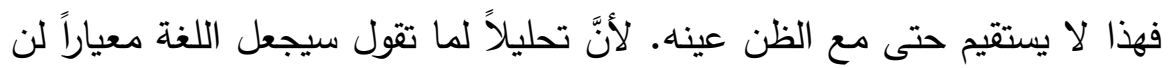
يتوقف عن الحضور . فاللغة تغطى الجسد بأردية جندرية تختارها بكامل توجهاتها

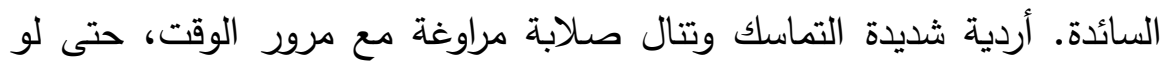

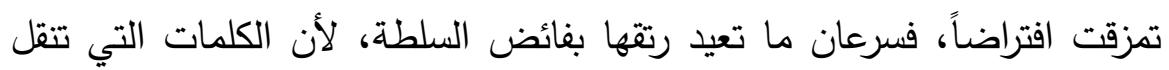

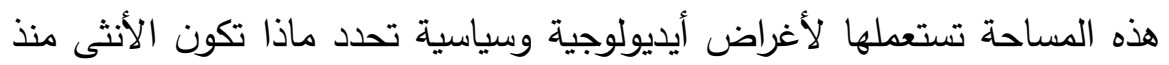
دلالتها لغوياً.

في المعجم الغربي للكلمات المستعملة، "تعني كلمة female الأنثى، وهي موازية في المعنى لكلمة امرأة Woman بالوقت نفسه، ورغم مرورها بتغيرات كثيرة

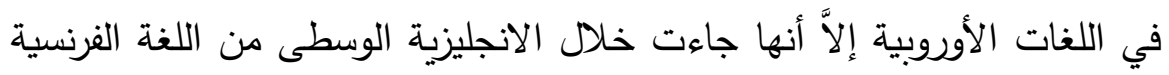
femelle

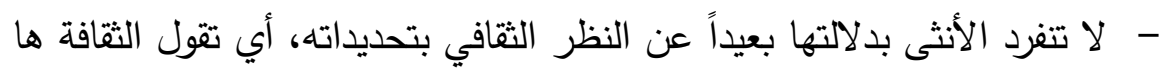

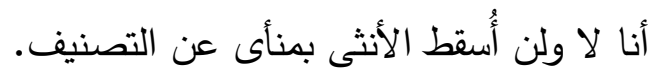

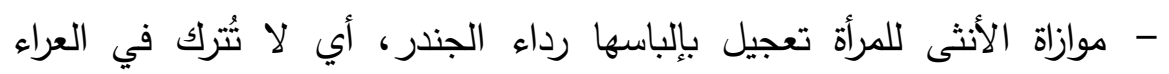
الجسدي ولا الطبيعي.

- ربط الأنثى بامرأة حتى في انجليزية العصور الوسطى يعدُ لوناً من التسوية بين الجندر وبين أي اعلان جسدي عن انثوية خارج الإطار .

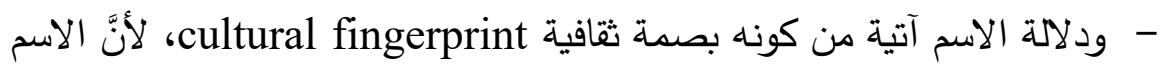
(كما تاريخ الفكر الغربي) لوغوس المعنى وقانون ثقافي كما يقول جاك لاكان

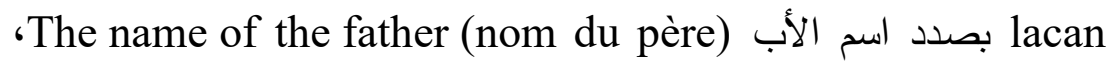

(2) - Webster's dictionary of English usage, by Merriam-Webster Inc, Publishers Springfield, Massachusetts, 1989, P439.

$$
(\leq v \leq)
$$




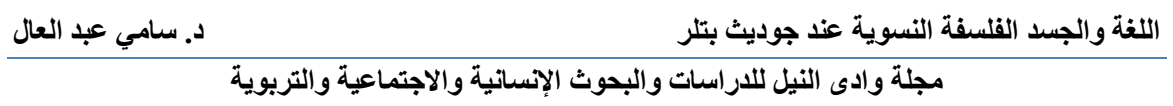

نظراً لارتباطه بالنظام الرمزي الذي يحكم الخطاب ويضفي المعاني على

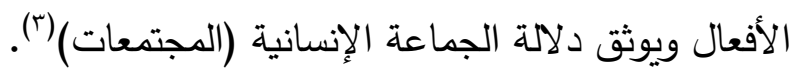

- ويمتد الاسم عميقاً في سياسات الجندر وممارسات المواطنة والعناصر المكوِنة للنزعة الأبوية في شكل السلطة الذكورية(؟).

وهذا يكثف مركزية معاني الخطابات السائدة إزاء المرأة كإحالةٍ دائمةٍ إلى وجودها التاريخي، ذلك الحال يجري بالمعنى المُنحاز جندرياً من الأساس.

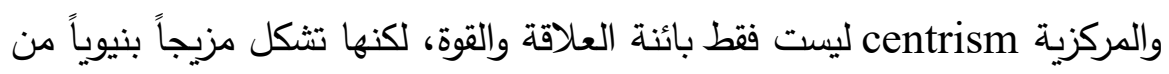

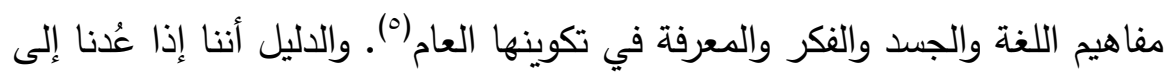
الخطاب الجندري في اللغة التي أتت بكلمة الأنثى إلى الانجليزية، سنجد الفرنسية التي أمدتها بذلك تقول إنَّ: "كلمة femelle مصطلح يثير إلى كائن حي أو عضو ينتج البويضات في سياق التكاثر الجنسي المتباين، وتطلق على الكائن البشري من اللاتينية femella امرأة صغيرة petite femme، امرأة شابه ونياقين femme، وتطلق على أنثي الحيوانات التي تتتج الأمشاج التكميلية للتناسل، وبالتالي يُسمى الحيوان الآخر الذي ينتج الحيوانات المنوية بالذكر "(؟). توثق اللغة مكانة الأنوثة في مملكة الحيوانات المتناسلة، فالأنثى هي التي تتتج البويضات بخلاف الذكور • وليس ذلك مصادفة، لكنه أمر يتقرر بالطبيعة

(3) - Jacques Lacan, The Psychoses 1955-1956) The Seminar of Jacques Lacan 3, Translated by Russell Grigg, Norton, New York,1993, P 96.

(4)- Paula Paron, In the Name of the Father: The Paternal Function, Sexuality, Law and Citizenship, Article in Victoria University of Wellington Law Review, July 2006, PP 307- 334.

(5) - Jacques Derrida, "Structure, Sign, and Play in the Discourse of the Human Sciences", In: Writing and Difference, Translated by Alan Bass, Routledge, London, New York, 2003, PP 278 -290.

(6) - Read word "femelle" on Wikipedia, On this link:

https://fr.m.wikipedia.org/wiki/Femelle

$$
(\leqslant \vee \bullet)
$$


التي لا حلَّ لنا منها. هكذا تمتدُ الدلالة المجندرة إلى مرجعية طبيعيةٍ يستحيل

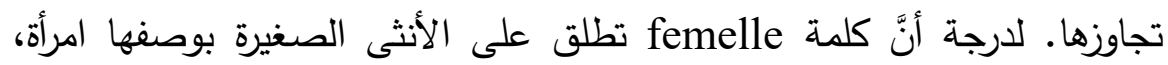

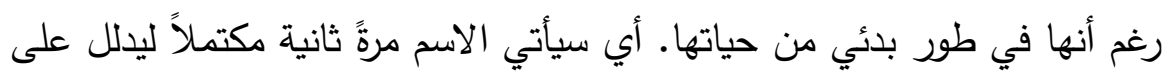

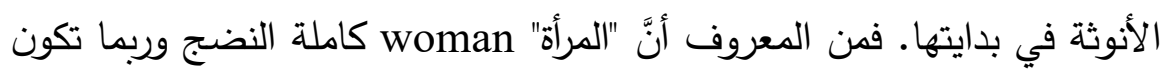

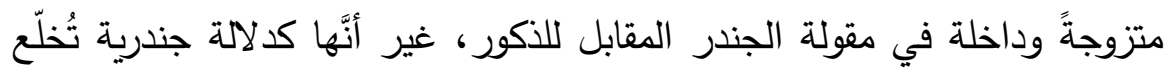
على الأنثى الثابة. وبالتالي سيكون المعجم معجماً ثقافياً، وستكون اللغة أداءً الجناء

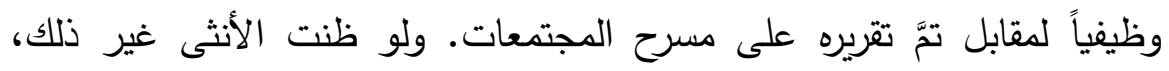

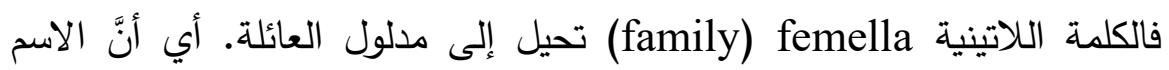

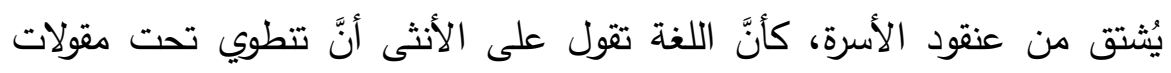

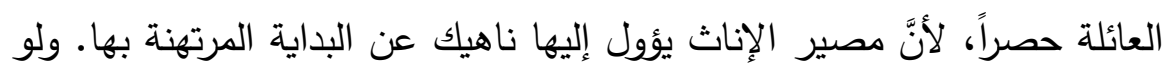
لم تكن هناك قناعة بالأصل، فالتاريخ سيثبت لك. لك.

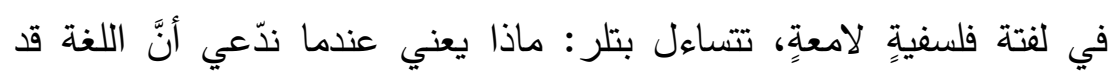

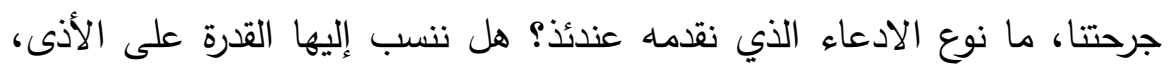

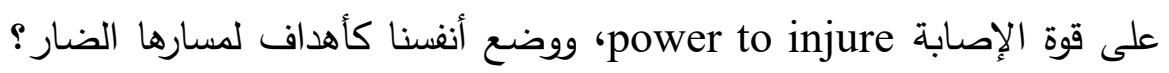

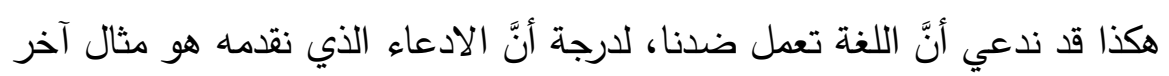

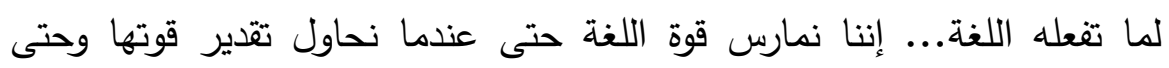

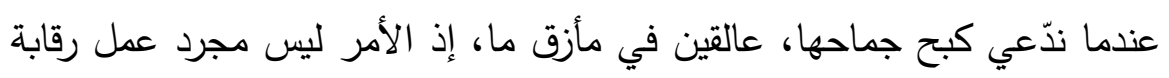

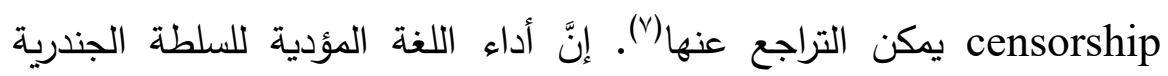
تصيب الأنثى، كأنَّا سكين يقطع أوردة الحياة التي تربط جسدها بحريته وتلقائيته لصالح ثقافة التصنيف.

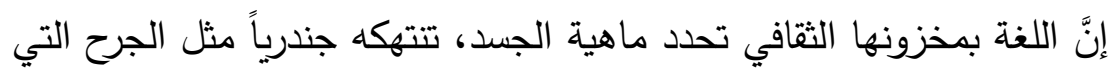

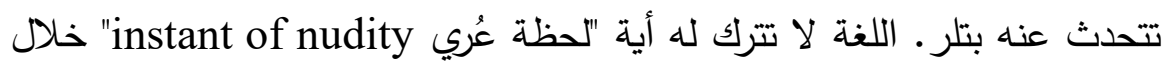

(7)- Judith Butler, Excitable Speech, A Politics of the Performative, Routledge, New York \& London, 1997, P1.

$$
(\leq \vee\urcorner)
$$


الحياة، والأهم أنها تتكلم (بالجسد)، أي تجعله قوة دلالية تتتج بها ماذا تريد أن تقول، وتواصل هيمنتها جندرياً عبر العلامات التي تخلعها عليه. واللغة هي التي

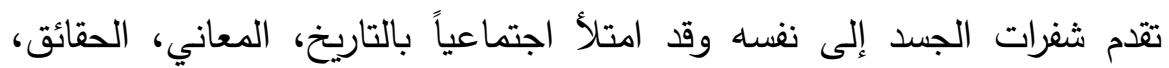

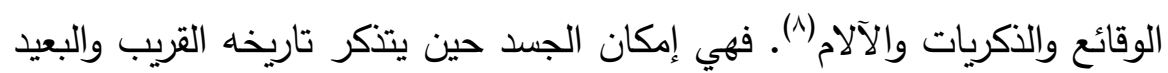

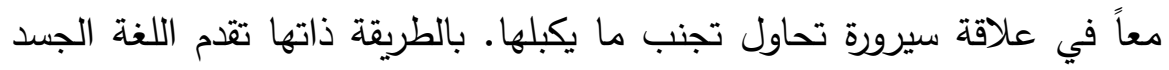
الأنثوي إلى المجتمع والحياة، تضعه على مائدة التواصل وقد أحاطته بكل رغبات دلالية محتملة. فالفضاء الذي تتحرك فيه اللغة والجسد فضاء رغبوي بامتياز، كل علامة جسدية تثكل ذاكرة تستدعي مخزون اللغة لا الوضع الطبيعي من حيث

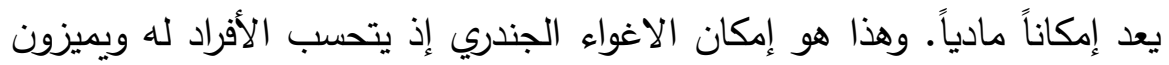

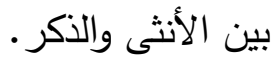
واللغة تثير الاغواء الجندري على نطاق عام، وبالوقت عينه سيكون الاغواء

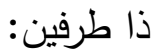
أولاً: التثكيل اللغوي- الفردي للجسد، وهذا الطرف قد يتخيل الفضاءات الحرة وإمكانية الفعل تجاه (الأنثى - الذكر) وطاقات التعبير المتاحة.

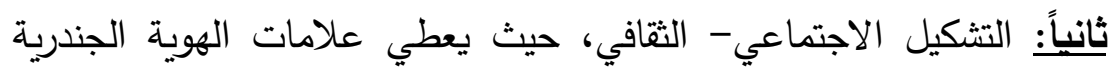
ويوثق مؤسسياً وخطابياً ماذا عساها أن تكون الأنثى. دوماً تبلور اللغةُ على الجانبين خلفيةً لا يمكن تجاوزها، وعندما يظن المري أنه اقترب من تجاوزها، تأتي اللغة لتشمل جوانب الجسد والحياة معاً. وارتباطاً باللغة سيكون السؤال المفيد كما تؤكد بتلر بصدد مقولة الجندر، هو: كيف تثكلت،

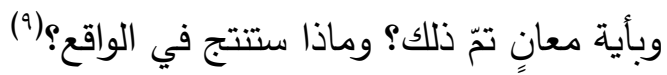

(8)_ Thomas J. Csordas, Body/ Meaning/ Healing, (Series; Contemporary Anthropology of Religion Edited by Robert Hefner), Palgrave Macmillan, New York, 2002, PP 11- 20.

(9) - Judith Butler and Elizabeth Weed, (Introduction), In: The Question of Gender, Joan W. Scott's Critical Feminism, Edited by

$$
(\varepsilon v v)
$$


على سبيل المثال، عندما تُطلق امرأة على نفسها اسم أنثى في ضوء هذه

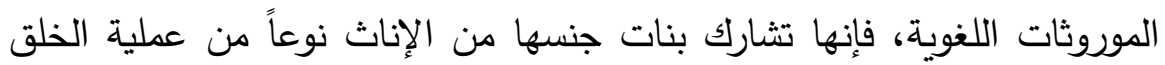
البهيمية brute creation،... يبدو أنّ استخدام كلمة المرأة كان في الاتجاهين السابقين. الاتجاه الأول وهو الأكثر سهولة، حيث يتم استخدام الانثى في صيغة

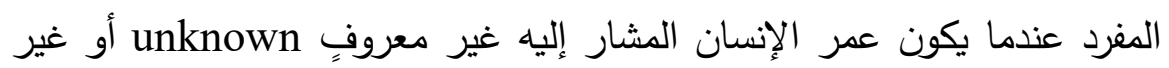
مؤكدٍ. الاتجاه الثاني: في صيغة الجمع للإثارة إلى مجموعةٍ من الأعمار

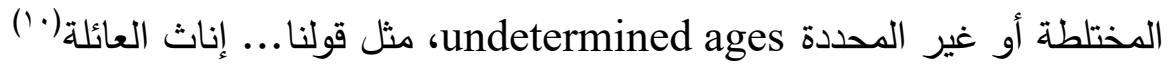
the females of the family

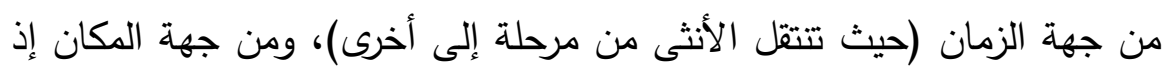
تعرف الأنثى كامرأة داخل العائلة. تقرر بتلر أننا بلسان الأنثى كائنات لغوية linguistic beings نحتاج إلى دلى اللغة لكي نكون، ففي أعماقنا لسنا سوى إمكانيات لغوية من الجسد حتى الفكر

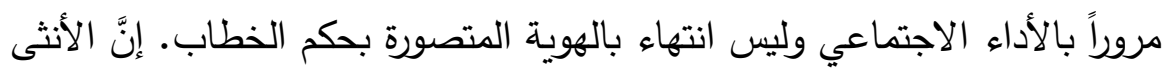

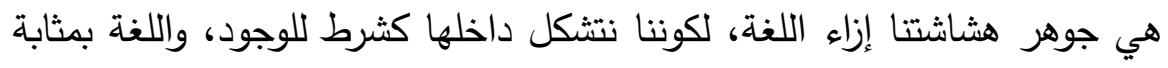

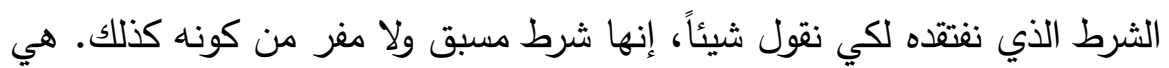
القوة التكوينية (التثكيلية) formative power بالدقام الأول ('"). وامتداداً لفكرة الاسم، ترى بتلر أنّ اسماً قد تحمله الانثى (مجرد هذا الاسم) يشكل إهانة مبطنةً، لكنها أيضاً إهانة تأخذ طابعاً مجندراً حتى تمر دون الهُ مشكلة.

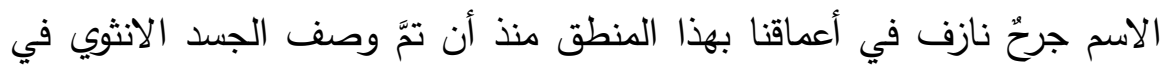

Judith Butler and Elizabeth Weed, Indiana University Press, Bloomington and Indianapolis, 2011, P 4.

${ }^{(10)}$-Webster's dictionary of English usage, by Merriam-Webster Inc, Publishers Springfield, Massachusetts, 1989, P440.

(11) - Judith Butler, Excitable Speech, A Politics of the Performative, P2.

$$
(\varepsilon \vee \wedge)
$$




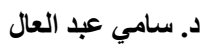
اللغة والجسد الفلسفة النسوية عند جوديث بتلر مجلة وادى النيل للاراسات والبحوث الإنسانية والاجتماعية و التربوية

ثقافة ما، وقد تكون بعض الثتائم غير مؤذيةٍٍ. لكن وحدَه الاسم المتعلق بهذا الإرث قبل تعلقه بكياننا الحر سيكون مدخلاً لأي ذات في اللغة. والذات أيضاً من تلك الجهة يعد ذاتاً يخضع للاسم طوال الوقت، واللغة تعبر عما تُتظر من آفاق مطروحةٍ للأفراد والمجتمعات. والاسم يرتبط عند بتلر بانعدام الحرية، بالقهر لأنه

$$
\text { يوضع في خطاب ممتد دون اختيار (r'). }
$$

بعض الاسماء الأنثوية في إطار اللغة تمثل فينومينولوجيا الاهانة القصوى لما

تراه الانثى مساساً بكيانها، لأنها تشترك في تعميم الحالة كظاهرة، تؤسس لخطاب الظاهرة خارج إرادة الأفراد وتتجلى للوعي كما تتكون. والاسماء تعنون الإهانة في مقولة قابلة للتداول، ومتى خرج الاسم من منطوق الأفراد، فإنه يمارس وجوداً دلالياً أقوى، فليس هناك من اسم بإمكان اللغة تجنبه. لقد اندمج عبر الأداء العام. ولذلك تؤيد جوديث بتلر الجانب الفينومينولوجي من اللغة لكثف الممارسات الثقافية- الخطابية cultural- discursive إزاء الأنثى. وثمّة، أخيراً، نظرية الأفعال الظاهراتية التي اسسها إدموند هوسرل وموريس ميرلو بونتي وجورج هربرت ميد وآخرون، وتسعى لإلقاء الضوء على الطريقة البسيطة mundane way والإيماءة، وخلاف ذلك من العلامات الاجتماعية الرمزية(r'). وبالتالي إذا كان للأنثى جسدُ حيُ يمثل مصدراً لتفاعلات اجتماعية، فلها كذلك جسد استعاري metaphorical body هو الخطاب الذي يصوغ التفاعلات بفضل سلطة الثقافة. والاثنان ليسا منفصلين، لأن البناء الدلالي هو نتاج ممارسات الفاعلين الاجتماعيين، وتغدو اللغة وعياً عاماً يُعاد التأثير به بحكم

(12) - Judith Butler, Bodies That Matter, On the of "Discursive Limits Sex", Roudedge, New York, 1993, P122.

(13) - Judith Butler, Performative Acts and Gender Constitution: An Essay in Phenomenology and Feminist Theory, P 519.

$$
(\leq \vee q)
$$


التعبيرات والأفعال اللغوية. بل تمارس سلطة لها فاعليتها الخفية إلى أبعد مدى.

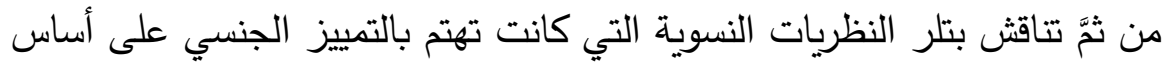

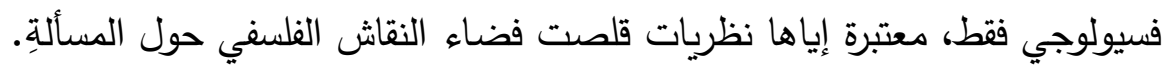
لأنَّ الجسد قد يكون حُراً بوصفه مركزاً للرغبات الذاتية، غير أننا لا نبني عليها

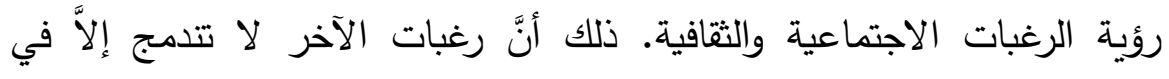
مستوى أكبر من التجاور الذاتي وحسب. تتنقد بتلر هكذا القول بالتثرقة بين الجنس sex والجندر gender، فلقد انهمك مُنظرات الفلسفة النسوية في بعض لهن التفسيرات السببية التي تفترض أنّ الجنس يُملي على تجربة النساء معانيَ

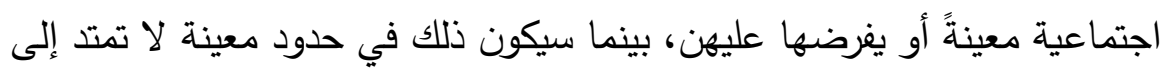

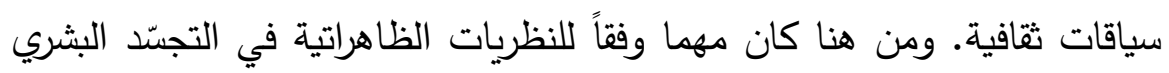

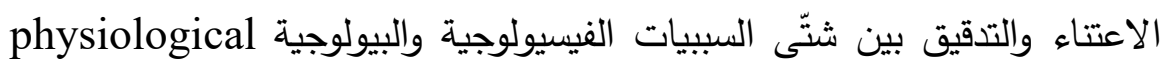
and biological causalities

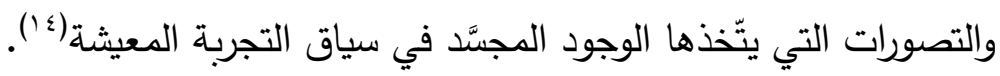

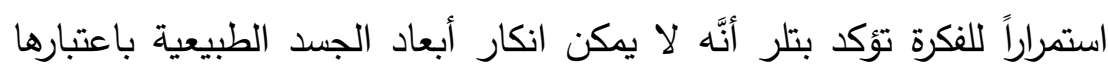

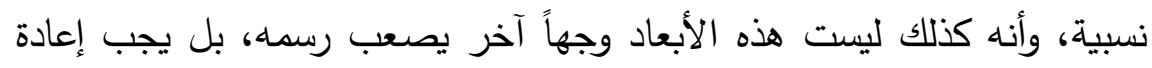

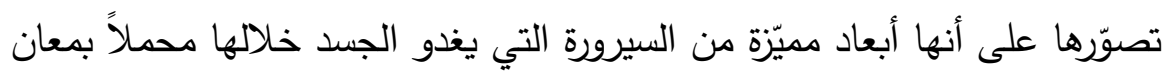

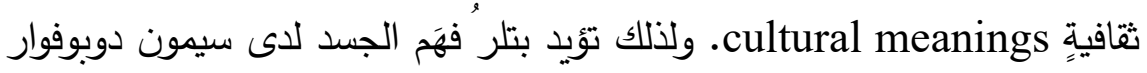

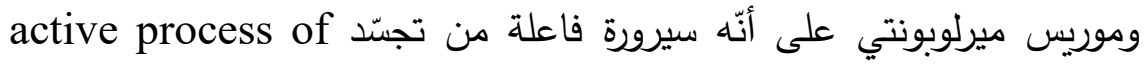
embodying complicated process of appropriation التجمّد أن تصفها. ومن هنا، فلكي يمكنها وصف الجسد المجندر gendered ستحتاج الظاهريات التي تهتم بموضوعات التكون توسيع النظرة التقليدية

\section{(14) - Ibid, P 520.}

$$
(\leq \wedge \cdot)
$$


إلى الأفعال لتعني ما يككِّن المعنى وما يُوََّّديه المعنى ويُنجزه من أدوار. بكلماتٍ

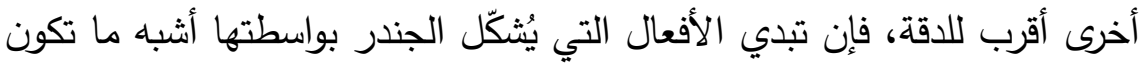
بضروب الأفعال الأدائية performative acts في السياقات المسرحية .(1) theatrical

إذن تتقق فلسفة اللغة عند بتلر مع نظرية أفعال الكلام عند أوستين، تلك النظرية التي ترى في اللغة مهمة انجاز وأداء المعاني حيث يكون الإيحاء فيها هو

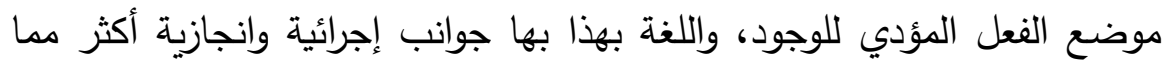
تصف الأشياء، بل إن كل عملية وصف لغوي تتطوي بطريقةٍ أو أخرى على ما

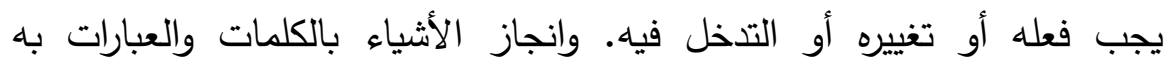
مستويان، هناك الانجاز الظاهر الذي يمثل أفعال الخطاب الصريحة illocutionary acts تفهم وتكرس في الخطاب، لأنَّها تنطوي على درجات الفعل (1). وهذا البُعد أطلقت

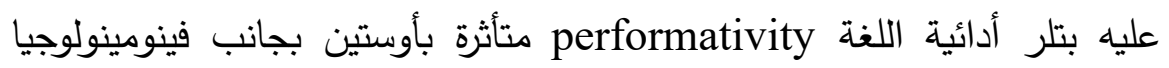
ميرلوبونتي وفلسفات مابعد البنيوية عند ميشل فوكو وجيل دولوز وجالك لاكان

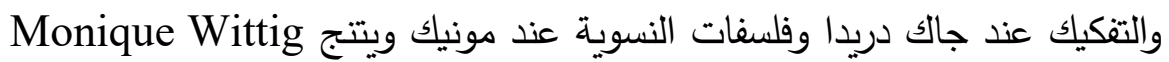
ولوسي وايريجاراي Luce Irigaray وجوليا كريستيفا Julia Kristeva، حيث

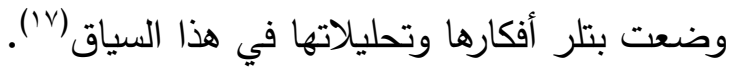
إنّه الإطار الفلسفي لعمل اللغة، والذي تواصل بتلر تطويره من خلال قراءات

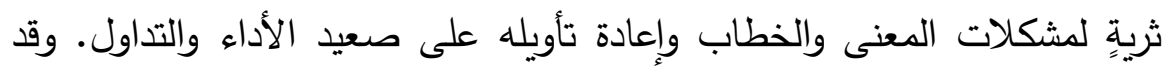

(15) - Judith Butler, Performative Acts and Gender Constitution: An Essay in Phenomenology and Feminist Theory, P 521.

(16) - Marina Sbisà, Austin on Language and Action, In: Brian Garvey (Editor), J.L. Austin on Language, Palgrave Macmillan, New York, 2014, PP13- 29.

(17) - Judith Butler, Gender Trouble: Feminism and the Subversion of Identity, Routledge, New York, London, 2007.P xxxiv.

$$
(\varepsilon \wedge 1)
$$


حرصت على أنْ تتمثل مهمتها بفحص الطرائق الخطابية وسبر أغوار الدلالات المبنى بها الجندر بواسطة أفعال جسمانية معينة تطلق صوبها مواقف ثقافية

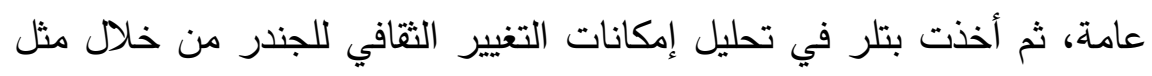

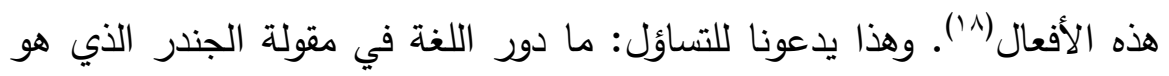

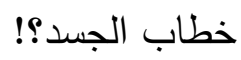
الللغة والجندر

يتأسس الجندر في اللغة كما تكونت صورة الأنثى طوال تاريخها. يقول فاولر في قاموسه، "الجندر gender مصطلح نحوي grammatical term فقط، للحديث عن أشخاص أو مخلوقات من الدذكر أو المؤنث، أي معنى الجنس ذكراً

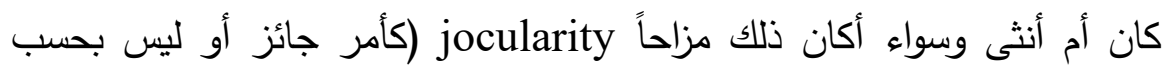

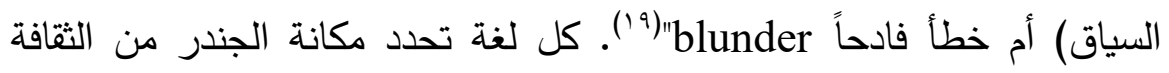
التي تبرز وظائفه، وتستبق اللغة إلى دلالته الخطابية دون عودة. وهذا معناه تحويل الثقافي إلى اختراع لغوي يضبط جهاز الجندر في مخيلتنا، ويعيد الاعتبار

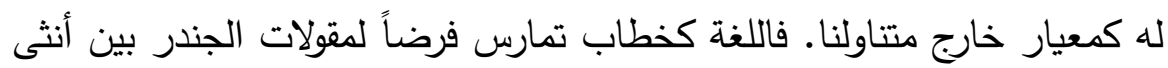

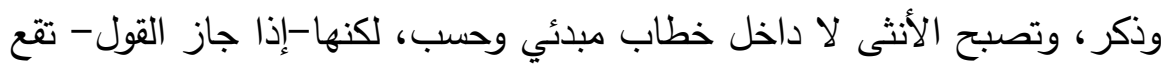
عبر مقولات النوع والثقافة. هذه التكوينات المدعمة لسلطة الهيمنة على جسد الأنثى، وسيأتي جسد اللغة كإطار بديلٍٍ تتحرك فيه بجميع التكوينات الجندرية.

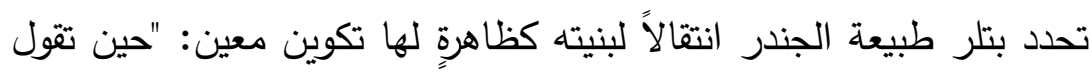

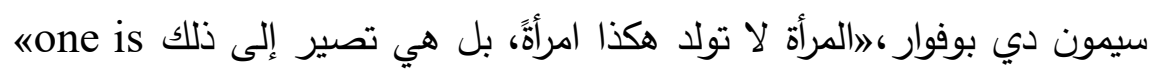
not born, but, rather, becomes a woman,

(18) - Judith Butler, Performative Acts and Gender Constitution: An Essay in Phenomenology and Feminist Theory, P 521.

(19) - H.W. Fowler, Dictionary of Modern English usage, Revised by Sir Ernest Gowers, Oxford University Press, Oxford New York, First Edition, 1926, P 221.

$$
(\leqslant \wedge r)
$$




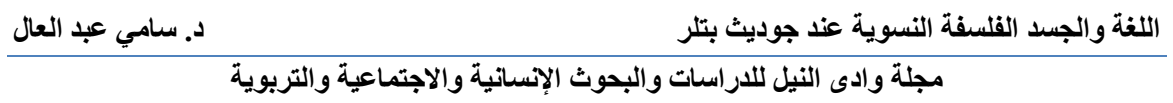

الظاهراتية مذهب الأفعال التكوينية constituting acts وتعيد تأويله stable reinterpreting وبهذا المعنى، لا يكون الجندر أبداً هوية ثابتة ونهية أو موضعاً لقوة فاعلة locus of agency تنبثق منها شتّى الأفعال؛ بل يكون هوية هشة التكوين تبلورت عبر الزمن؛ هوية قامت عبر عملية تكرار

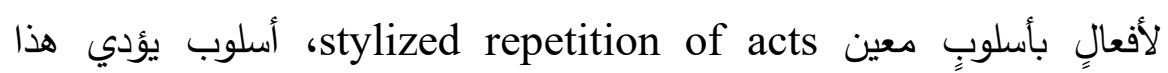

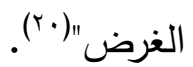
لا توجد للجندر هوية في ذاته، وحدُه التكوين هو ظاهرته التي تجعله مختلفاً من ثقافة إلى أخرى. وليس هناك أدل على ذلك من قول دي بوفوار إنَّ الجندر ليس ميتافيزيقياً ولا بيولوجياً، لكنه سيرورة تحول الأنثى إلى مجرد نوع، وتختفي الأنثى وراءه مثلما يكمن المعنى في تفاصيل العبارات. ويظل الجندر فقط هو المقولة التي تكتسب عن طريقها كل أنثى مكانتها اجتماعياً. أي المقولة شروع دائم في ممارسة سلطة ما، ورغم أن الأنثى فردية غير أنَّ السلطة في هذه الحالة تسقط عليها بأساليب جمعية collective. سيقال مثلاً إنَّ جسداً ما هو جسد أنثويٌ، غير أنَّ ذلك لا يتم دون اللغة كخطاب يأتي بجميع تراكمات التمييز الجندري. فحينما تتداول هكذا مقولة، سرعان يُضاف إليها تلقائياً تاريخ معين، والأخير يأخذ بوصلة التفكير لتحديد ماذا يُراد من صاحبة الجسد. هي امرأة كاملة التحديد عندئذ وإن لم تكن كذلك. وبالتالي سيتولى الخطاب باقي المعاني التي تحمل رسالته. إنَّ رصيد الجندر من الموروثات والأيديولوجيات الاجتماعية والسياسية سيوظف المقولة لا محالة. ولن ينظر إلى أي جسدٍ سوى من هذا المنظور • وستصر اللغة على تكثيف التكوين التاريخي وما يضاف إليه، لأن حدود المسرح تثمل كافة الدلالات التي تعلق بالمقولة.

(20)- Judith Butler, Performative Acts and Gender Constitution: An Essay in Phenomenology and Feminist Theory, PP 519.

$$
\text { ( } \mathrm{sir} \text { ) }
$$


وبمقدار فاعلية الثقافة عميقة الجذور، فهي سترسم الاطر القابلة للإعادة من

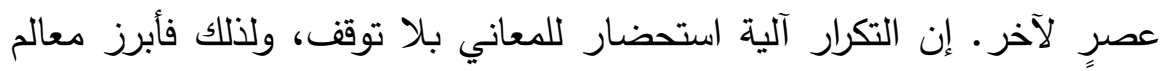

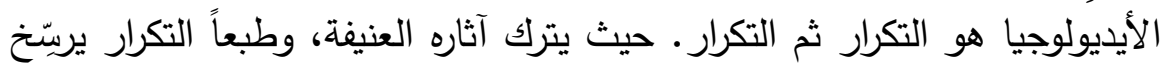

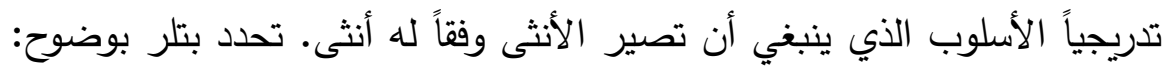

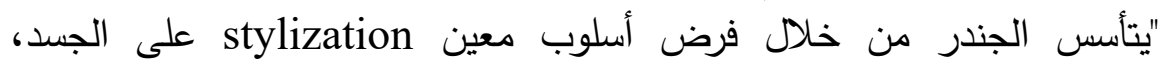
وبالتالي يجب فهمه بوصفه الطريقة البسيطة التي تثكل فرضن بواسطتها مختلف

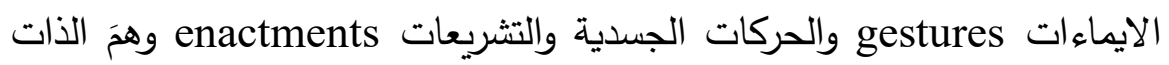

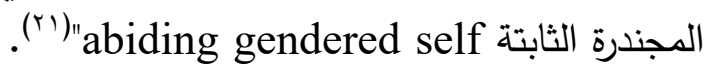
وتباعاً يستمد الأسلوب صوره الثقافية من اللغة، لأنَّ اللغة "مسرح مفتوح" تتيح

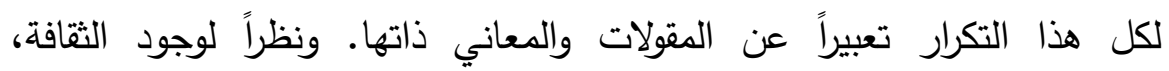

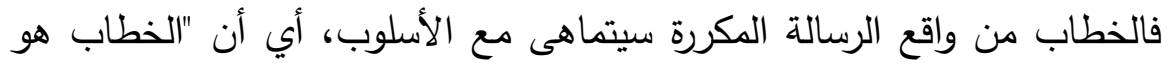

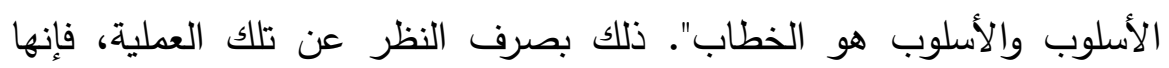

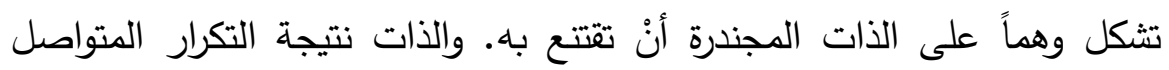

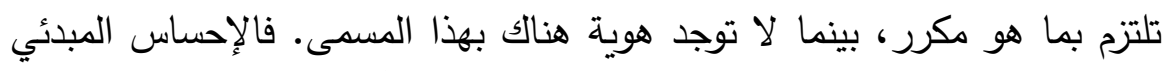

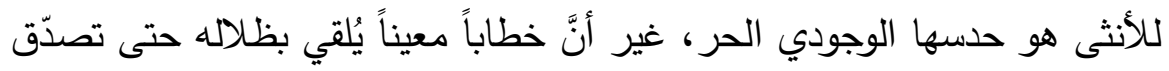

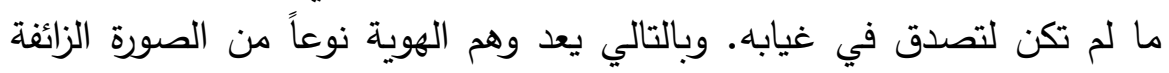
التي تُرسم بموجب اللغة في الأساس.

ربما يعود ذلك الوضع لسلطة اللغة وتحولاتها نظراً للمبررات الآتية:

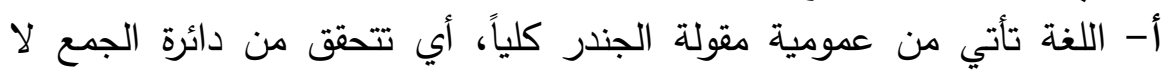

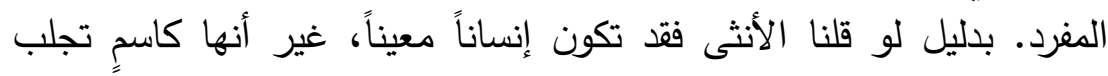

سمات عامة وهذا يخالف الحالة المتحدث عنها.

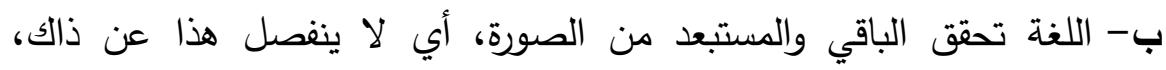

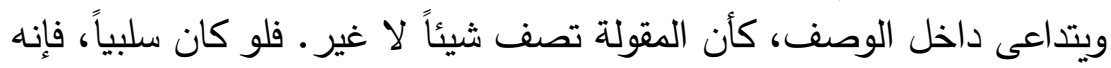

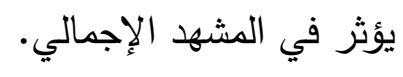

ت- يُكرر الخطاب ما يُقال، ليس فقط بالنسبة للحالة المنطوقة، لكن بالنسبة لجندرها العام من حيث المبدأ.

(21) - Ibid, 519. 
ث- التكرار يخلق سلسلةً من المعاني الزائدة، ويخلق طبقة سميكة من الأوصاف الجندرية غير الدقيقة.

ج- عدم المراجعة والاتجاه صوب ما يقال يخلقان وعياً مغايراً وليس حقيقياً، لأنه ضرب من عدم انطباق المعنى على حالته. ح-الأسلوب أداء تكراري للأفعال وردود الأفعال ضمن ألئ ألية حالة جندرية. فلئن كان ثمة عنف تجاه المرأة، فاللغة تجعل تداوله مقبولاً، ويجب أندان أن يكون مقبولاًا

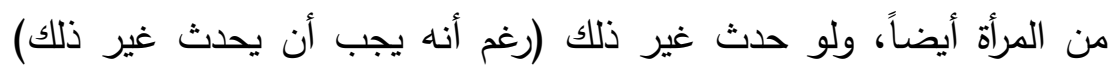
يعتبر سلوكاً غريباً.

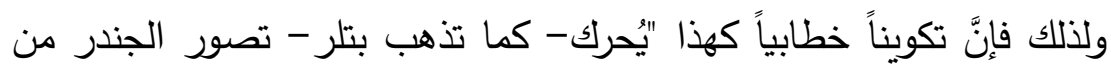

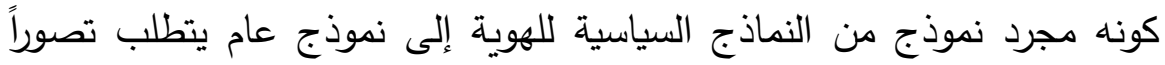

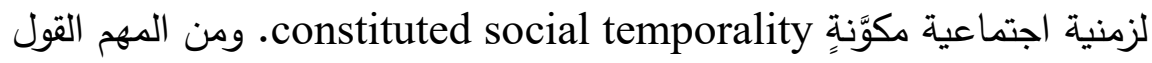

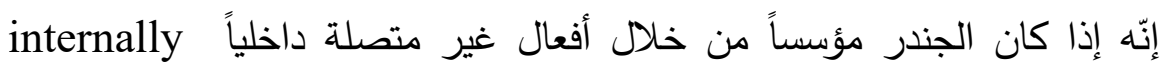
discontinuous فإنّ ظهور جوهر النموذج يعد تحديداً، مثل هوية مبنيّة الفيّة،

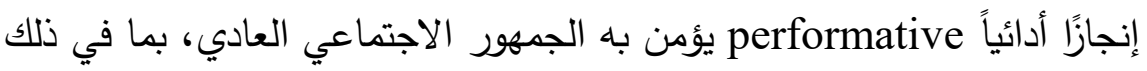

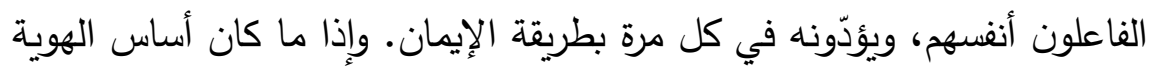

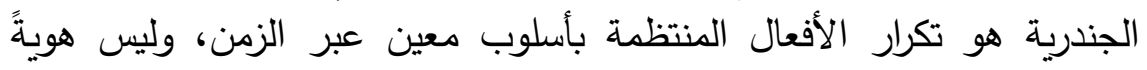

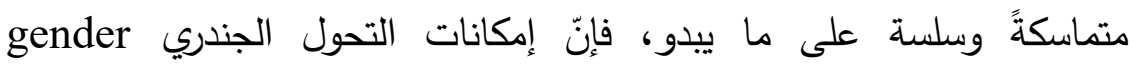
transformation

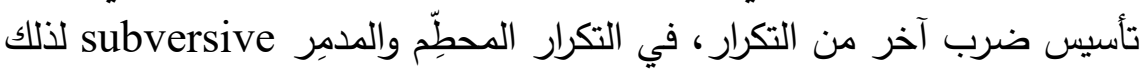

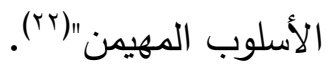

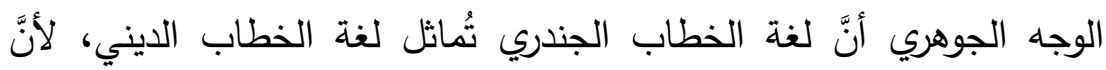

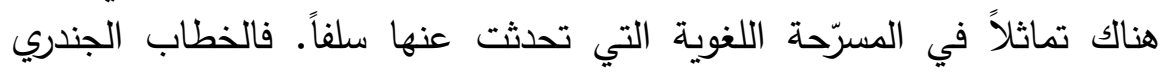
يُصور المقولات بحكم جندريتها، وكنلك الخطاب الديني لا يخلو من أبعاد تمثيلية

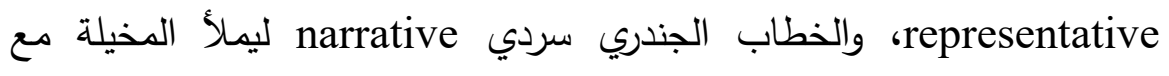

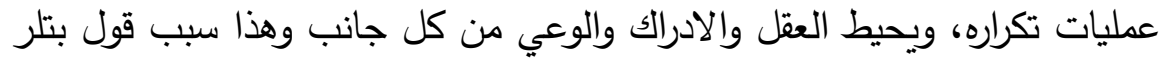

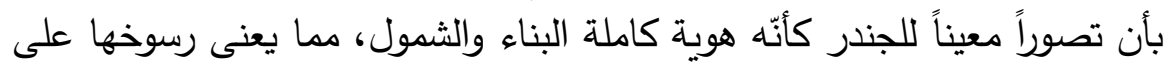

\section{(22) - Ibid, P520.}


نطاق جماهير واجتماعي يصعب تجنبه. وبالطريقة ذاتها يخطط الخطاب الديني

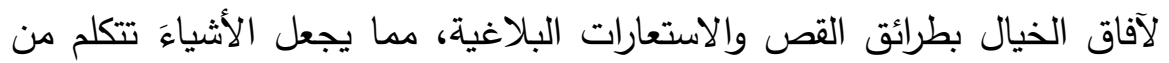

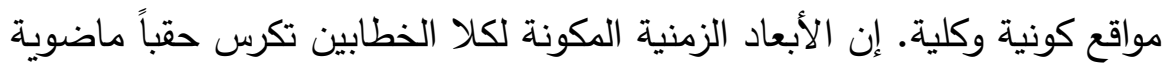

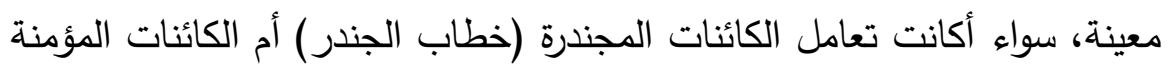
وغير المؤمنة (خطاب الدين).

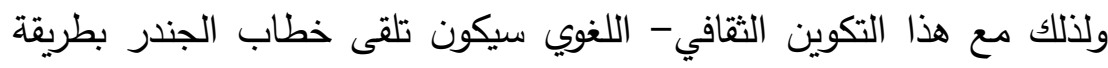

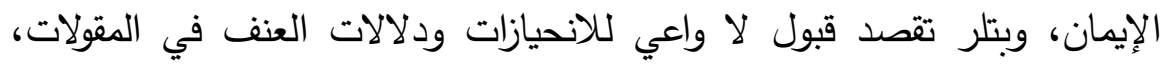

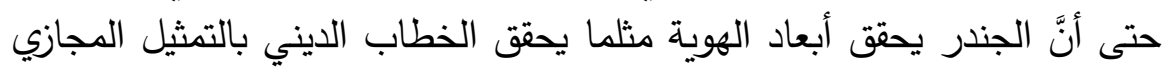

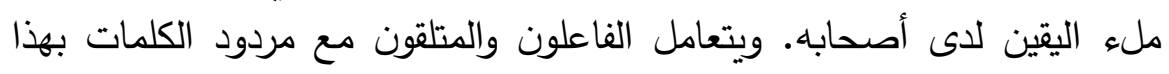

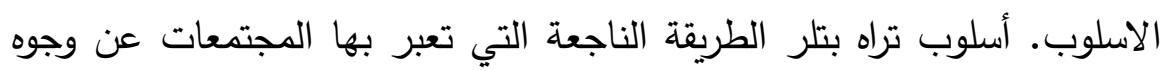

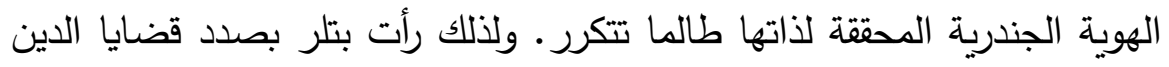

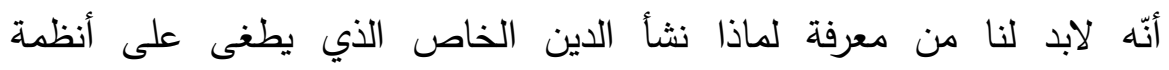

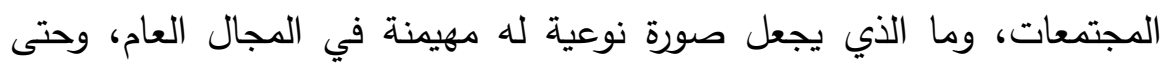

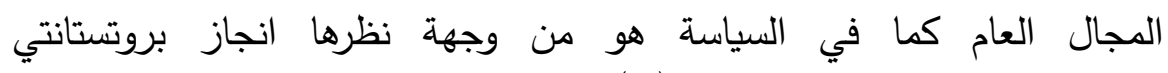
. ${ }^{(r)}$ Protestant accomplishment إنَّ كلمة الإيمان بصدد الجندر توجد في موضعها تماماً، فحين تتناقل الأجيال

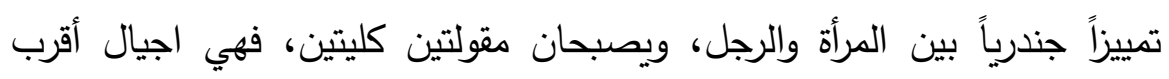

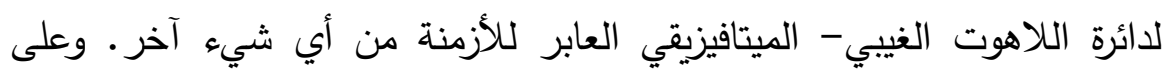

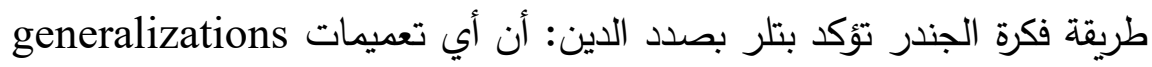

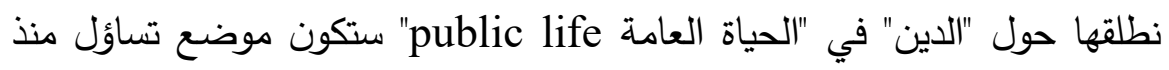
البداية، إذا لم نفكر في مسألة: ما هي الأديان المفترضة مسبقاً في الجهاز

(23) - Judith Butler, Is Judaism Zionism?, In: Judith Butler, Jurgen Habermas, Charles Taylor and Cornel West, The Power of Religion in the Public Sphere, Edited with an Introduction by Eduardo Mendieta and Jonathan Van Antwerpen; with an Afterword by Craig Calhoun,(Columbia- SSRC Book), Columbia University Press, New York, 2011, P 71.

$$
(\varepsilon \wedge 7)
$$




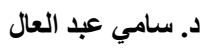

اللغة والجسد القلسفة النسوية عند جوديث بتلر

مجلة وادى النيل للاراسات والبحوث الإنسانية والاجتماعية والتربوية

المفاهيمي conceptual apparatus نفسه، وما إذا كانت هذه الآلة الدفاهيمية هكذا أم لا، بما في ذلك فكرة الجمهور التي لا تُفهم في ضوء نسبه الخاص. الأمر الذي قد يجعل هناك نوعاً مختلفاً من المعنى للدلالة على اليهودي العلماني secular Jew أكثر من الإثارة إلى العلماني الكاثوليكي

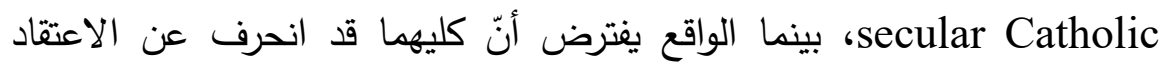

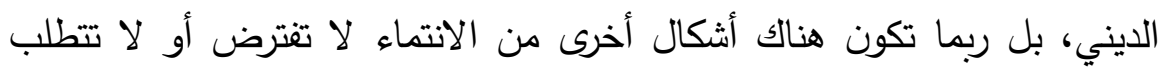
الإيمان أصلاً؛ فقد تكون العلمنة الطرق الوحيد الذي تستمر الحياة اليهودية خلالها كحياة يهوديةٍ (ז).

أي لا يمكن لنا تعميم نمطاً من التدين مثلما يستحيل ذلك بالنسبة للجندر

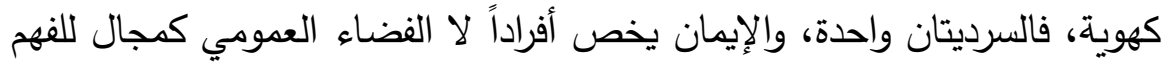
والحريات والحقوق والنقاش العام والنقد التبادلي والعقلانية التواصلية وهذا يشكل

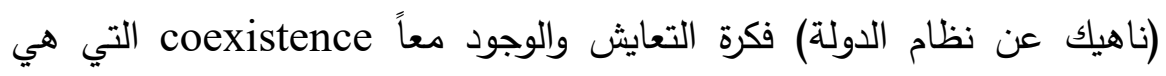
مسيرة تبلور تطورات المجال العام public sphere كما أبرزها يورجين هابرماس(ror). إن تعميم الأمر الخاص مثل التجمُد الذي ينحو لأنْ يكون كلياً بلا

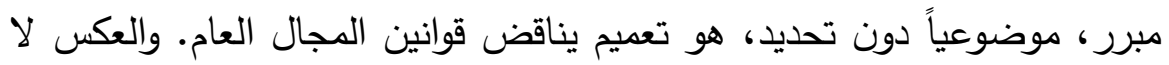

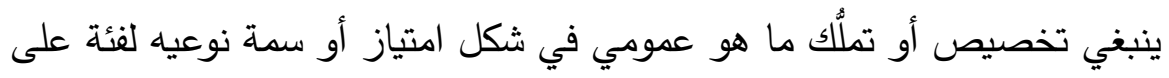

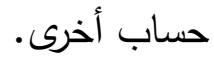

يري هابرماس أنَّ المقدس في اللغة يماثل هذا الوضع، لأنه يخص فئة لا

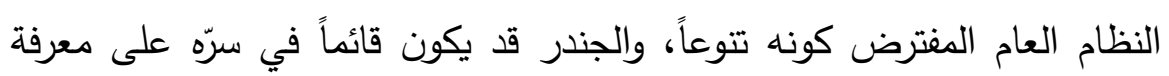
مقدسة وتصورات فوق الواقع كحال المجتمعات التي تسود فيها النزعة الذكورية.

(24) - Ibid, P 72.

(25) - Jurgen Habermas, The Structural Transformation of the Public Sphere :An Inquiry into a Category of Bourgeois Society, Translated by Thomas Burger with the Assistance of Frederick Lawrence, The MIT Press, Cambridge, Massachusetts, 1991, P 223.

$$
(\varepsilon \wedge v)
$$


حيث يرتبط الخطاب الذكوري بالخطاب الديني وستُدرج المرأة بطبيعة الحال في مرتبة مدنية. ويلتقي هابرماس مع توجهات بتلر في أن اللغة تخدد نزعات

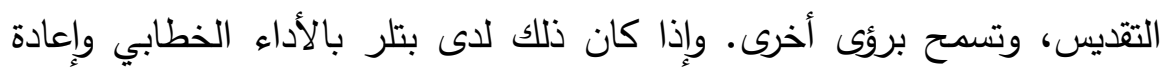
نقده، فإن اللغة عند هابرماس تحررنا من هيمنة الأوهام بموضعتها عن طريق هذه

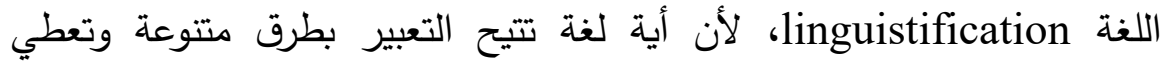
العقلانية مساحة للحركة المحتملة في عمليات التواصل (بrان. ومن خلال اللغة تتنقد بتلر هذا التوجه الجندري تجاه المرأة: من المؤسف أنْ

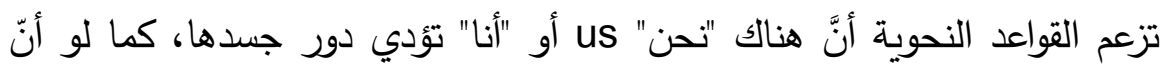
قوةً غير مجسدة disembodied agency سبقت ووجهت المظهر الخارجي المتجسد لهذه الضمائر . والأكثر ملاءمة فيما ترى بتلر أن تقاوم المفردات

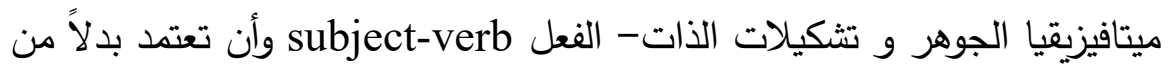

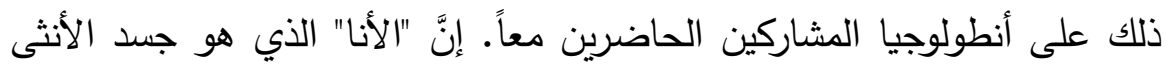

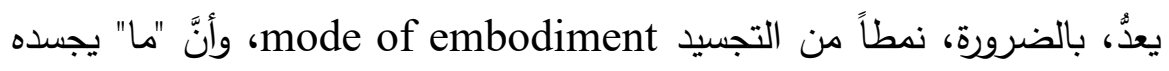

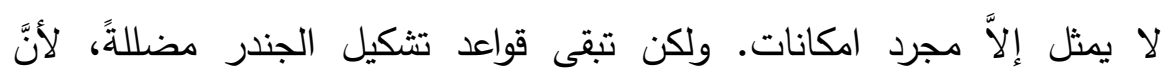

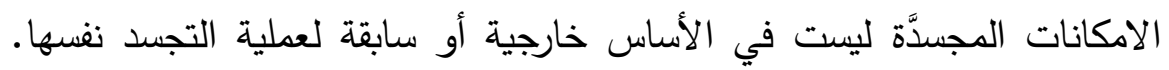

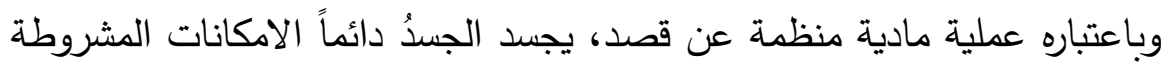

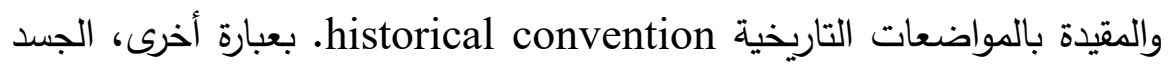
هو حالة تاريخية صائرة إلى كيانها، كما قالت دي بوفوار، وهو طريقة للفعل

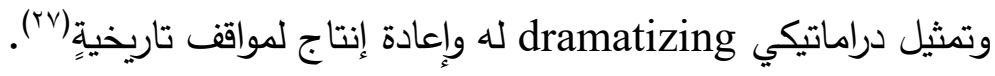

(26) - Jurgen Habermas, The Theory of Communicative Action (Volume 2), Lifeworld and System: A Critique of Functionalist Reason, Translated by Thomas McCarthy, Beacon Press, Boston, Massachusetts, 1987, P 77.

(27)- Judith Butler, Performative Acts and Gender Constitution: An Essay in Phenomenology and Feminist Theory, P 521.

$$
(\varepsilon \wedge \wedge)
$$


إنَّ الجسد يغدو لغة بجلاء، لأنه خطاب سيميائي يعكس دلالات المواقف التاريخية. فإنتاج التاريخ وإعادة الطابع الدرامي القصصي والسردي لها يقعان في صلب اللغة من جهة كونها استراتيجيات دلالية تعبيراً عن الذات. وفي هذه المرحلة لا ترى بتلر أي مسافة بين الجسد كدال ووجوده التاريخي من واقع اللغة والإيماءات والاشارات. واللغة هي النظام الذي يضفي المعاني على الاجساد، وتدخلها في حياة دراميةٍ، تعيد الإنتاج على مستويات أكبر من الزمن. ولذلك سيكون الجسد كلغة هو وسيط التجسيد الأول للممارسات التي توجد فيها. وهذا الخلْق اللغوي لتراث الجندر ليس طريقةً فحسب، يظهر الفاعلون المجسَّدون مكثوفين، سطحيين، وفي متتاول إدراك الآخرين. أي هم ليسوا ظاهرةً سلبية منفعلة على نحو اعتيادي، لكن الفاعلين يمارسون استراتيجيات معبرة عن أساليب العيش. ذلك أنّ التجسيد يُظهر بوضوح مجموعةً من الاستراتيجيات أو ما كان يمكن لسارتر أن يطلق عليه أسلوباً من أساليب الوجود، أو ما كان يمكن لفوكو أن يسمّيه "أسلوبية الوجود "stylistics of existence. وفي هذا لا يأتي الاسلوب اعتباطاً، لأن كل أسلوب يتكثف عبر تاريخ أنماط العيش وممارستها. لكل أسلوب موروثات من جهة، كما أنه يحدد ويشرط الإمكانات المعبر عنها من جهة أخرى. خذ على سبيل التوضيح فكرة الجندر كأسلوب جسدي corporeal ‘performative أو كفعل، لنقل مزدوجاً، قصدياً intentional style فإنه كأداء يجمل الوجهين: أنه دارماتيكي dramatic وغير مرجعي ${ }^{(r \wedge)}$ referential بشكل غير مباشر، تستعمل بتلر أدوات نظريات اللغة المعاصرة ولا سيما عند دي سوسير وبخاصة في قوله إن المدلول لا يتطابق مع الدال وإنه بمثابة الصورة

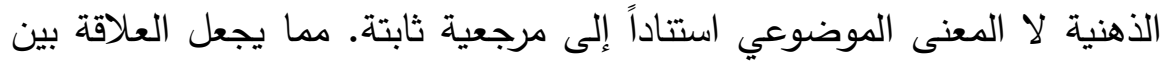
الدال signifier والمدلول signified ذات طبيعة اعتباطية arbitrary nature.

(28) - Ibid, PP 521-522. 
linguistic Sign is ولذلك يرى دو سوسير أنَّ العلامة اللغوية برمتها اعتباطية arbitrary

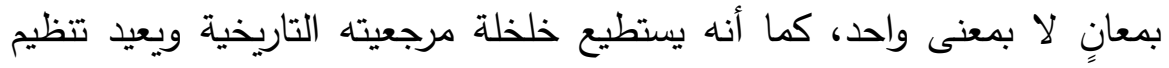

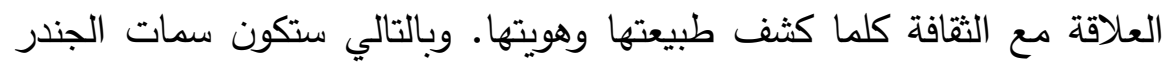

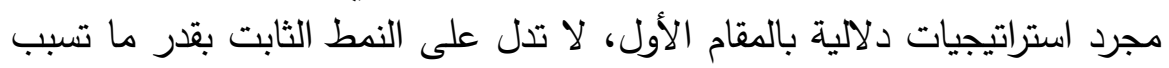

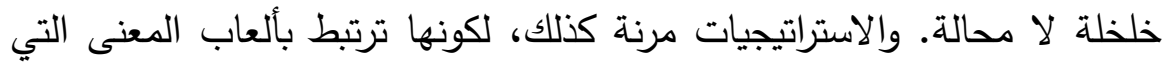
(تؤكد وتخلخل) وضعية الجندر في تاريخ المجتمعات.

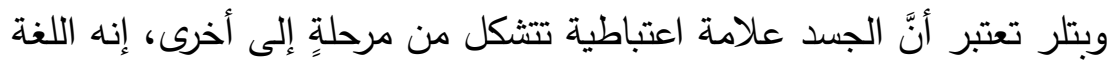

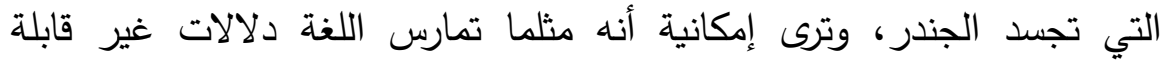

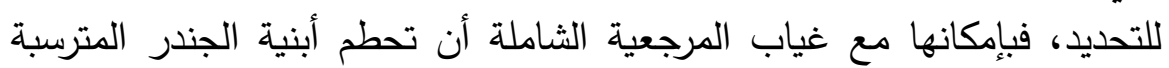

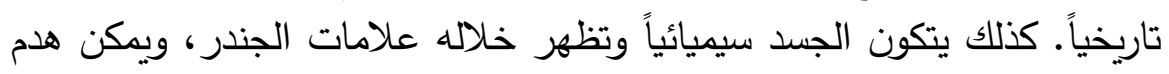

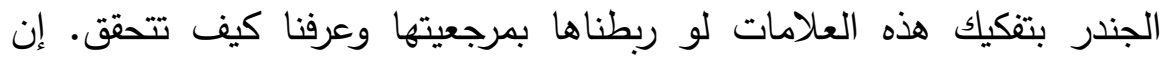

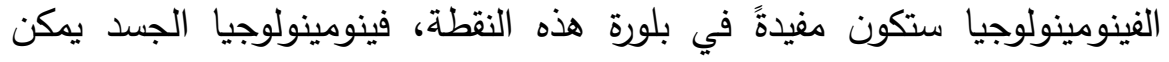

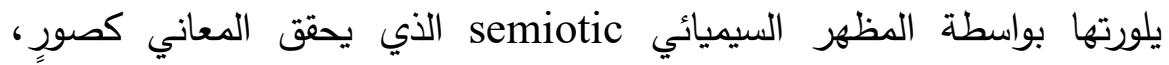

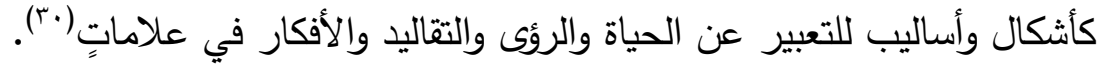

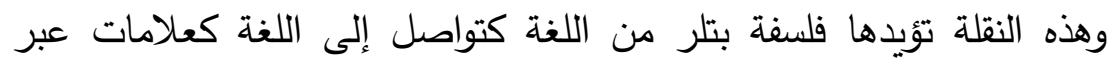

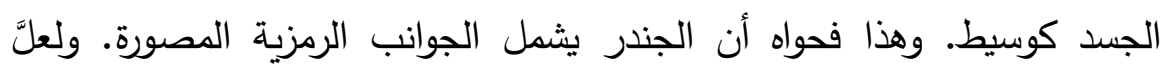

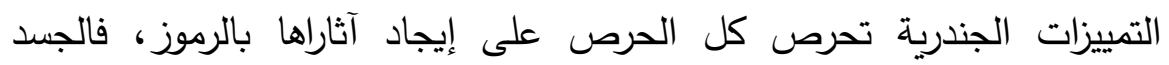

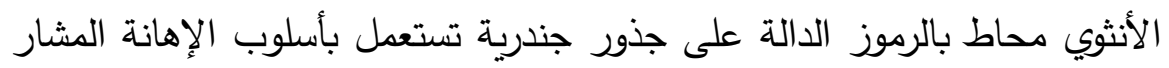

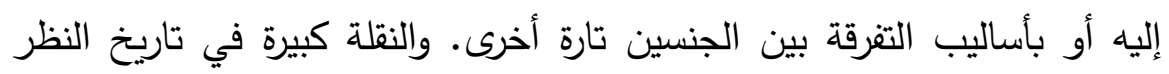

${ }^{(29)}$-Ferdinand De Saussure, Course In General Linguistics, Edited by Charles Bally and Albert Sechehaye, In collaboration with Albert Reidlinger, Translated from the French by Wade Baskin, Philosophical library, New York, 1959, P 67.

(30)- Goran Sonesson, From the Meaning of Embodiment to the Embodiment of Meaning: A study in Phenomenological Semiotics, In: Tom Ziemke,Jordan Zlatev and Roslyn M. Frank ( Editors), Body, Language and Mind Volume 1: Embodiment, Mouton de Gruyter, Berlin - New York, 2007, P92.

$$
(\leq q .)
$$




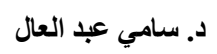

اللغة والجسد الفلسفة النسوية عند جوديث بتلر

مجلة وادى النيل للاراسات و البحوث الإنسانية والاجتماعية والتربوية

البصري للجندر وعلاماته إجمالاً كما هي موجودة الآن في الوسائط التواصلية

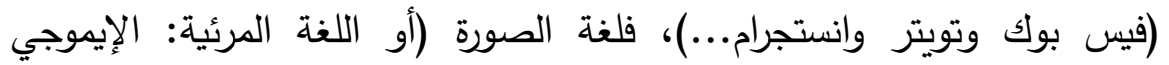
عالمي (") Emoji

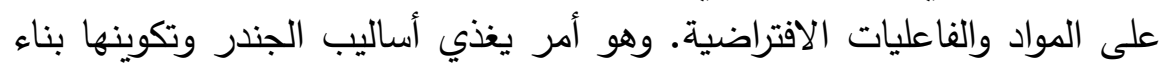

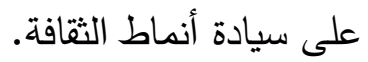
اللغة كأحداث

as بصرف النظر عن وجود الجندر، فاللغة تجعله مدكناً، حدثاً (كحدثٍ

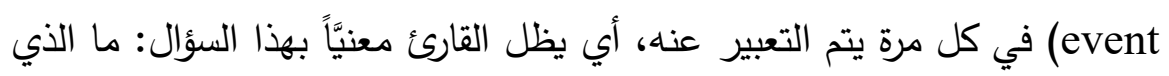

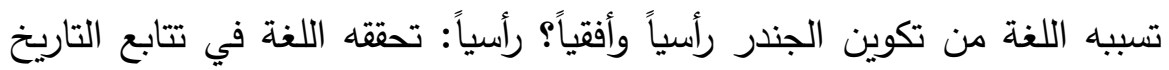

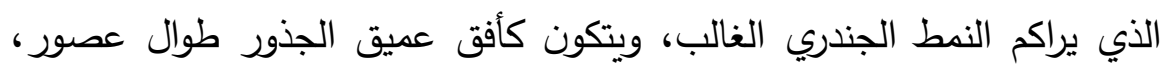

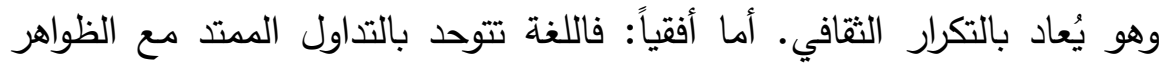

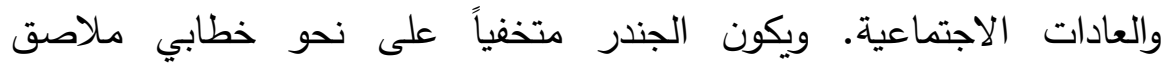

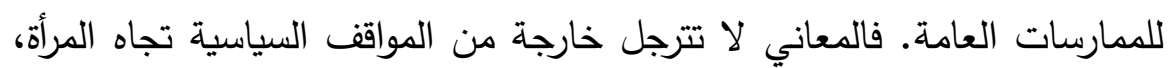

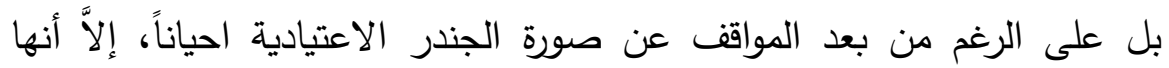
تتورط في تدعيم التمييز الجندري، لدجرد أن يكون هناك رأي يقلكُ من شأن المرأة مثلاً. الرأي في ضوء هذين الاتجاهين يحرك جوانب اللغة عملياً، وكل تعبير بمثابة تكرار مفاجئ، تكرار اختلاف وتعدد بالمثل. لكن السؤال المهم: كيف يكون التكرار

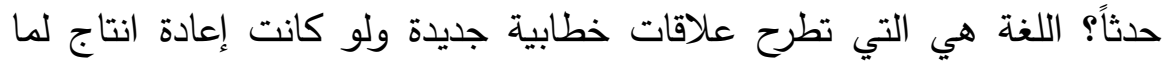

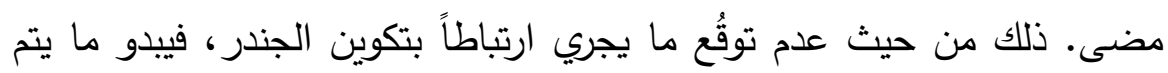

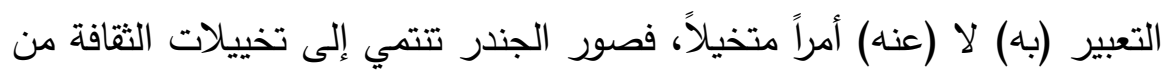

(31) - Marcel Danesi, Semiotics of Emoji, The Rise of Visual Language in the Age of the Internet, Series: Bloomsbury Advances in Semiotics, Bloomsbury Academic, Bloomsbury Publishing Plc, London- New York, 2017, PP 171-179. 
تلك الزاوية، عبر الفاعلين الذين ينخرطون في تحقيق ذواتهم والمشاركة في

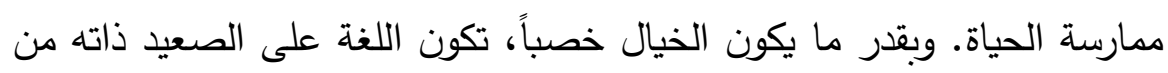

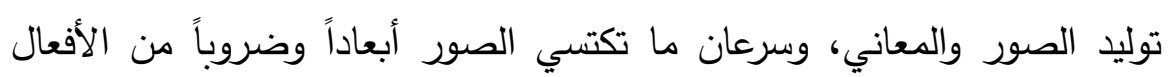
الأدائية performative حقاً تصبح تجليات اللغة، الإثارة، الإيماءة، العلامة الجسدية حدثاً بوصفها أداءً. في نص بعنوان "عندما تكون الإيماءة حدثا" When Gesture Becomes Event

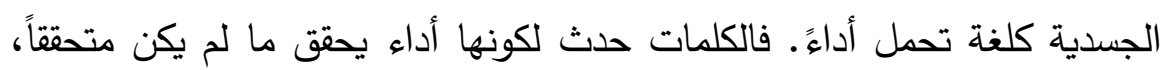

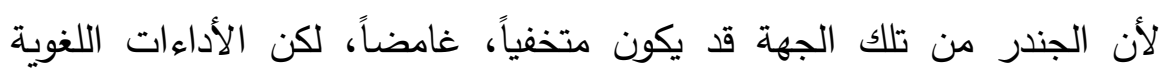

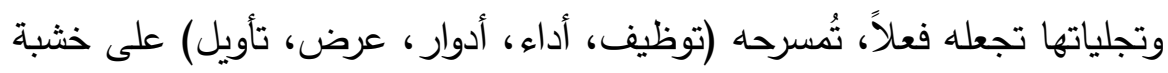

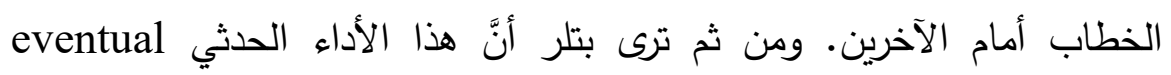
performance

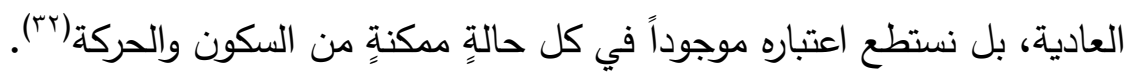
واللغة حين تمسرِح المعاني، فهي تمتد، تقع هناك على على ناصية الخطابات،

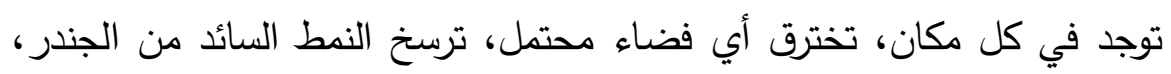

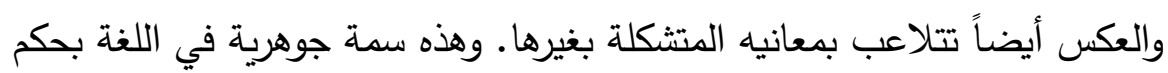

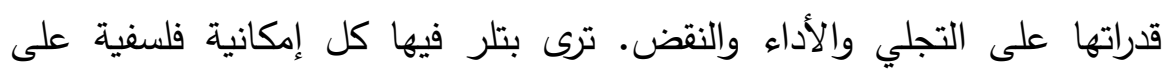

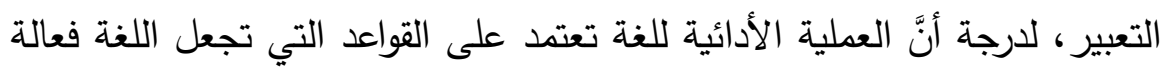

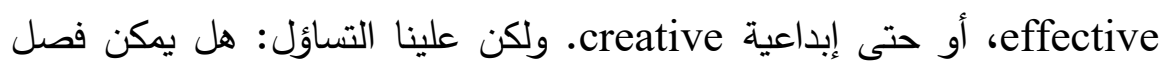

(32) - Judith Butler, When Gesture Becomes Event, In: Anna Street, Julien Alliot and Magnolia Pauker (Editors), Inter Views in Performance Philosophy: Crossings and Conversations,( series :Performance Philosophy, Edited by Laura Cull Ó Maoilearca, Alice Lagaay and Will Daddario), Palgrave Macmillan, London, 2017, P171.

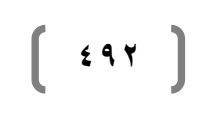


الجوانب الأدائية للغة تماماً عن فعل الكلام؟ هنا يظهر الإحساس بالأداء الذي نجده ضمن فعل الكلام الأدائي، بل في الأداء ذاته بشكل عام، وذلك لفهم أين

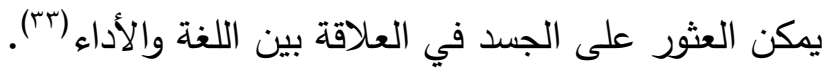
إنّ الحدث في هذه الحالة يعني خروج المضامين الجسدية بما ما تحتويه اللغة

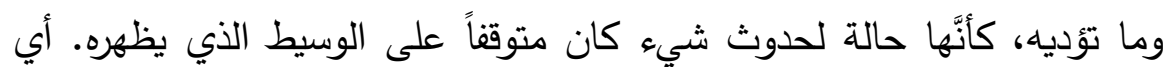
ظهور ما ليس متوقعاً من أفعال مختلفة، ولذلك تشيد بتلر بفعل الإيماءة رغم محدوديتها، لأنها تقصد إلى الفعل المتميز بأكثر من وجها، وتبرز الايماءة كترجمة

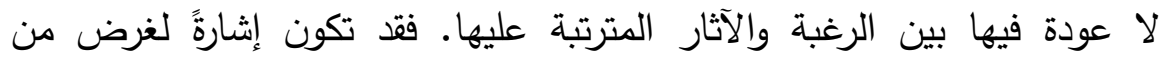

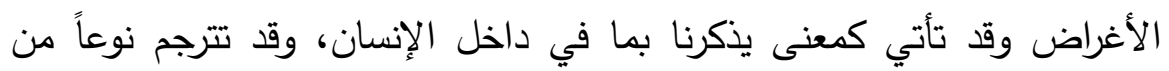

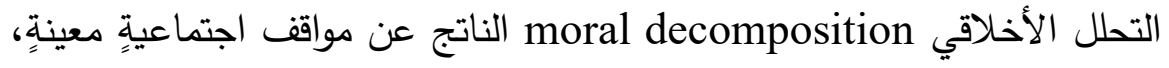
لأنَّ البعد الاخلاقي لا يثترط أن يأتي صريحاً، بل قد يكون مضمراً في

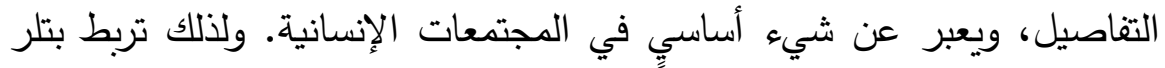
الإيماءة (كوجه من اللغة) بالأداء الجسدي الجنسي مثلاًُ أعَ).

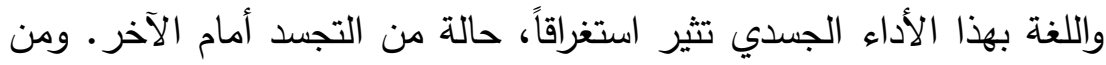

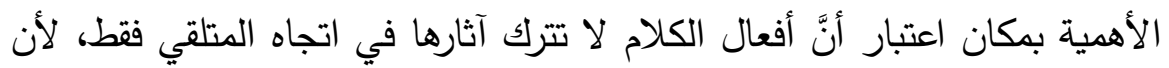
ردود الأفعال على أساسها أكثر أهية من أي شيء آعآ آخرام لونتيجة الجانب الأدائي

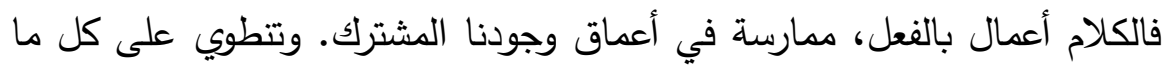

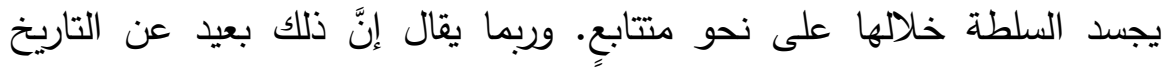
وقريب من الواقع، وهذا ليس صحيحاً لأنَّ كل كلام ينطوي على تاريخ بعينه، وقد

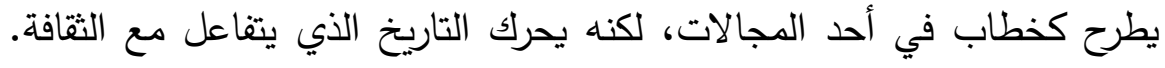

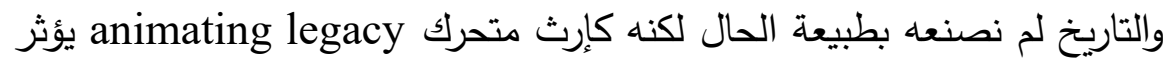

(33) - Ibid, P 172.

(34) - Ibid, P 172. 
على الخطابات بثكل أو آخر، ليس في سياقها فقط، بل في عدة سياقات مختلفة (ro).

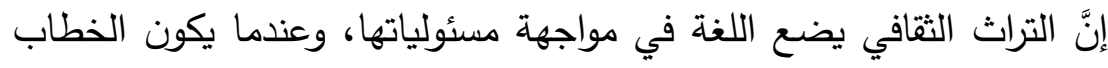

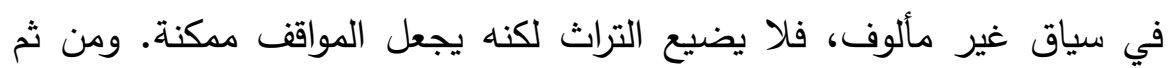

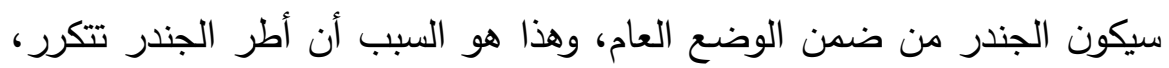

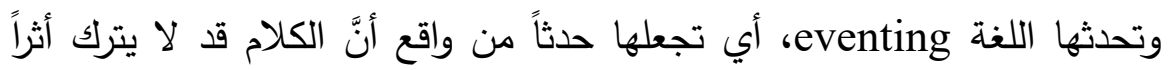

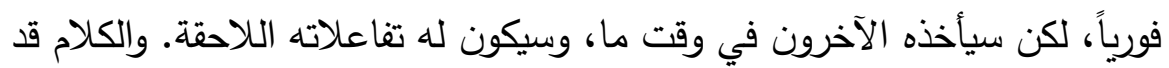

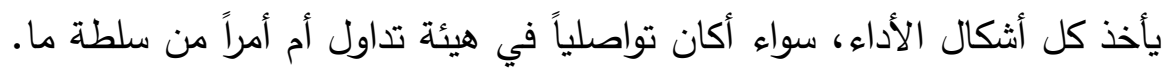
وبأغلب الأحوال سيحمل الكلام إمكانية حدث قابل للتحقق.

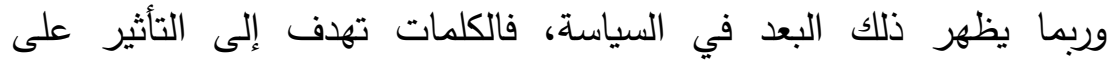
الآخرين، والعبارات مقصودٌ منها المآرب ليس أقل، والسياق يضم القوى الفاعلة عبر لغة تجسد ذلك. حتى أن هنالك توجهاً بتثكيل الآخر. فالخطاب السياسي ولئي

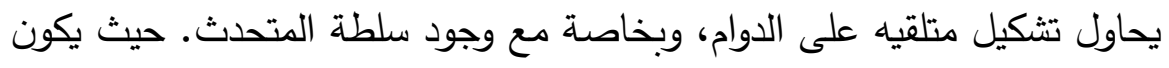

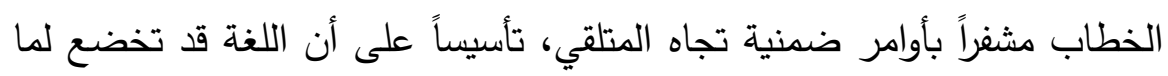

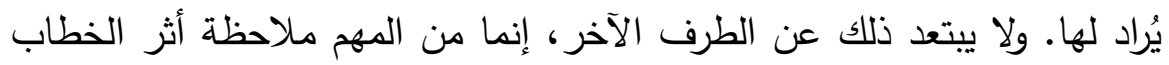
بقدر ما يقبل المواطنون الخطط والاستراتيجيات المطروحة.

وعادة قد لا يمتلك السياسي قوة لتجسيد المعنى. لكنه يلجأ إلى اللغة الخطابية

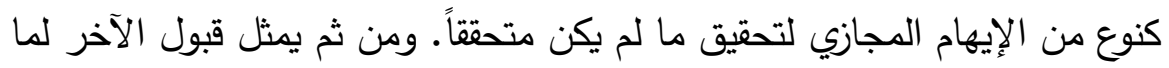

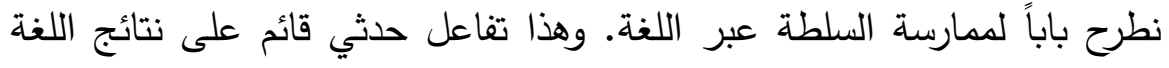

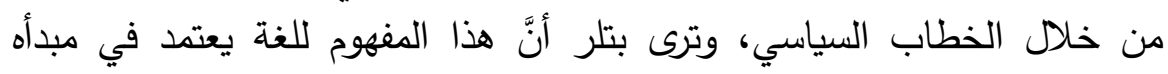

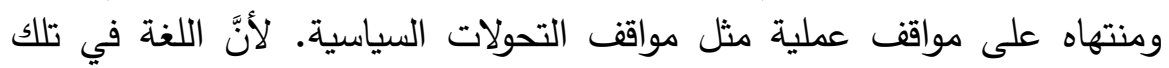

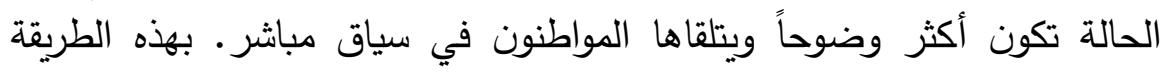

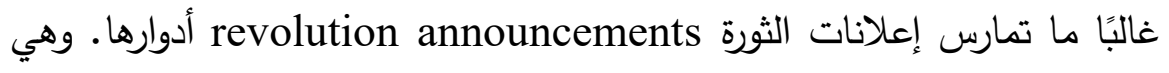

\section{(35) - Judith Butler, When Gesture Becomes Event, P 174.}

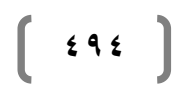




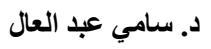
اللغة والجسد الفلسفة النسوية عند جوديث بتلر مجلة وادى النيل للاراسات والبحوث الإنسانية والاجتماعية و التربوية

لغة عملية practical تؤثر في مجرى الأحداث. والطريقة نفسها بصدد لغة التجارة (الأسواق) حين يتحدث أحدهم عن وضع الأسهم، ليثير إلى أنَّ قيمة

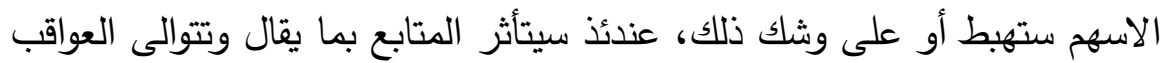
المترتبة عليه. وهذا صحيح فقط إذا كان هؤلاء المتحدثون داخل نطاق مجال منظم للسماع organized field of hearing، ضمن المكان والزمان اللذين يتم فيهما النطق بالوسائل والأمور الحادثة(r؟r). وبحكم وجود الجندر، فإنَّ اللغة كحدثٍ تمس المواضعات الاجتماعية، لكونها تكثفها وتتتقدها على طول المدى، أي تجعل الجندر حدثاً بتفكيك أواصر التعبيرات التي يحتملها ويدافع عنها. واللغة بثقلها الثقافي مجموعة من التهن الأفعال

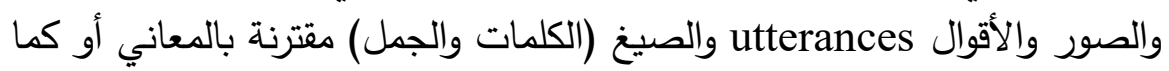

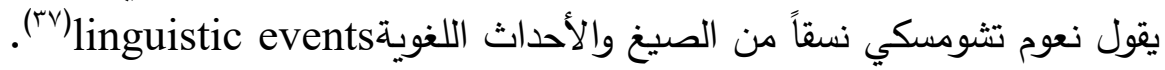
إذن داخل تفاصيل اللغة، توجد الأحداث كإمكانية فعلية، إمكانية قيد الممارسة

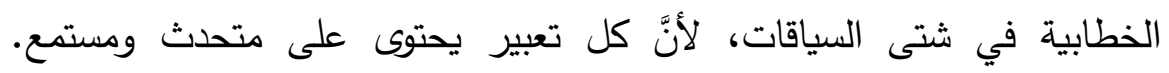
وبالتالي يحتاج إلى نتائج. بلغة المنطق التي تحدد بشكل أكثر دقةٍِ، يقترح دونالد

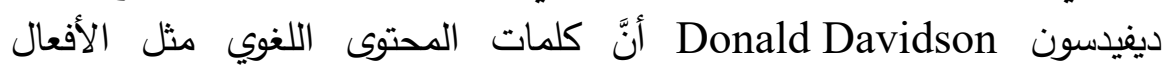

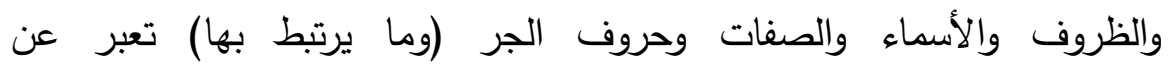

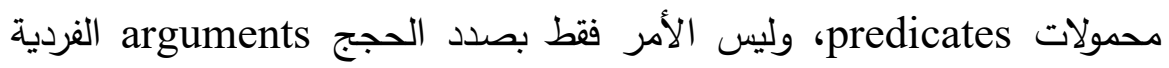
من النوع التقليدي الذي تشير إلى الكائنات الحية وغير الحية أو بصدد الأشياء، وربما الأشياء المجردة أيضاً، ولكن الأمر يجري كذلك على خطابات الأحداثأي متغيرات وسيطة intermediate variables مرتبطة وجودياً وقيمها تكون الاثياء

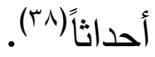

(36) - Ibid 175.

(37) - Noam Chomsky, Knowledge of Language: Its Nature, Origin, and Use (Series of Convergence Edited by Ruth Nanda Anshen), Praeger, Westport Connecticut, New York, London, 1986, P 19.

(38) - Eric Pederson and Jurgen Bohnemeyer, On Representing Events- An Introduction, In: Jurgen Bohnemeyer, Eric Pederson (Editors), Event Representation in Language and Cognition,(Series:

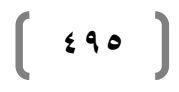


وبصدد الجسدِ ستكون علاقته باللغة والثقافة علاقة حدثيّة، لأن بتلر تراها من

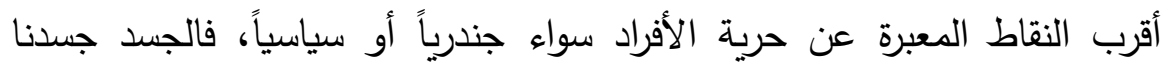

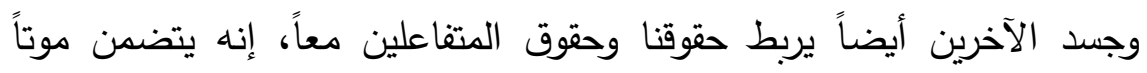
mortality الجانبان (السياسي والجندري) متثابكان وغير محسومي التأثيرات، فكما تقول فلتئل

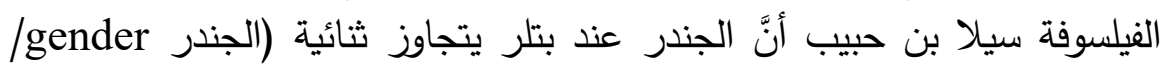

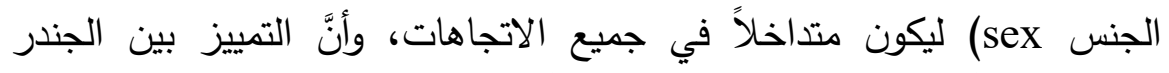

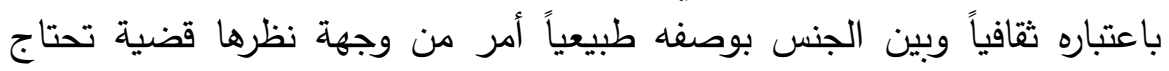

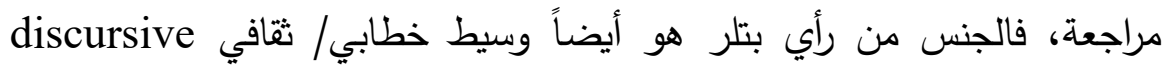

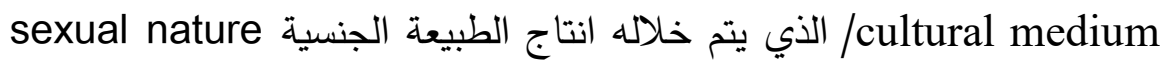

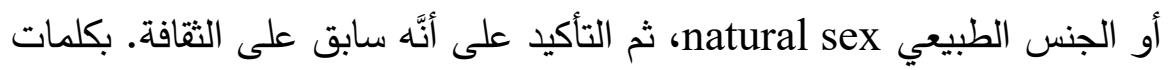

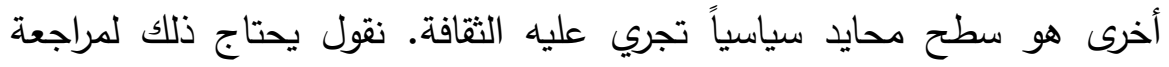
لارجة أن أسطورة الجسد الجنسي هي في الواقع المكافئ الإدراكي لأسطورة معينة:

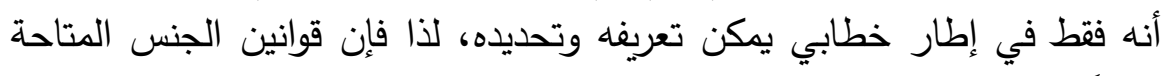

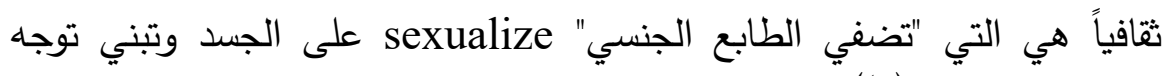

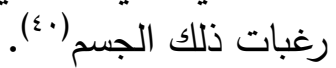

إذن تتداخل مع خطاب الجندر والجنس أطياتُ سياسية من واقع استعمال

الإطار الذي يحدده، وبالتالي سيحتوى توجهات هذا الجسد أو ذالك بقدر ما تُضفي التئي

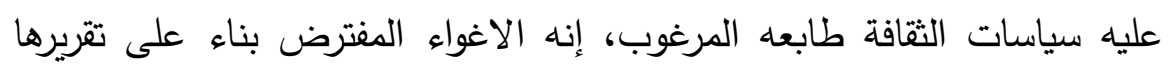

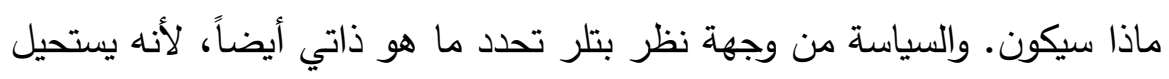

Language, culture and cognition, Edited by Stephen C. Levinson) Cambridge University Press, New York, 2011, P3.

(39) - Judith Butler, Undoing gender, Routledge, New York and London, 2004, p21.

(40) - Seyla Benhabib, Feminism and Postmodernism, In: Seyla Benhabib, Judith Butler, Drucilla Cornell, Nancy Fraser (Editors), Feminist Contentions: A Philosophical Exchange, Introduction by Linda Nicholson, Routledge, New York and London, 1995, P21. 


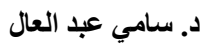

اللغة والجسد القلسفة النسوية عند جوديث بتلر

مجلة وادى النيل للاراسات والبحوث الإنسانية والاجتماعية والتربوية

التكلم عن الذات دون البعد السياسي، سياسة الحقيقة وسياسة الخطاب، وسياسة الرغبة وسياسة المعنى.. وكل ذلك يصعب معالجته دون سياسة. ولذلك سيكون معنى الذات غير منته، وإذا قيل بموت الذات أو نهايته، فذلك كما يثير فوكو أنَّ أحد مفاهيم الذات خادع سياسياً politically insidious ليس أكثر (اء). المغزى أنَّ الحديث عن الجسد حديث عن الجنس والسياسة والثقافة، ولا ينفصل ذلك عن حركة اللغة في المجالات الثرية بهذه الجوانب، فاللغة خطاب أفعال وأقول جنباً إلى جنب كما نوهت. وعندما تتنقد بتلر وضعية الأنثى، فهي

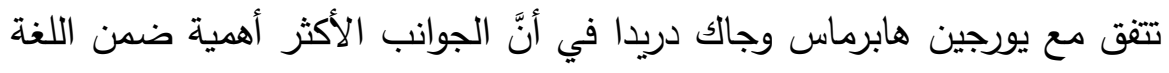
المستعملة تحدث خلال المواقف التي لا توجد فيها قواعد اجتماعية محددة وصارمة. مثل هذا الفهم للوضع يختلف تماماً عن الوفاء بمعيار أو اتفاق ثابت (2)

وهنا حين تكون اللغة حدثاً بهذا الزخم المتتوع، ستكثف أبنية السلطة

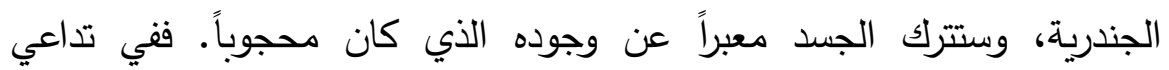
الحدث، لن تتمكن أية سلطة من السيطرة على مصيرها ولا مصير موضوكوعاتها. هي لحظة تجلٍ دلالي فعلي حر للأجساد، وهذا يفسر كيف تكون الأنثى قادرة على التحرر الجسدي أوقات الأحداث كما الثورات والحراك السياسي والاجتماعي. إن الثورات ضد أنواع التمييز الجندري والسياسي والعرقي ومركزيات السلطة هي

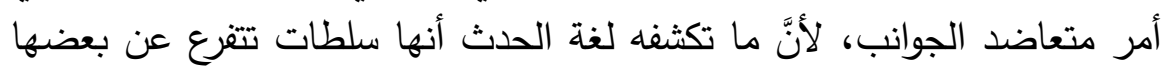

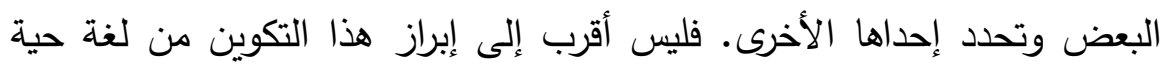
وتجريبية طوال الوقت.

(41) - Judith Butler, Contingent Foundations: Feminism and the Question of "Postmodernism", In: Seyla Benhabib, Judith Butler, Drucilla Cornell, Nancy Fraser (Editors), Feminist Contentions: A Philosophical Exchange, Introduction by Linda Nicholson, Routledge, New York and London, 1995, P47.

(42) - Seyla Benhabib, Sexual Difference and Collective Identities: The New Global Constellation, Signs, Volume 24, Number 2 (winter, 1999), The University of Chicago Press, pp 335-361. On this link: http://www.jstor.org/stable/3175645 


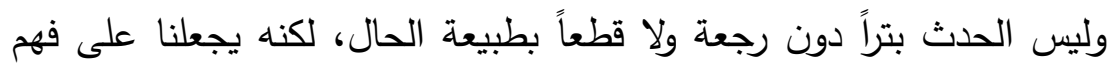

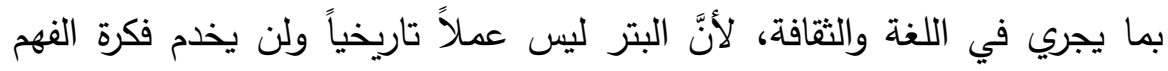

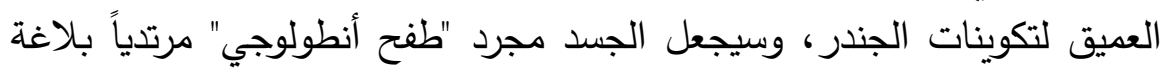

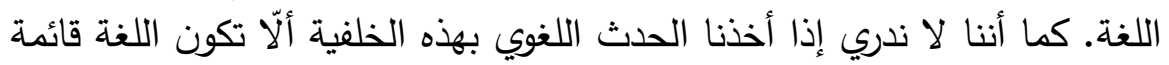

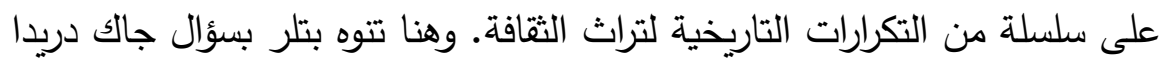

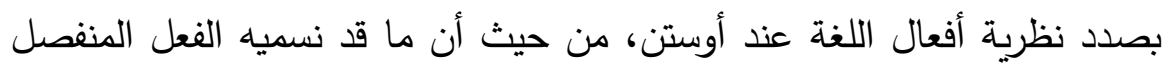

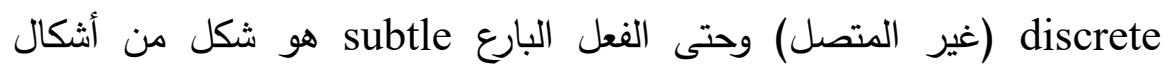

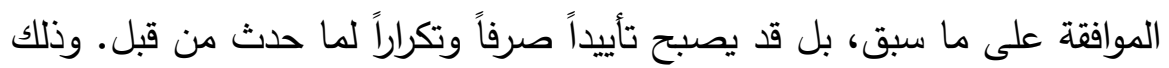

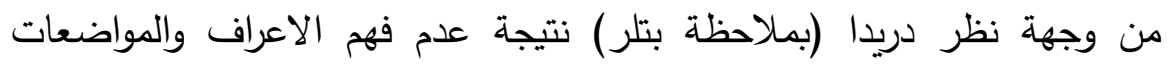

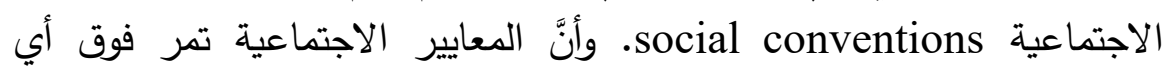

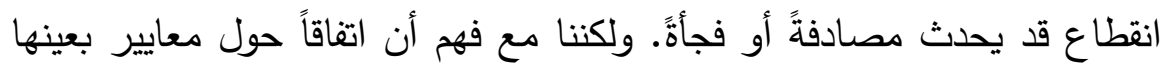

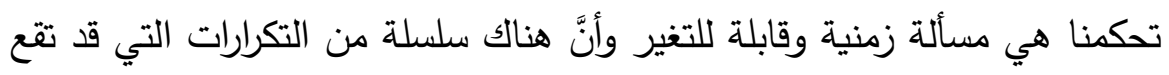

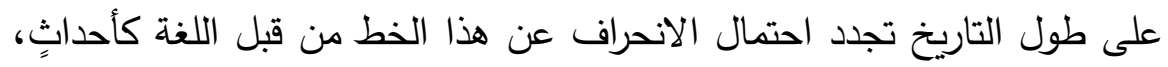

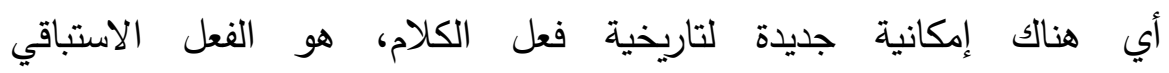

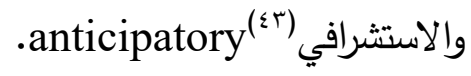
هذا فحواه في إطار اللغة كأحداثٍ ما يلي:

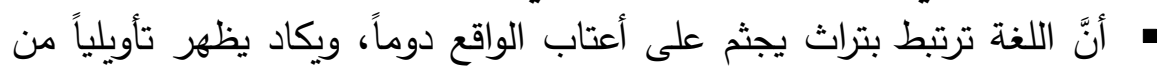
حين لآخر دون انفصال. لا توجد قطيعةٌ في عمل اللغة، لأن المعاني والأفكار تترابط بثكل أعمق مما لفال يظهر على السطح. - فهم المواضعات الاجتماعية والتراث الثقافي يحمل إمكانيات هذا التراث وصور الزمن الكامنة فيه.

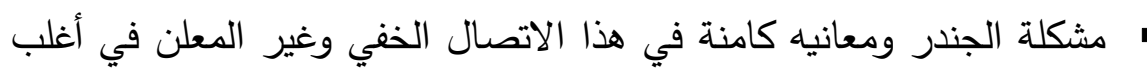
المواقف، وتغطيه الظواهر الاجتماعية والثقافية. - اللغة بوصفها حدثاً أن تكثف الإمكانية الاستباقية لاحتمالات كامنة في هذا

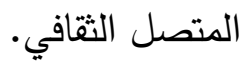

(43) - Judith Butler, When Gesture Becomes Event, P 175. 
هن جانب الحدث اللغوي تتجلى قوى الثقافة المختلفة، ويكون التكوين قابلاً للانفتاح والتغير ، ولابد لذلك الانفتاح أن يمس صميم السلطة السائدة.

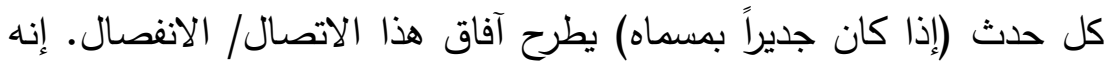

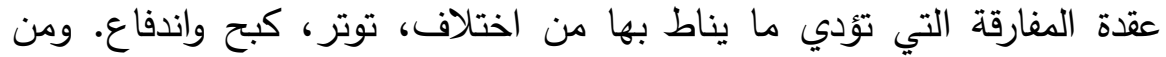

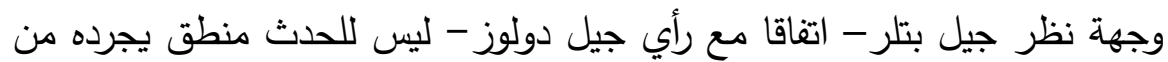

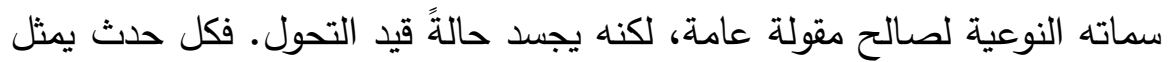

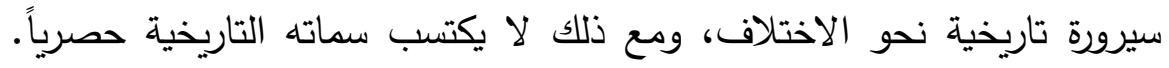

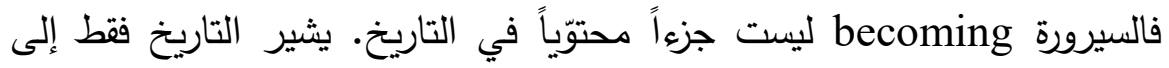

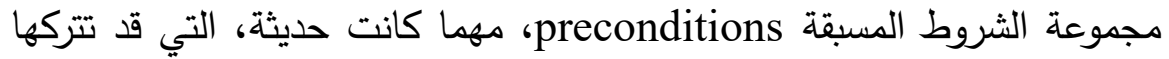
الأشياء وراءها لتصير نحو حالة تاليةٍ، أي يتخلق شيء جديد بخلاف ما سبق،

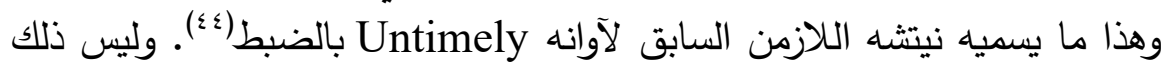

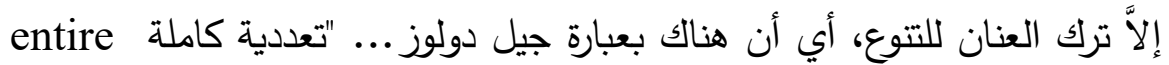

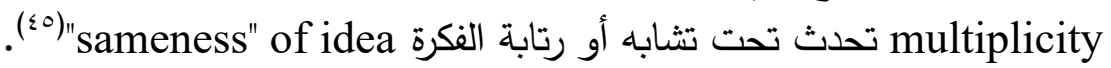
من ثََّ يجيئ الدور الخطير للغة في فلسفة بتلر، لكونها قادرة على الإفضاء طالما هناك تعتيم وحجب وأحادية الرؤية الجندرية، فاللغة تذهب إلى كل احتمال

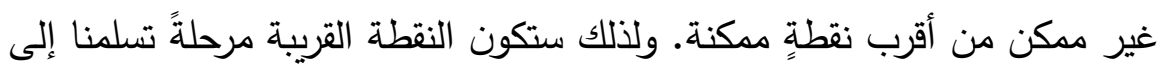
أخرى بالضرورة، تكتبها بتلر باستراتيجيات مسرّحة اللغة، وترتبط في النهاية

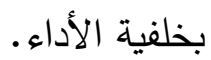
اللغفة والأداء

لناحظ أن فرضية الأداء performance، الأدائية performativity، مشتركة ضمن جميع النقاط السابقة، فما هو الأداء فلسفياً إذن؟ هل للأداء فلاء فلسفة

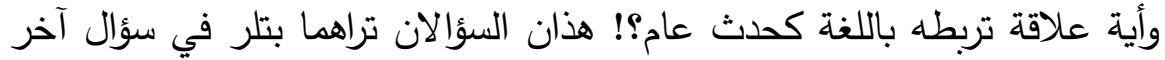

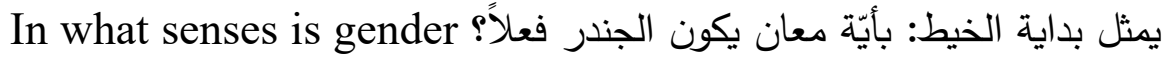

(44) - Gilles Deleuze, Negotiations, Translated by Martin Joughin, Columbia University Press, New York, 1990, P171.

(45) - Gilles Deleuze, Difference and Repetition. Translated by Paul Patton. Columbia University Press, New York, 1994, P344. 
حيث يقتضي الفعل الاجتماعي أداءً ما الذي هو أداءٌ مكرَّر an act?

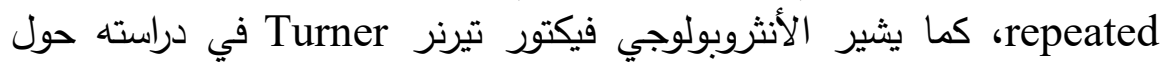

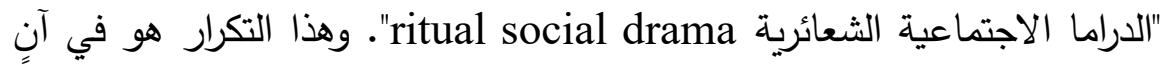

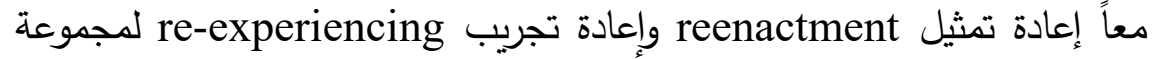

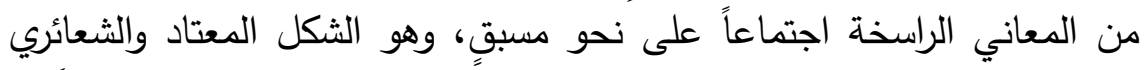

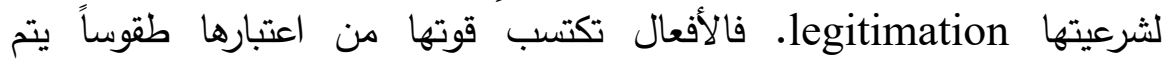

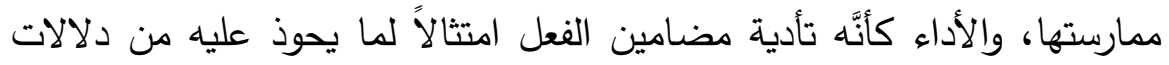

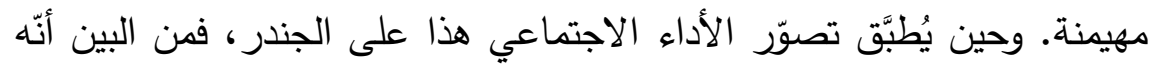

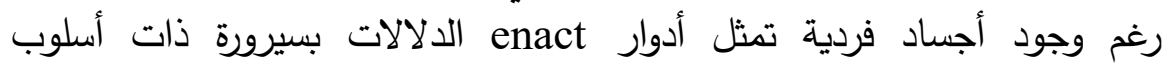
stylized

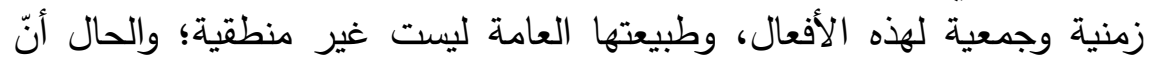

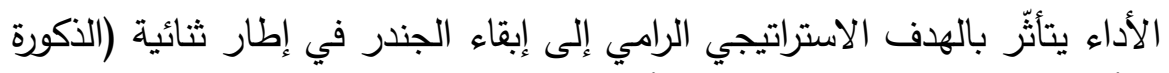

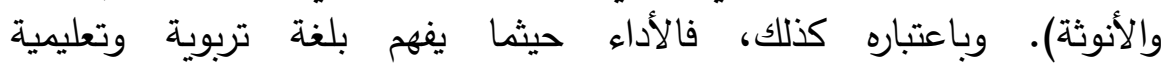
pedagogical

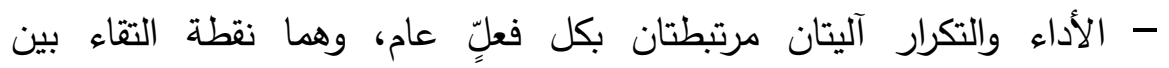

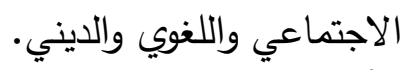

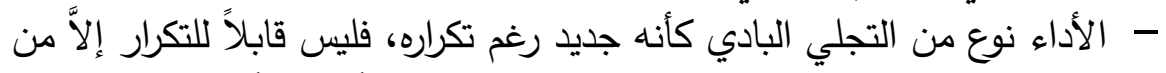

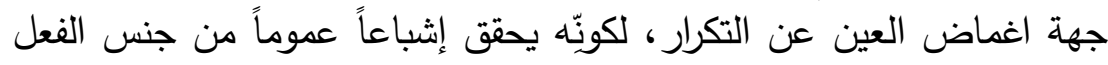

- الأداء يمتد إلى جذور الطقوس، لأن الجندر كأسلوب يحتاج سلطة تملأ الأفق

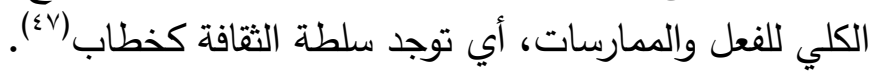

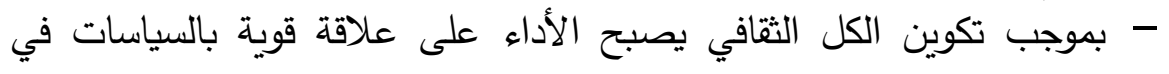

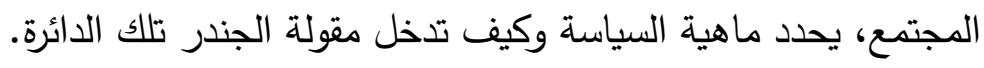
- الأداء والدراما والثعائر والطقوس.. كاهية كلمات تثترك في حالة الممارسة البديلة

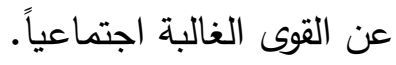

(46) - Judith Butler, Performative Acts and Gender Constitution: An Essay in Phenomenology and Feminist Theory, P526.

(47)- Judith Butler, from "Critically Queer", GLQ: A Journal in Gay and Lesbian Studies, 1: 1, 1993, pp. 17-32.

$$
(\circ)
$$


- الأداء يمثل وسيطاً لإظهار القوانين الاجتماعية التي يسير بواسطها، إنه مجال تأويل يجسد الاجتماعي حاضراً بشكل مضاعف، الأداء زائد القوانين.

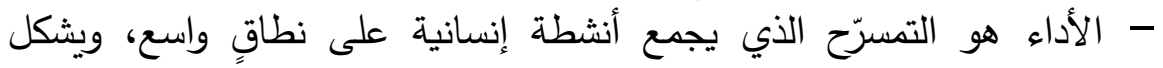

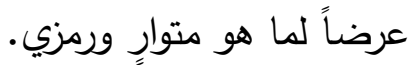
- الأداء بهذا فاعلية انتاج وابتكار إنساني ليس مقصوراً على الأفراد، لكنه يستغرق الثقافات بالطريقة ذاتها.

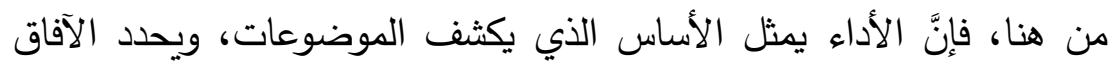

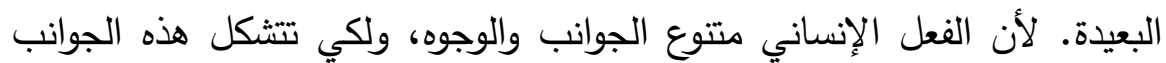
فإنها تحتاج إلى وسيط يظهر إمكاناتها ويعطيها فرصاً للظهور · ومع التاني التاريخ

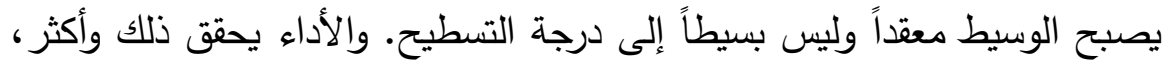
لكنه في الوقت ذاته يشارك في جميع الجوانب سلباً وايجاباً وأعمق من الأن الثنين.

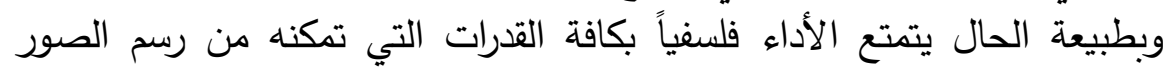

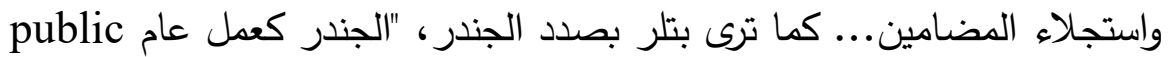

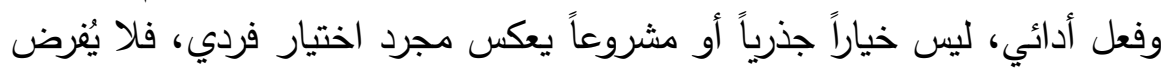

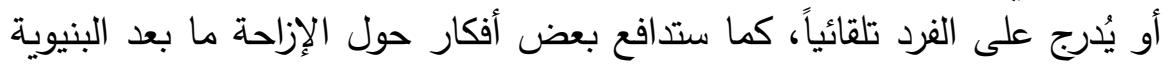

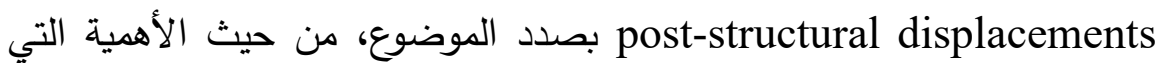

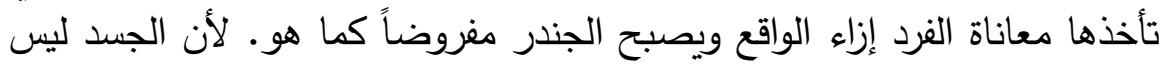

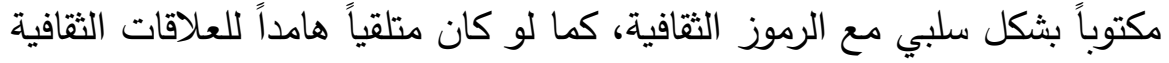

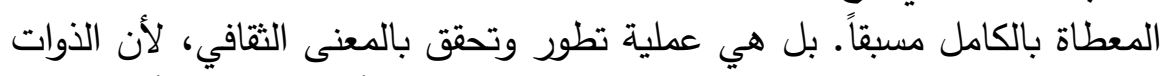

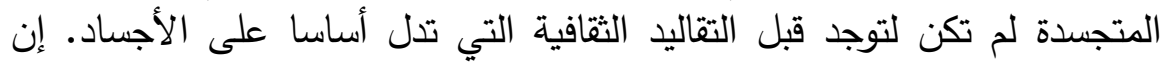

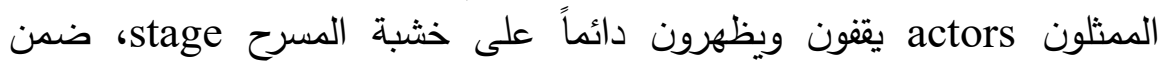
شروط الأداء ولغته. تمامًا كما قد يتم تمثيل النص بطرق مختلفة، وكما تتطلب

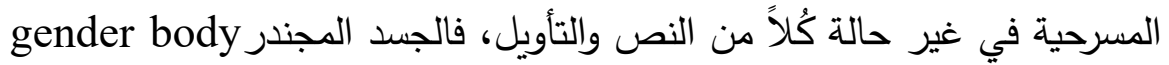
يلعب دوره خلال مساحة جسدية مقيدة ثقافياً ويؤدي التأويلات ضينات ضمن حدود

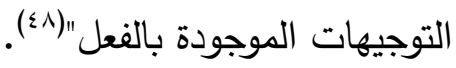

(48) - Judith Butler, Performative Acts and Gender Constitution: An Essay in Phenomenology and Feminist Theory, p 526.

$$
(0.1)
$$


لعلَّ اللغة هي مسرح جذري لهذا الأداء، لكن بأي شكل وبأية طريقةٍ؟! يظهر

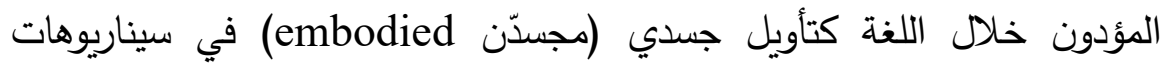
الواقع، لأنَّ الجسد لا يظهر للآخر كما هو، إنه الرغبة القصوى التي تأتي إليه

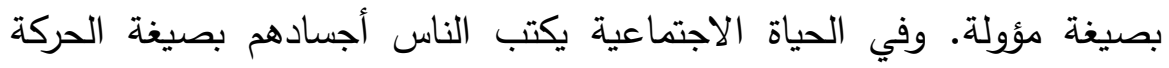

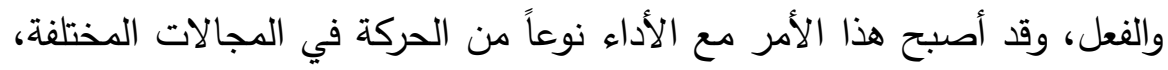
وهو أشبه بالفنون الأدائية مثل الرقص (الايقاعي- الحركي)، فهذا الفنون تأويل

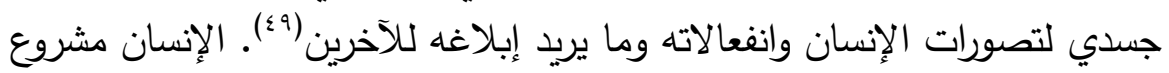
تأويلي من خلال جسده وحياته، وليس لله من وجود عارٍ من التأويلات المتتابعة

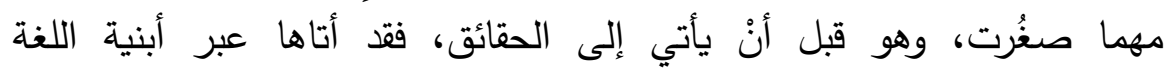
واستعاراتها التي تتوسط عالمة الثر • وتخلق هذه اللغة من كيانه مادة لا تُريّتخ

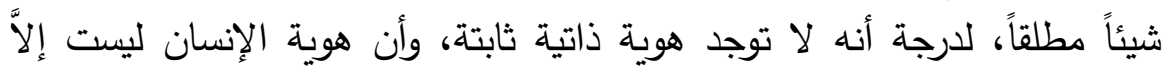

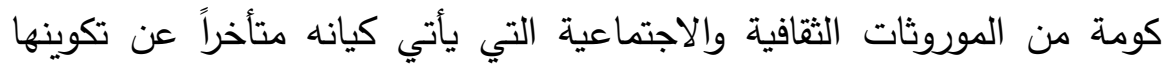
دائماً، وأنَّ اللغة تتغلغل في أدق تفاصيل الجندر لكون الأخير خطاباً يستحضر وظائفها من جهة الأداءات الممكنة في حدود الجسد سواء كان أنثاء

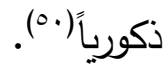

من ثمَّ، سيكون الأداء عند بتلر متغيراً يضم إلى ساحته كافة المعاني السياسية والاجتماعية التي تحيط وتتخلل مفاهيم الجندر، وهذا ما يدع الفلسفة تهتم بكونه

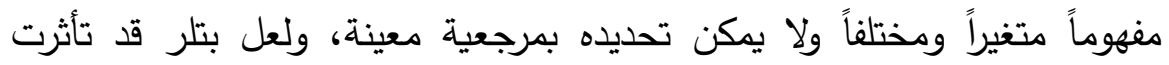

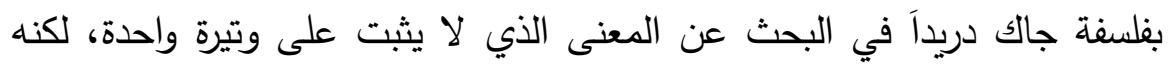
يحرك سواه ويستحضر دلالات مغيبة ومتتاقضة من الصورة الغالبة التي يأخذها

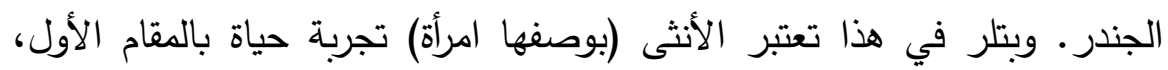

(49) - Kenneth King, Writing in Motion: Body- LanguageTechnology, with a

Foreword by Deborah Jowitt, Wesleyan University Press, Middletown, Connecticut, 2003,pp xvi- xxi.

(50)- David Gauntlett, Media, Gender and Identity; An introduction, Routledge, London and New York, 2002, P135.

$$
(0 . r)
$$


وتترك السياق يتداعى حتى ترسم ماهية حياتها وكيف تكون وما الذي آلت إليه،

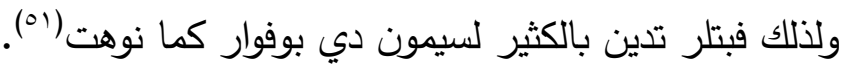

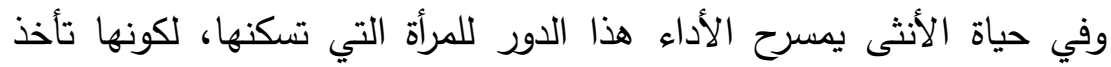

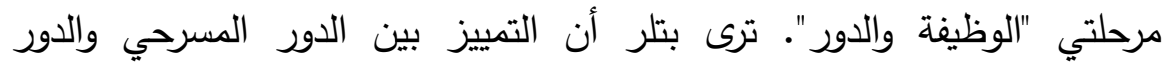

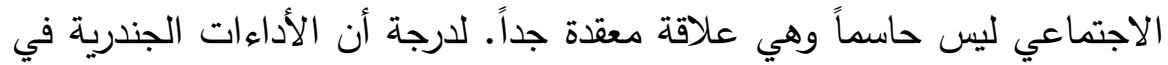

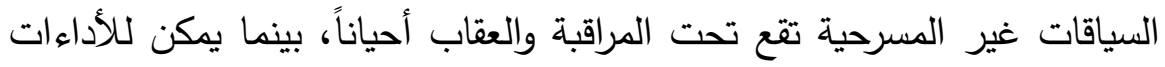

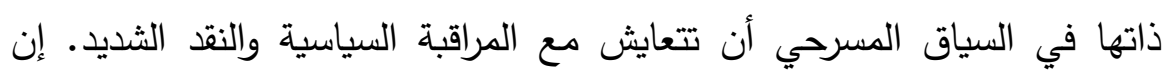

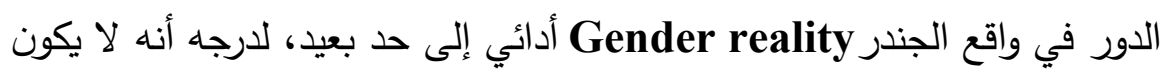

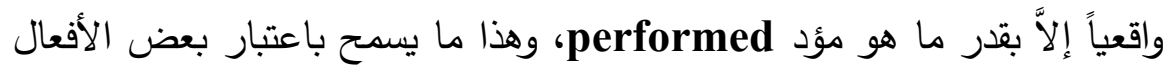

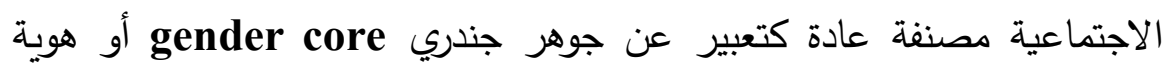
جندرية، وأن هذه الافعال إما تخضع لهوية جندرية متوقعة أو تعارض ذلك الك التوقع التع

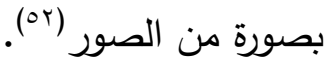
ولذلك فيما تواصل بتلر يستند ذلك التوقع إلى تصور حول الجنس باعتباره

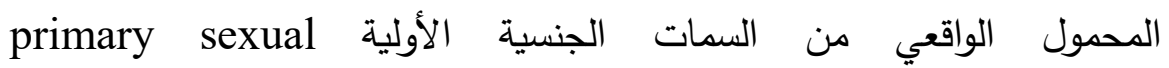
والإياءlics

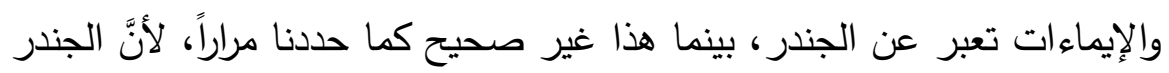

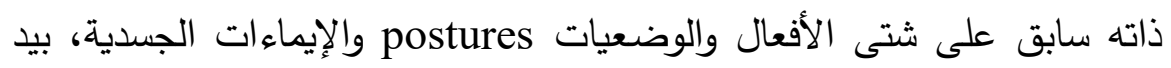

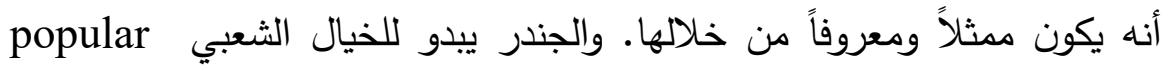

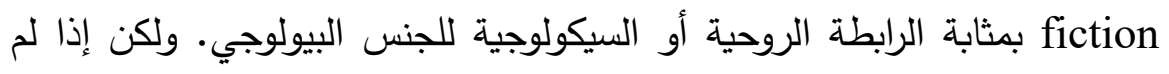

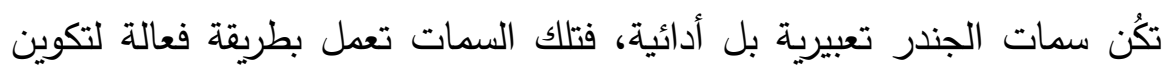
هوية يقال إنها تعبر عنها. من هنا ترى بتلر أن التثرقة بين التعبير والأداء أمراً

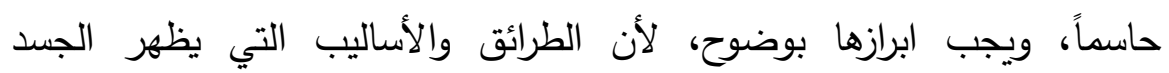

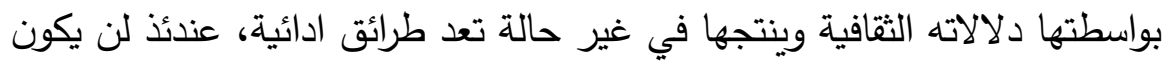

(51)- Moya Lloyd, Judith Butler, From Norms to Politics, Polity Press, Cambridge, 2007, P37.

(52) - Judith Butler, Performative Acts and Gender Constitution: An Essay in Phenomenology and Feminist Theory, P 527.

$$
(0 . r)
$$


هناك هوية موجوده يمكن قياس عليها أفعال أو سمات، حيث لا توجد ثمة أفعال

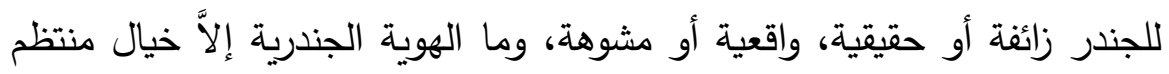
organizational fiction

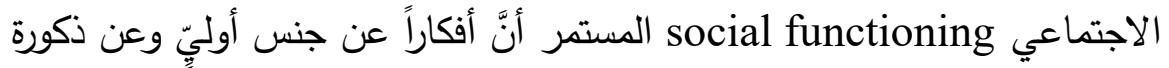
وأنوثة هي أفكار تتكون كجزء من استراتيجيات يتم عبرها إخفاء الجوانب الأدائية

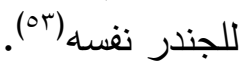
وفي موضع أخر تؤكد بتلر أن الأداء فضلاً عن ارتباطه بالتصنيفات

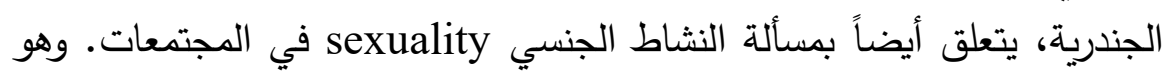

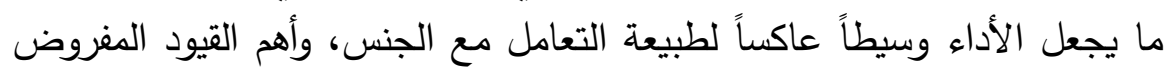

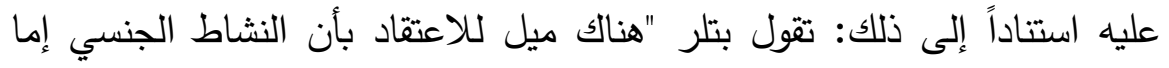

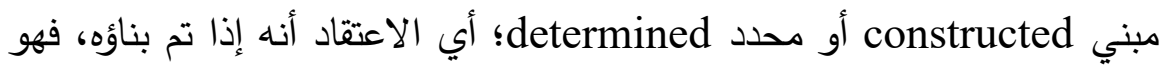
إلى حد ما بمعناه الحر ، وإذا تم تحديده، فهو إلى حد ما بمعناه الثابت. وهذه

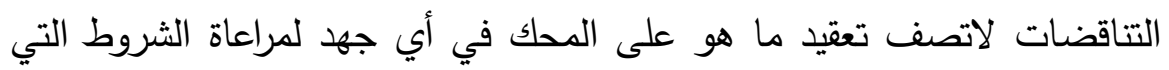

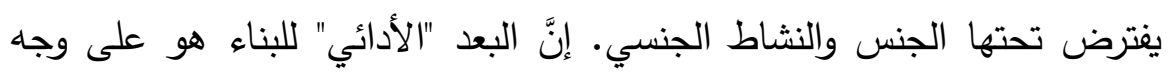

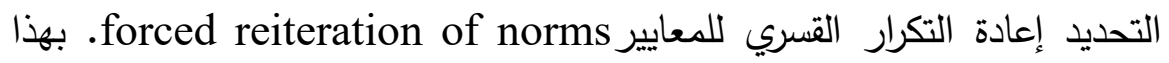

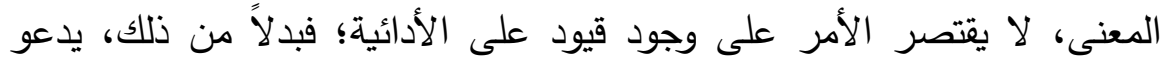

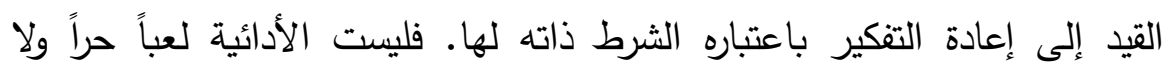

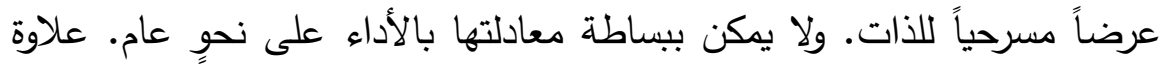

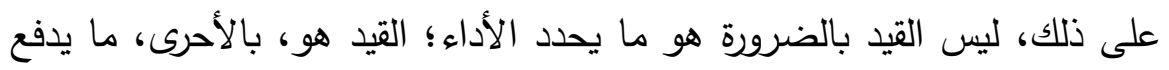

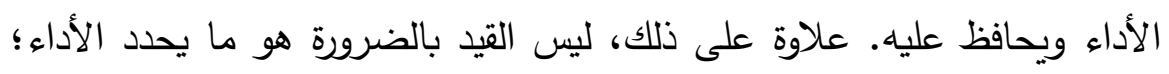

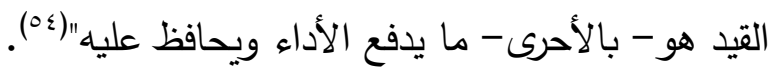

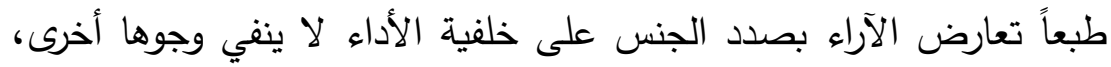

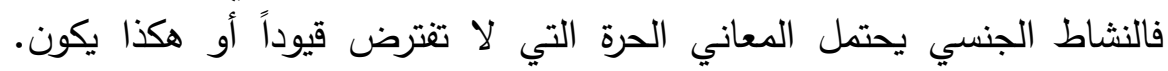

(53) - Ibid, p 528.

(54) - Judith Butler, Bodies That Matter, On the of "Discursive Limits Sex", P 59.

$$
(0 . \varepsilon)
$$


والتكوين يعني أنَّ هناك مساحة حرة للممارسات الجنسية في المجتمعات التي

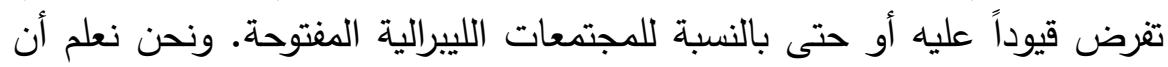

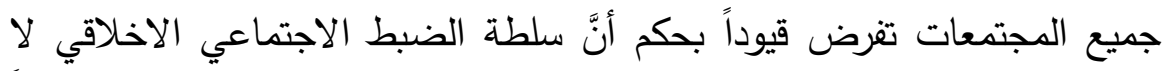

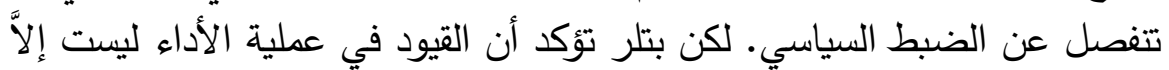

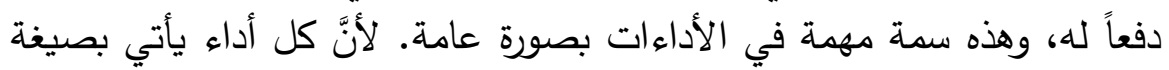

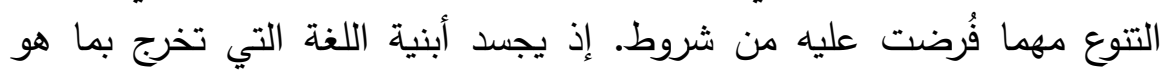
مختلف رغم كونها تسير وفقاً لقوانين وقواعد، ففي القيود تخرج الثروط عن نطاقها وتكتشف حدوداً أخرى.

تصر بتلر على تأكيد الفكرة: "أود أنْ أقترح أنَّ الأدائية لا يمكن فهمها خارج

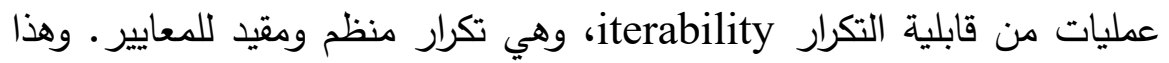

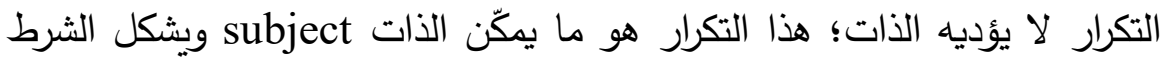

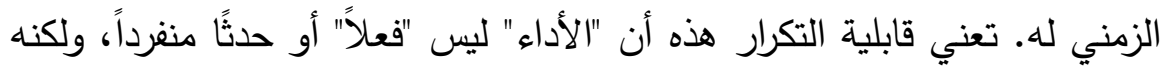

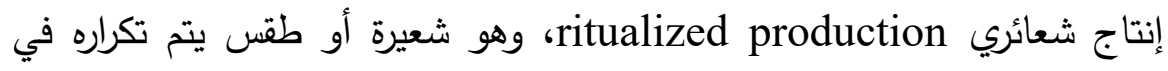
إطار القيد ومن خلاله، تحت وعبر قوة الحظر والتابوهات. مع التهديد بالنبذ ostracism وحتى التهديد بالموت للتحكم في شكل الإنتاج والهيمنة عليه، ولكن

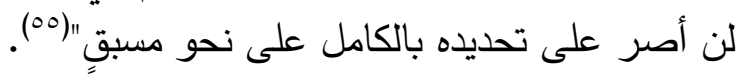

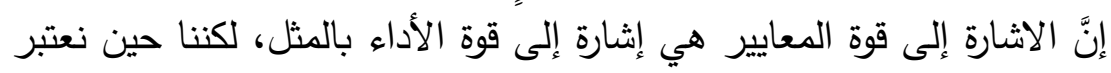

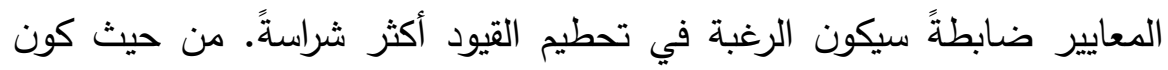

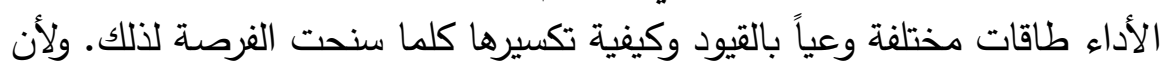

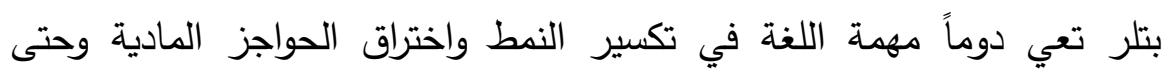

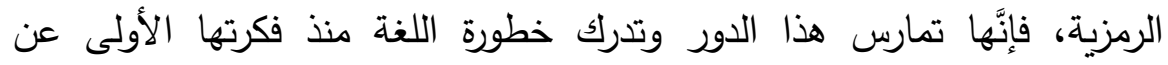
الأداء. فلئن كانت المعايير تحدد أهدافاً لربط المرجعية الثقافية بالغايات فهناك الكأك داخل اللغة قوة الانحراف والتجاوز ولو كانت بسيطة.

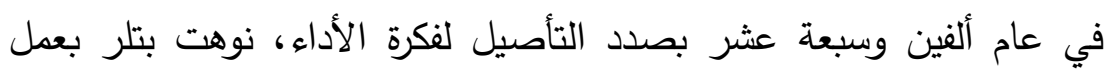

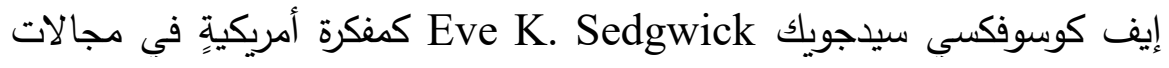

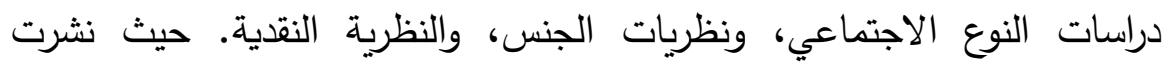

\section{(55) - Ibid, P 60.}

$$
(0.0)
$$




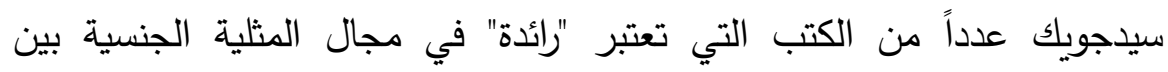

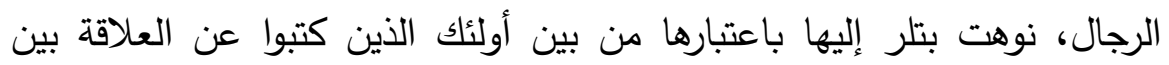

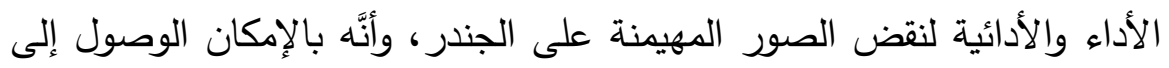

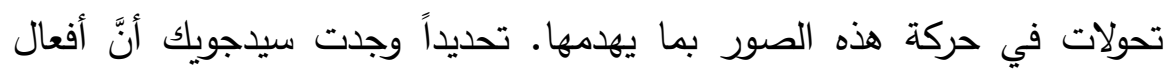

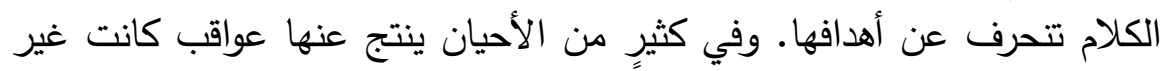
مقصودةٍ، ولكن لها تأثير عميق في التصني التصنيفات الجندرية.

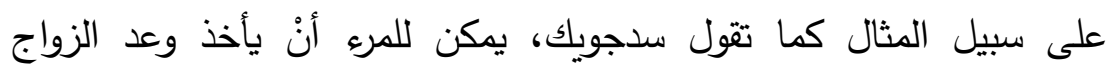
marriage vow

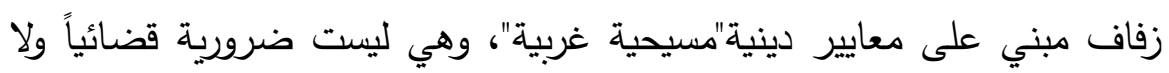

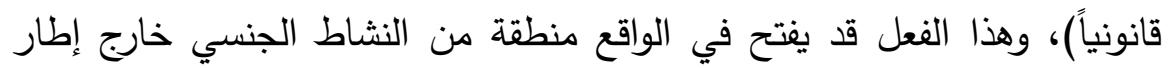

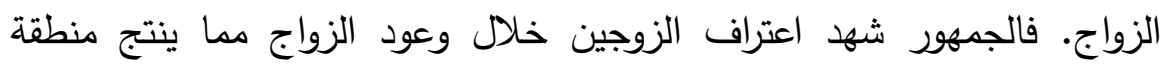

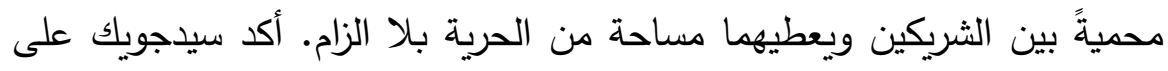

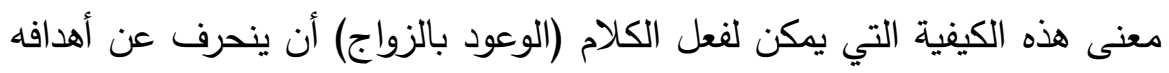

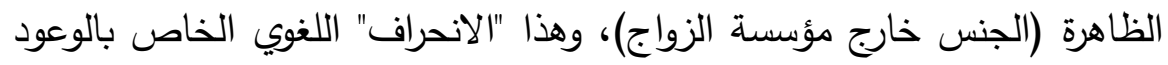

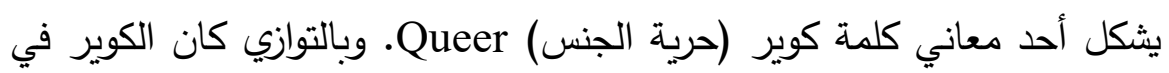

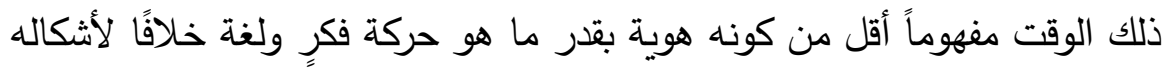

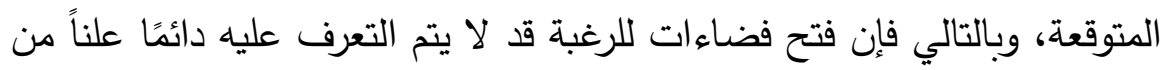
خلال الفئات والمقولات الموجودة(107).

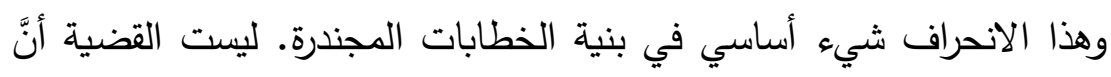

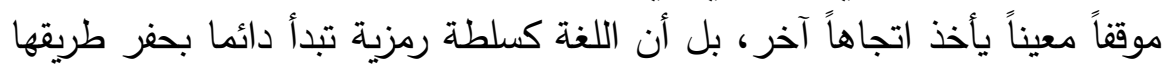

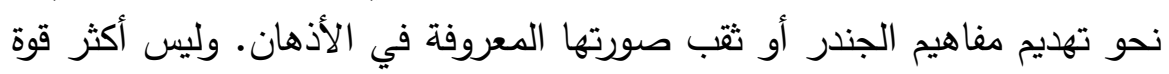

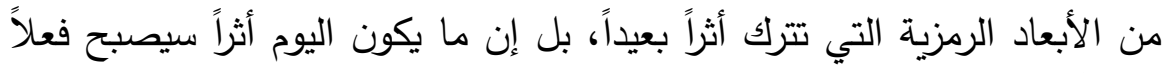

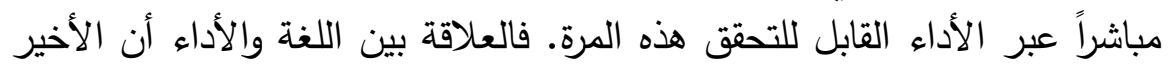

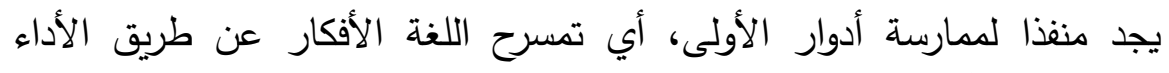

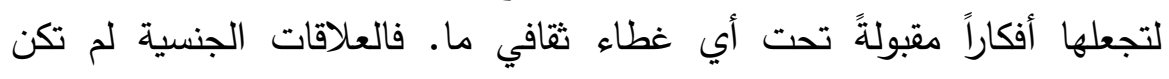

\section{(56) - Judith Butler, When Gesture Becomes Event, P 176.}

$$
(0.7)
$$


متصورة بعيداً عن مؤسسة الزواج، غير أنَّ الوعود (غير الضرورية قضائياً) كأنَّها

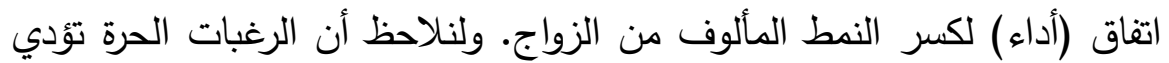

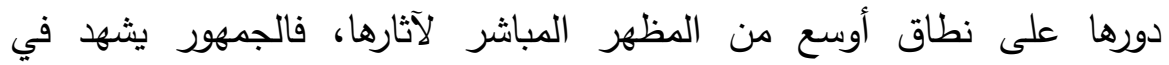

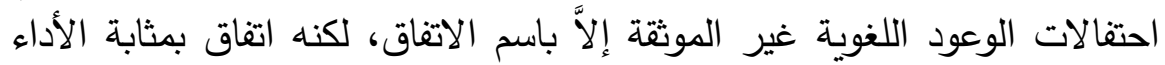
العام الذي يؤكد انحراف الكلمات وكسر الأنماط السائدة.

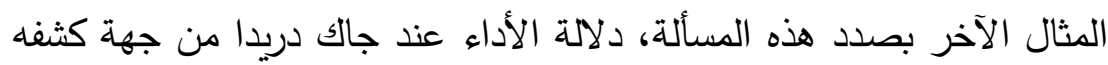

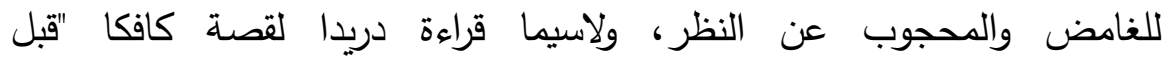

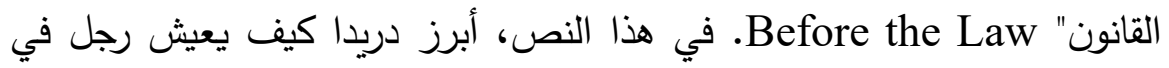

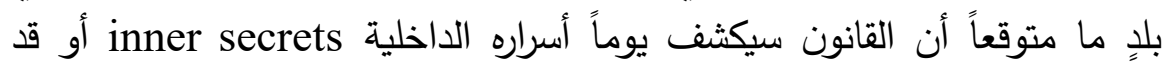

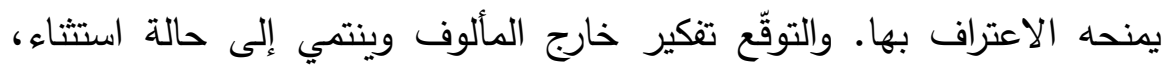

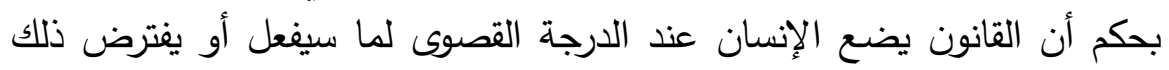

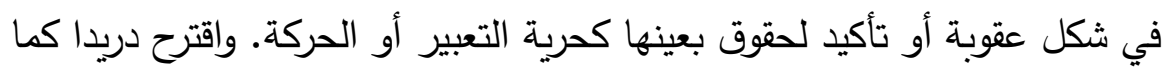

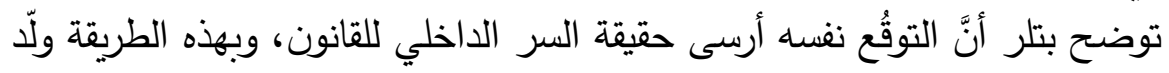

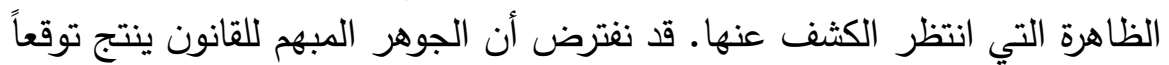

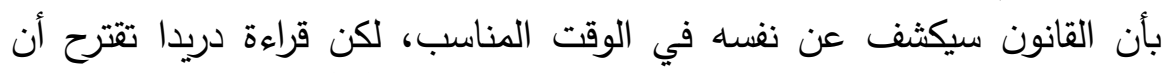

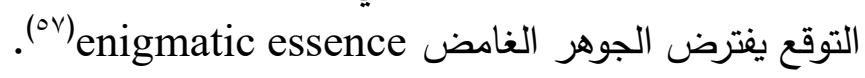
هناك ضرب من تبادل الانكثاف بين ما يحتويه القانون كحالات متوقعه

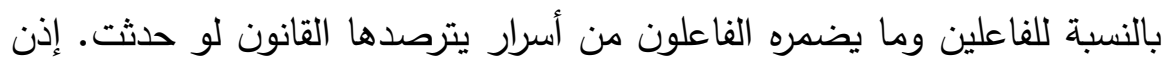

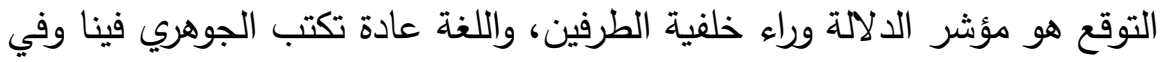

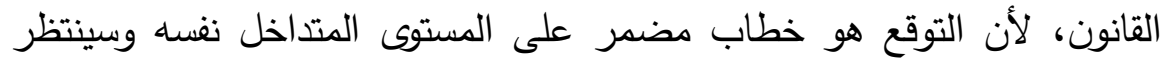

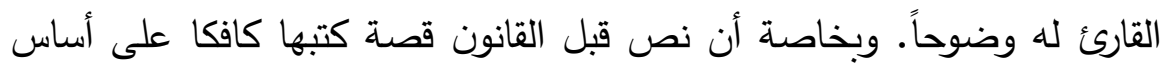

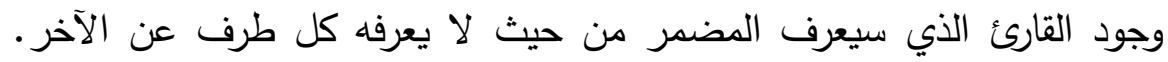

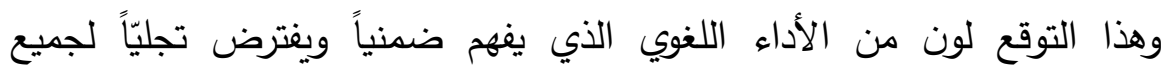

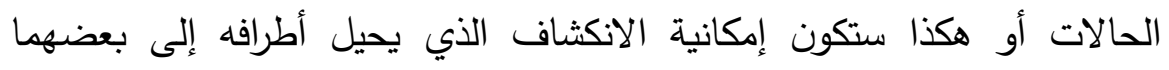

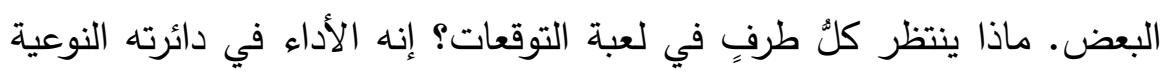

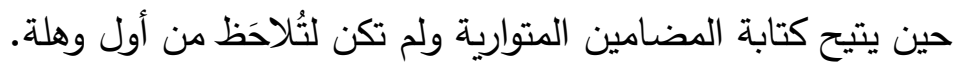

\section{(57) - Ibid, P 177.}

$$
(0 . v)
$$


وبالنسبة لجوديث بتلر، فقد أثبت هذا الانعكاس أهميته عندما فكرت في

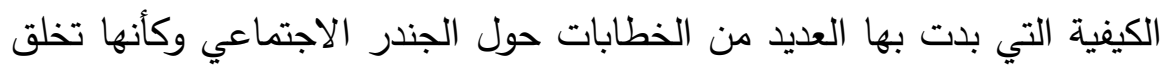

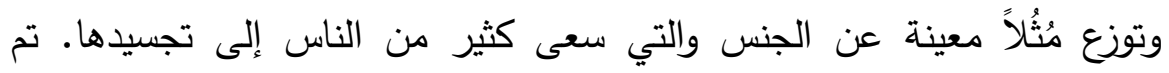

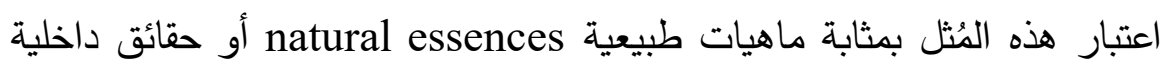

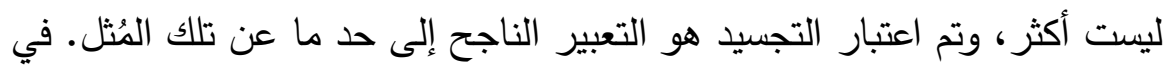

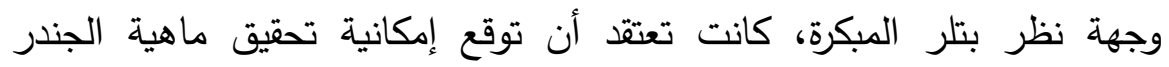

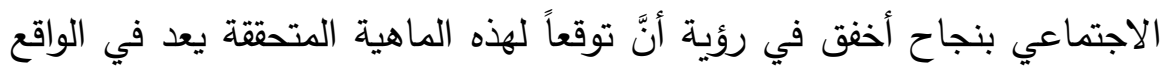

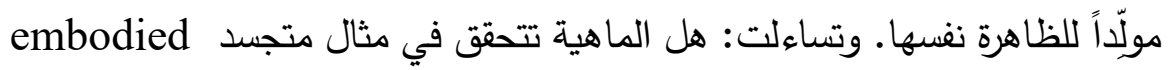

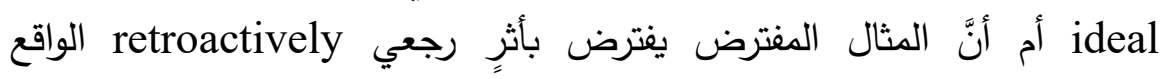

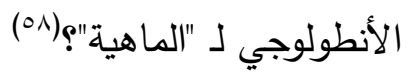

والسؤال هنا يخلخل الصورة التي يقف عندها الجندر ، لأنَّ أداء التوقع يُراوح

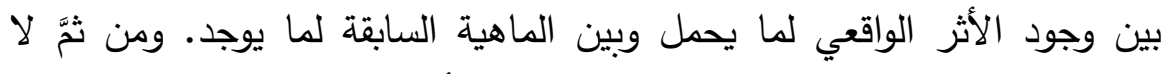

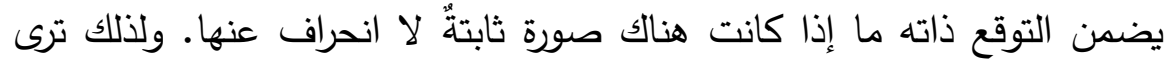

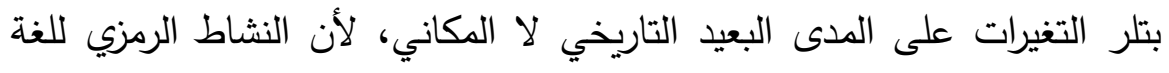

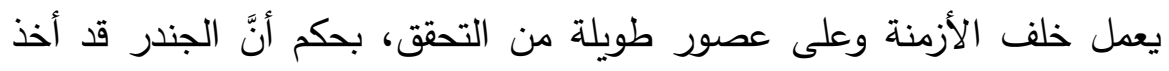

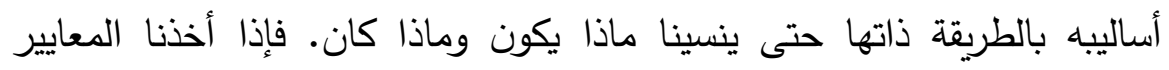

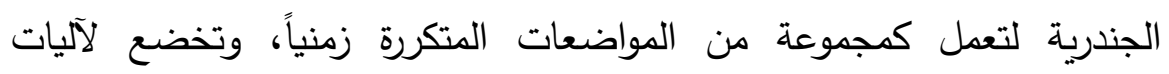

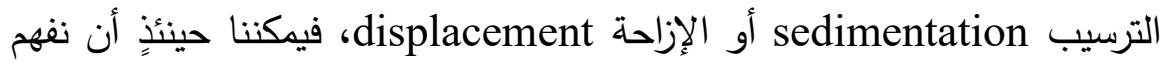
كيف ولّدت مجموعة متكررة من المواضعات آثار الجوهر الداخلي لتلك المعايير .

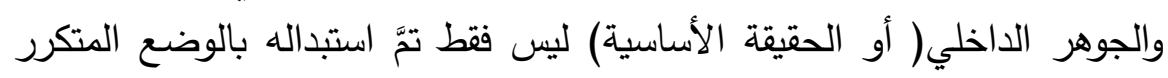

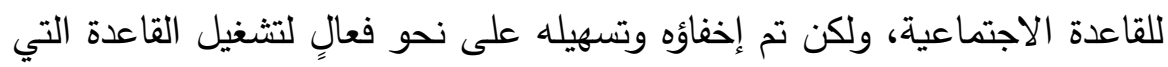
يقف خلفها (09.0. وللّلك فإنَّ ممارسة الكلمات المعبرة عن الجندر لا تلتم بسهولةٍ كأنَّ الأمر محسوم، لأننا سنسمع الكلمات ونتكلمها بينما تحدث ثمة انحرة انحرافات في تكوينها

(58) - Judith Butler, When Gesture Becomes Event, P 177.

(59) - Ibid, P177.

$$
(0.1)
$$


الدلالي، وليس التغير برانياً لكن في أعماق المعايير الجندرية التي تهيمن على التى

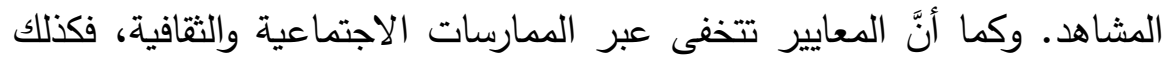

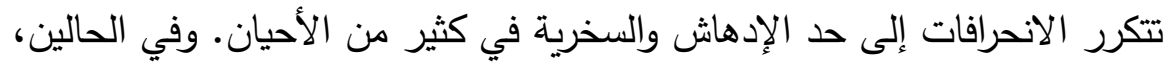

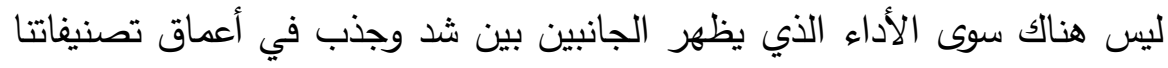

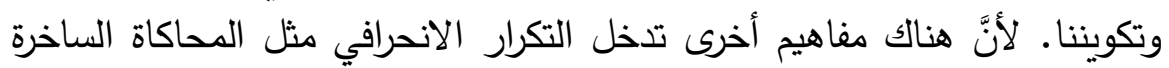
Parody

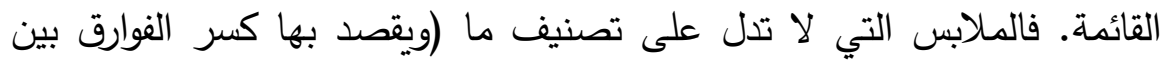

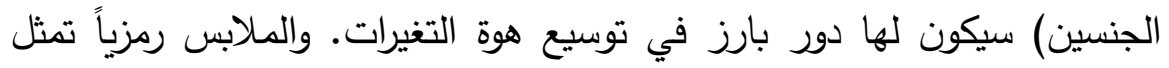
عدم قابلية التصنيف وتحدث لهان تشوديشاً في بنية الجندر وخطاباته. وقد كانت المحاكاة الساخرة محملة حتى بدلالات سياسية إزاء السلطة التئي تمسك بالأنثطة الجندرية، وقد أثثارت ردود أفعال فلسفية، اتخذها البعض للإنثارة

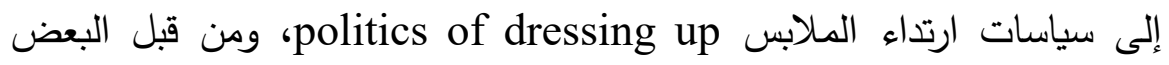

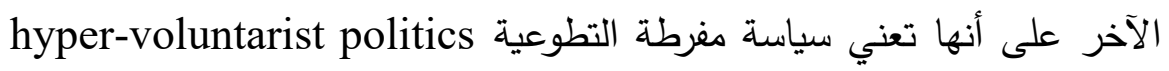
حيث يمكن للذوات تغيير الجنس بسهولة مثلما يمكنهم تغيير الملابس. وبصدد الإنة

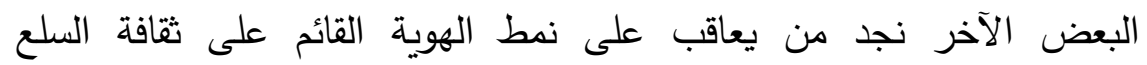
commodity culture

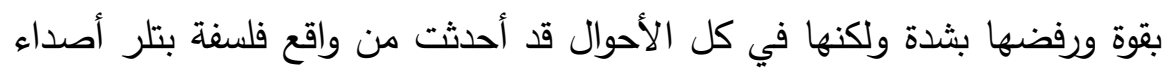

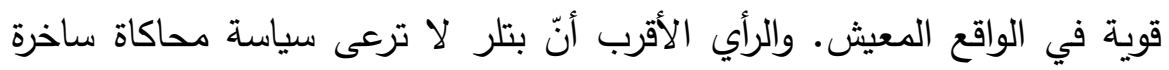

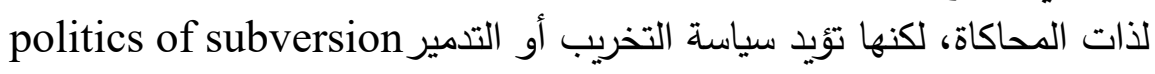

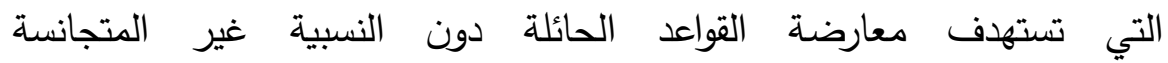
heteronormativity بالتوازي (·).

\section{اللغة: هل يمكن تجاوز الجندر؟}

مثلما أنَّ الجندر يبحث تجارن تاريخياً عن حماية معيارية تجعله سارياً، ترى بتلر

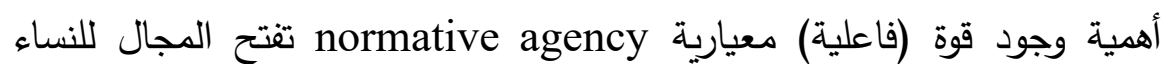

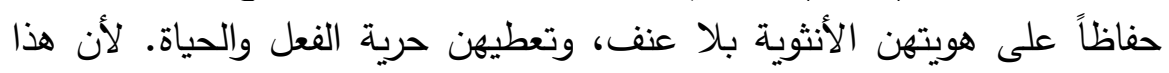

(60) - Moya Lloyd, Judith Butler, From Norms to Politics, P 49.

$$
(0.9)
$$


الاحتفاظ لم يكن متاحاً بسهولة، بل كان ممنوعاً إلاًّ داخل قوالب جندرية وفقاً

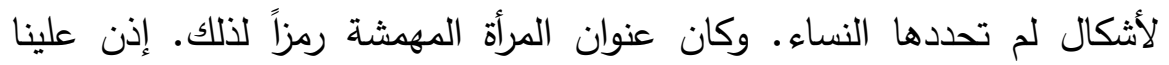

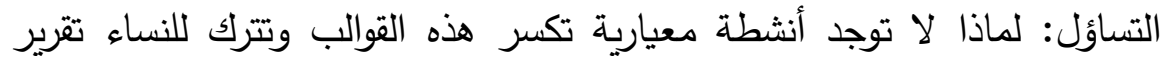

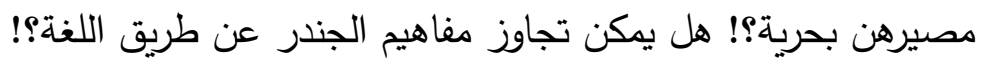

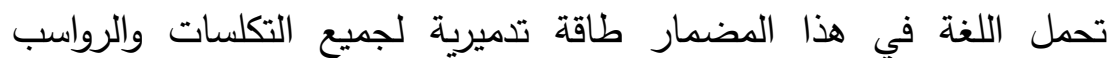

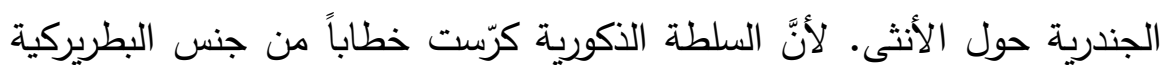

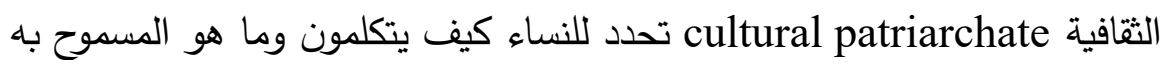

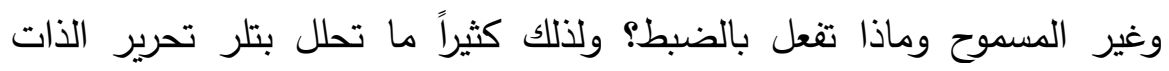

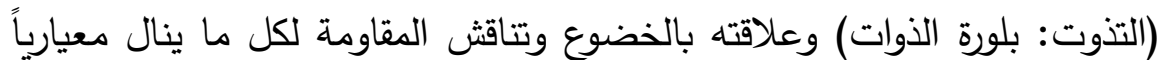

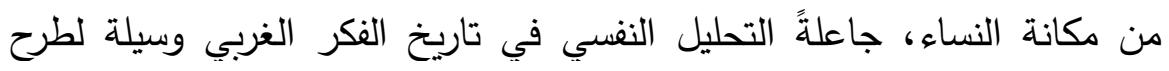

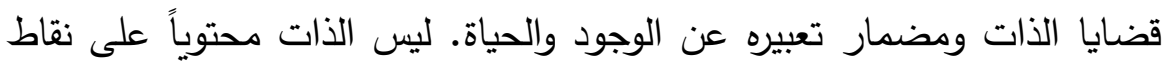

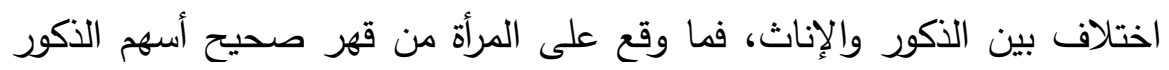

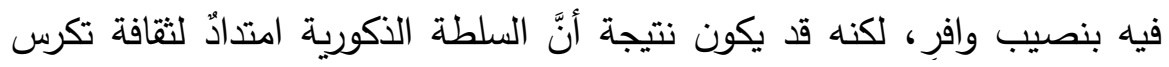

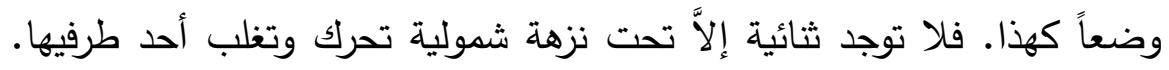

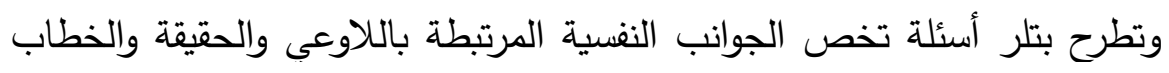
والممارسات الاجتماعية الجندرية، ولقد اتخذت فكرَ ميشل فوكو وسيجموند فرويد التيات

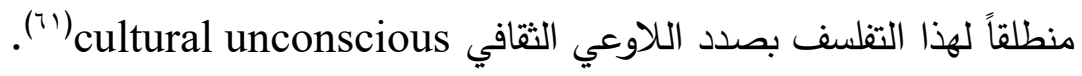
إنّ الفاعلية المعيارية تمارس كثف عمليات التزييف الحاصلة للنساء نتيجة

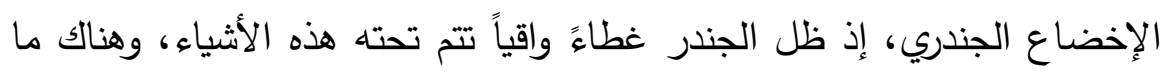

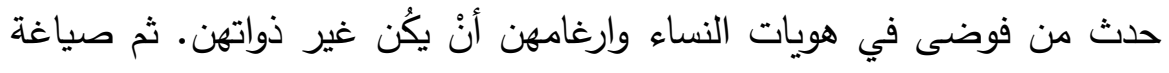

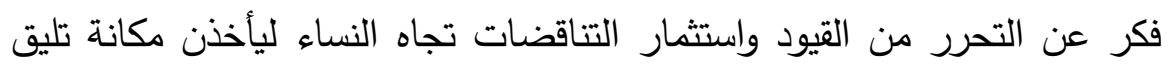

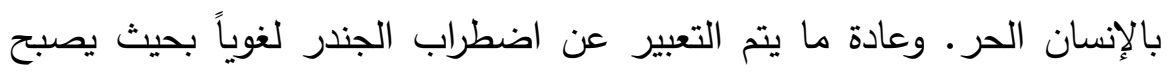

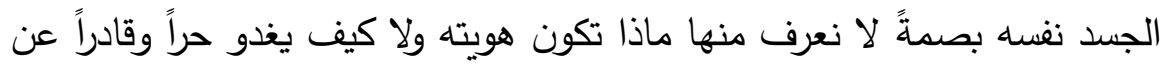

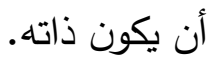

(61) - Judith Butler, The Psychic Life of Power: Theories in Subjection, Stanford University Press, Stanford, California, 1997, PP 87-89.

$$
(01 .)
$$


تثير بتلر إلى رأي مونيك ويتج Monique Wittig بأنَّ الاضطهاد قد يحيل الجسد الأنثوي إلى علامة تظهر الآثار الدالة على الإكراه والقمع، وربما يشكل

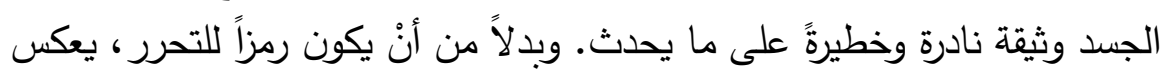

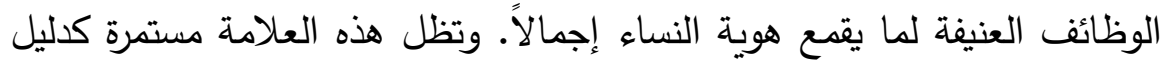

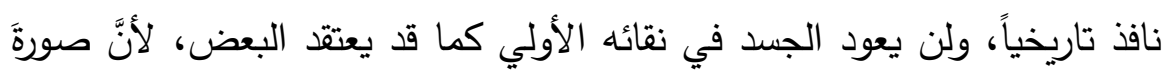
الجسد كمعطى مباشر- -بخلاف هذه العلامات- ليست أكثر من أسطورة طبيعية (Tr). وعلامات الجسد توّثق وجودها في المرجعية الثقافية، ولا تكون فقط مجالاً

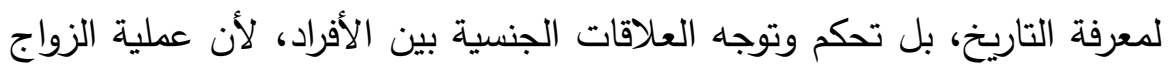

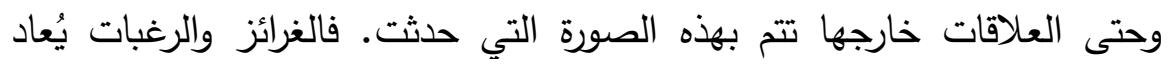

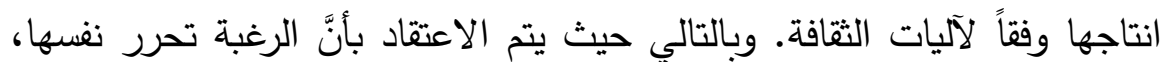
فلن يجري الفعل المترتب عليها سوى عن طريق الاختلافات الجندرية المتاحة.

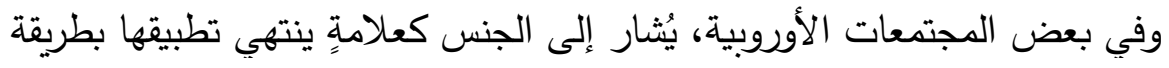

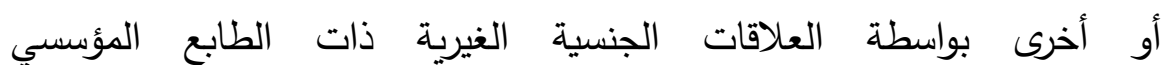
institutionalized heterosexuality من خلال الممارسات التي تناهض بقوة هذه المؤسسة(זّآ.

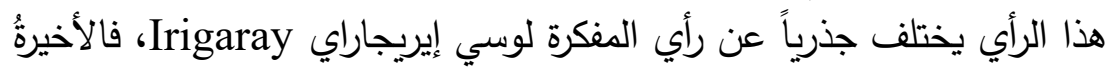

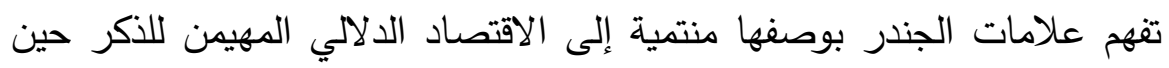

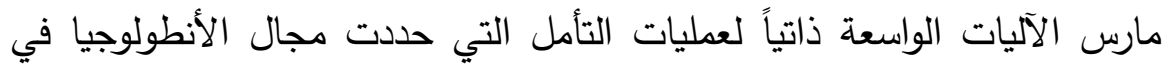
تاريخ الفكر الغربي. وبالنسبة لوتتج كانت اللغة مجرد وسيلة أو أداة ليست كارهية الأنيات

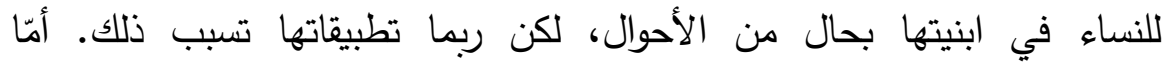

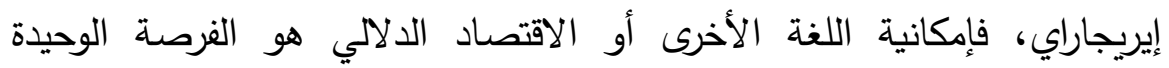

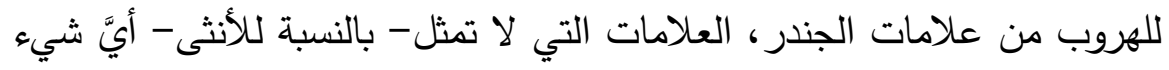

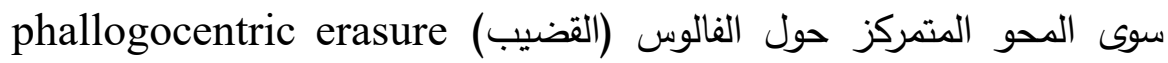

${ }^{(62)}$ - Judith Butler, Gender Trouble: Feminism and the Subversion of Identity, $\mathbf{p} 64$.

(63) - Ibid, P64. 
تجاه الجنس الأنثوي. وبينما تسعى إيريجاراي لفضح العلاقة الثنائية المزعومة بين

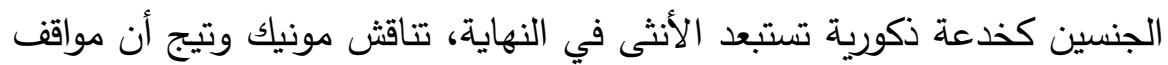

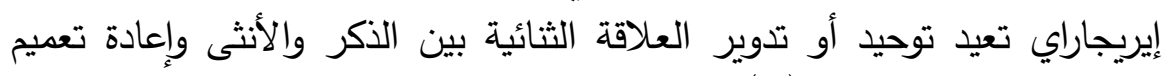

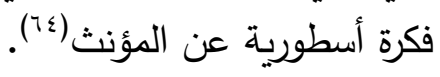

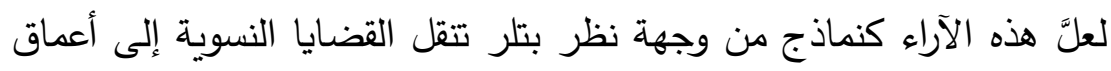

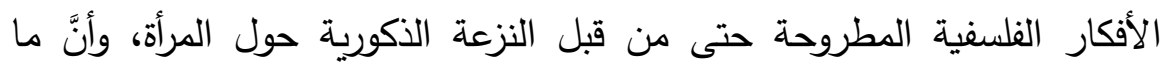

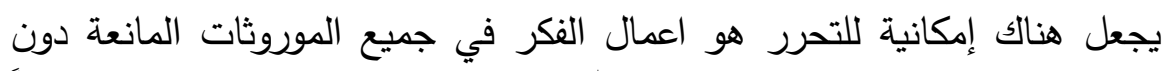

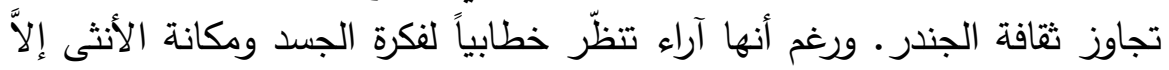

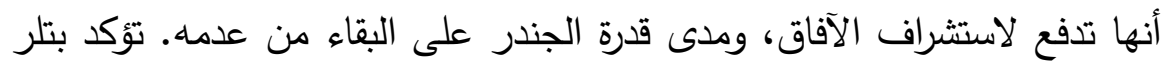

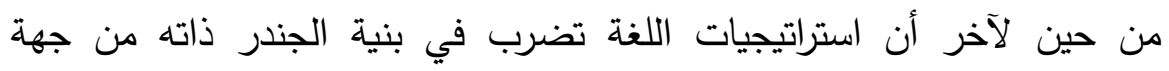
التكوين والأداء والمعاني التي يحتملها.

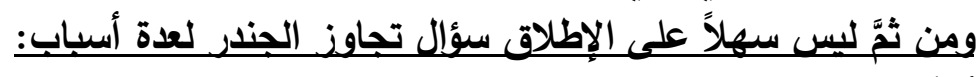
أولاً: أن التراث الجندري لا يفتأ يعود في أشكال متباينة ولا يأخذ بالضئل بالضرورة

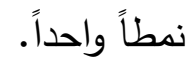
ثانياً: لابد للغة أنْ تحذر من التعبيرات المباشرة وحتى الملتوية حول قضايا

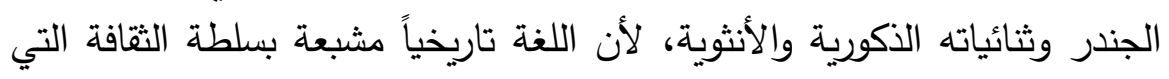
تفرزها.

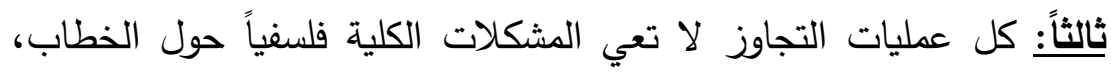

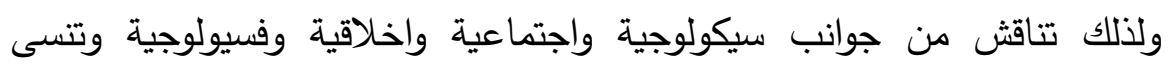
التأسيس الفلسفي. لريعاً: المعالجة الجزئية للمعايير الجندرية يجعل الباقي منها قادراً على القفز

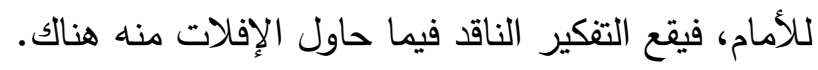

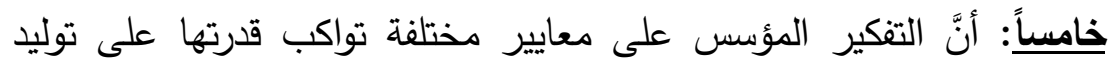

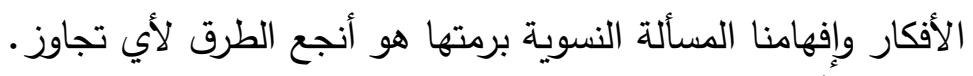

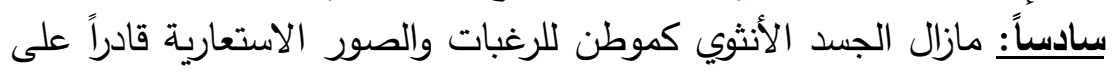

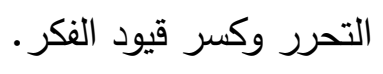

\section{(64) - Ibid, P65.}


سابعاً: سيظل ابتكار أساليب جديدةٍ في الكتابة والتعبير له الاسهام الأبرز في تكسير صور الخطابات النمطية والقابلة للتكرار. على سبيل المثال هناك الكتابة بشكل ساخر، أو المحاكاة الساخرة كما نوهت بتلر بصدد المودات والمظاهر

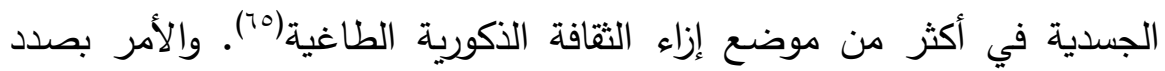
اللغة يمثل التفاعل المعقد complex engagement مع النصوص والأفكار (بי) لتحدث هناك مسؤولية فهم الجندر ومناقشة إمكانية تجاوزه. ترى بتلر أنه في الفكر المعاصر، يتم الحديث عن الجسد عبر الخطاب كأنه كلام ملّفق أو كاذب. وهذا غير صحيح بالمرة، وأحيانا يجرى ذلك كما لو أنذض الجسد مخلوق من عدم بحسب الخطابات المتداولة. ولذلك يجب على المّلى المفكر ألَّا

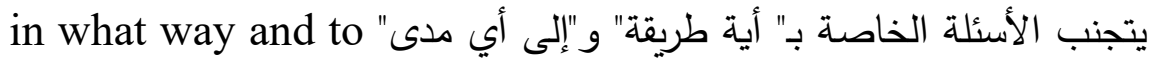
what extent أنه يجب الاهتمام بالذات التي تعبر عن جسد حي أو العكس: جسد حي يجسد الذات، أو كما تعنون بتلر كلامها عن ذلك المعنى بعنوان دال: كيف استطيع

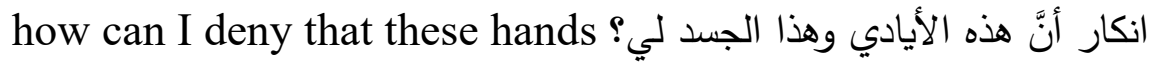
(كم) and this body are mine?.. كما هي نحن خلال أجسادنا، يمكن أن نرى ماذا فعلت به المواضعات الجندرية.

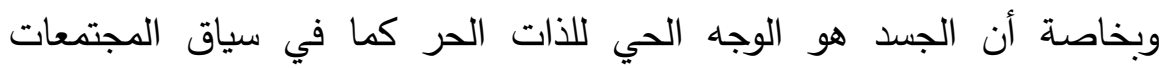
الليبرالية، وأنَّ الجسد ليس موضوع انكار إلاَّ من جهة اللغة التقليدية التي تتناوله. أمَّا اللغة الحية، اللغة التي تستجلي علامات القهع بصدده، وتزيح عنه القيود التي يرسف فيها، فهي لغة ترسم وجوها أخرى دوماً، وتستطيع سبر أغوار الجندر والوعي المنقسم (المتنوع- المختلف) بتراكماته.

${ }^{(65)}$ - Judith Butler, Merely Cultural, In: Social Text 52 / 53: Entitled by Queer Transexions of Race, Nation, and Gender, Magazine is published quarterly (Volume 15, Number 3 and 4, Fall / Winter 1997), Duke University Press, Durham, 1997, p267.

(66) - Judith Butler, Senses of the Subject, Fordham University Press, New York, 2015, P149.

(67) - Ibid, P18.

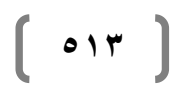


linguistic ينئذ ينبغي تجنب- كما تذهب بتلر - النزعة الواحدية اللغوية

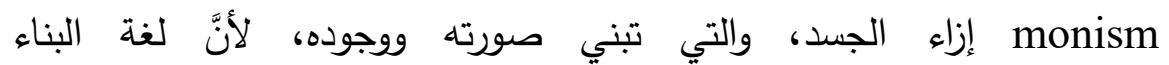
construction

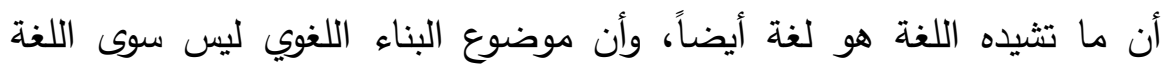
نفسها. علاوة على ذلك، يتم نقل فعل هذا البناء من خلال التعبيرات اللفظية التي التي التياء

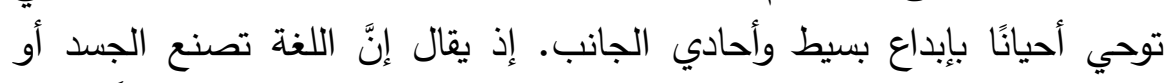

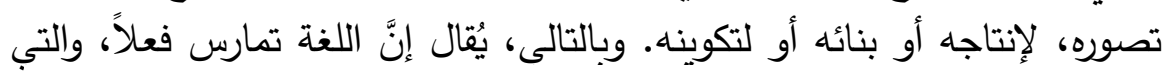

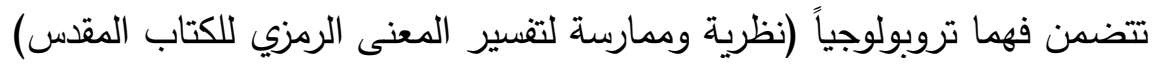

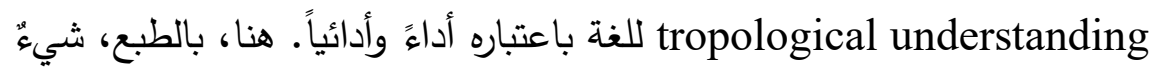

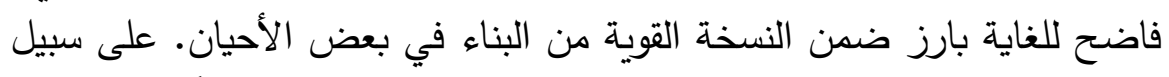

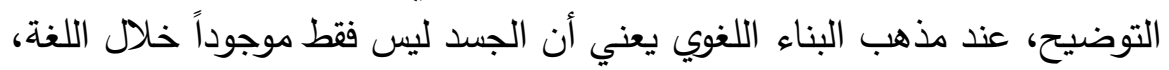

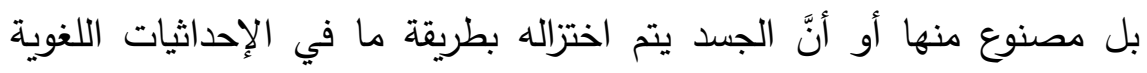
linguistic coordinates هناك أشياء غير لغوية في القضية"(7N).

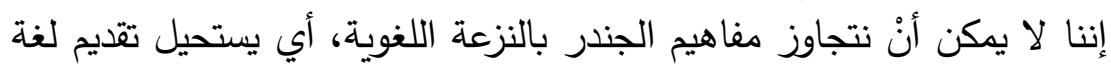

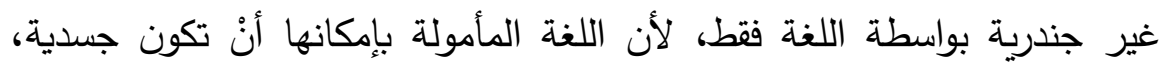

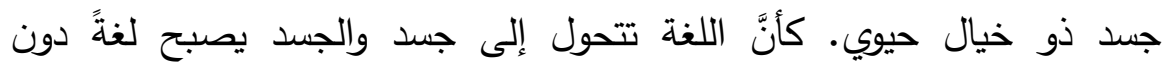

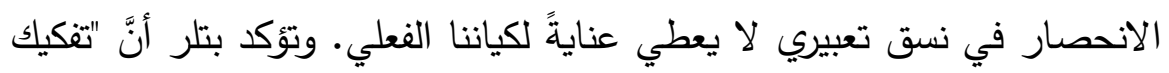
deconstruction

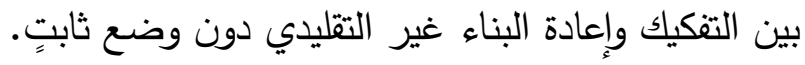

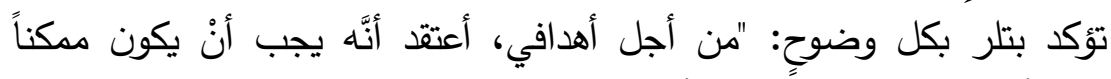

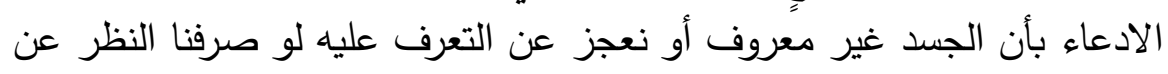

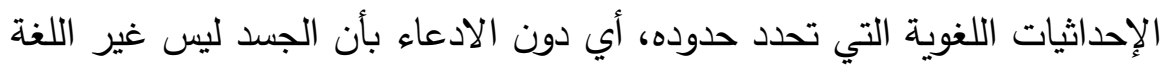

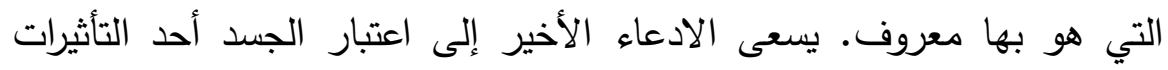

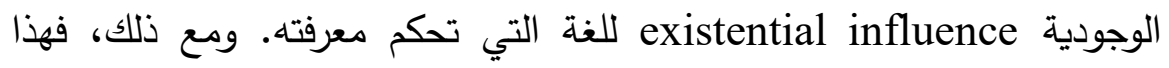
الرأي يفشل في ملاحظة عدم قابلية القياس non-measurability بين المجالين

\section{(68) - Judith Butler, Senses of the Subject, P19.}

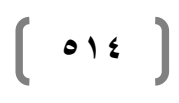


(الجسد واللغة)، وهو عدم قابلية للقياس ولا يمثل تعارضاً بينمها على وجه

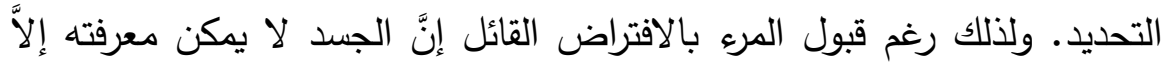

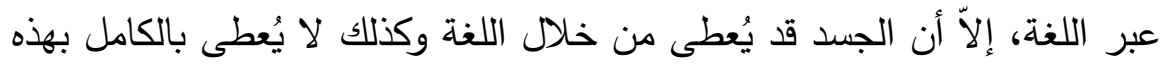

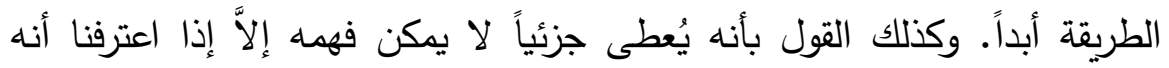

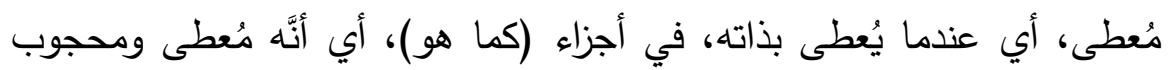

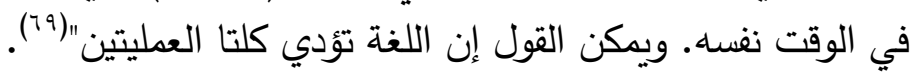

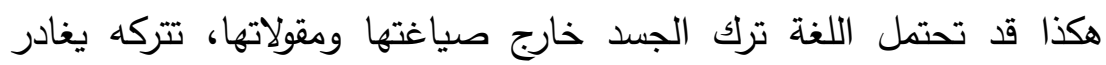

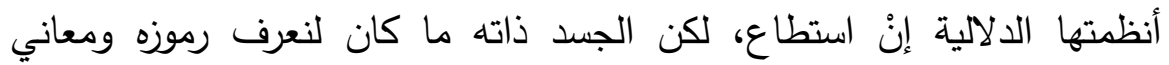

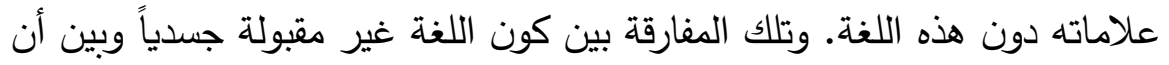

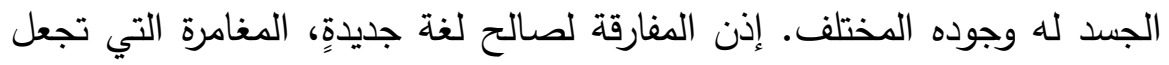

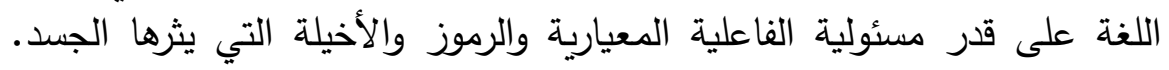

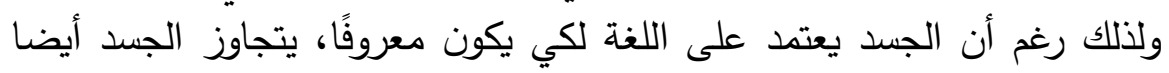

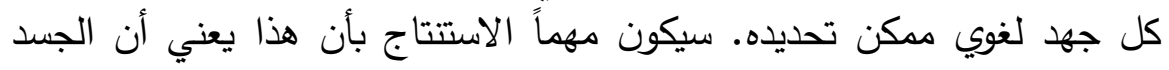

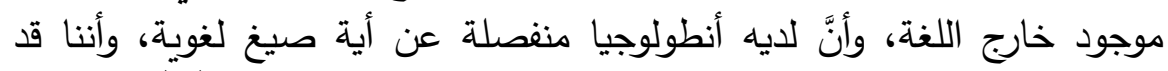

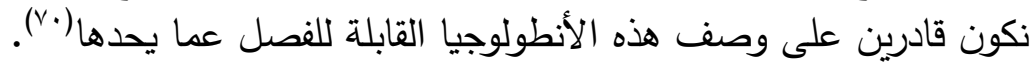

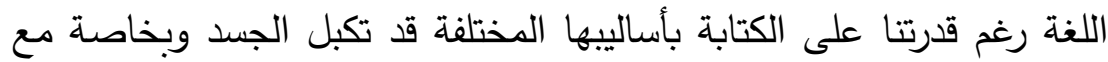
تحميلة بأنساق الدلالة التي يُفهم في إطارها، فالثقافة كنظام رمزي

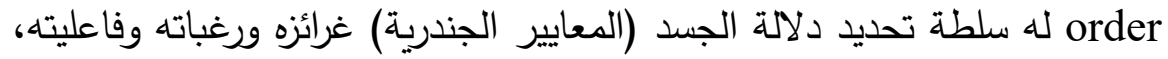

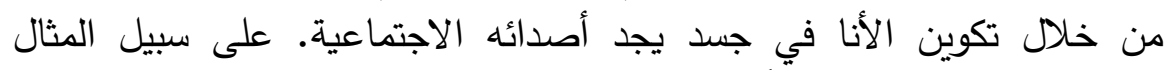

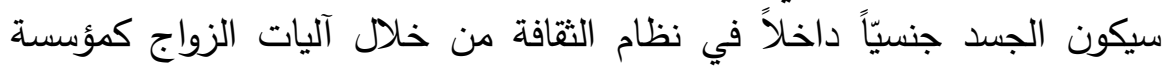

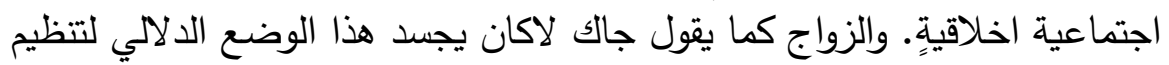

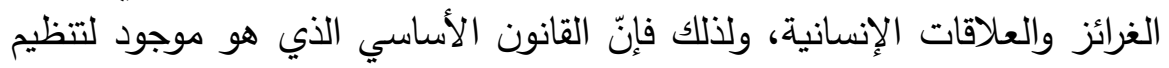
العلاقات الزوجية يفرض مملكة الثقافة kingdom of culture على مملكة الإنيانية

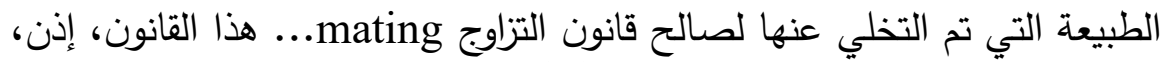

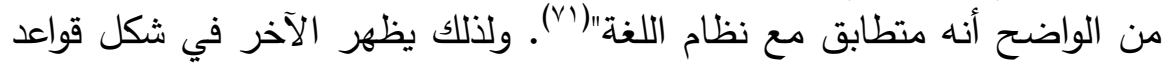

(69) - Ibid, p 20.

(70) - Judith Butler, Senses of the Subject, P 21.

(71) - Jacques Lacan, Écrits, A Selection, translated by Alan Sheridan (W. W. Norton, New York, 1977), p 66.

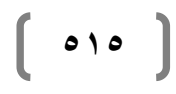


لغوية وقوانين ومؤسسات ومبادئ حاكمة للسلوك الإنساني وترمز إلى الهيمنة التي يفرضها المجال العام عبر اللغة والعلامات. كلٌّ فعلٍ جسدي حر يُحرك رواسب اللغة بهذا الأساس، ومن ثمَّ كانت خطورة اللغة أيضاً ارتباطاً بالجسد أن اللغة تخدش المعايير السارية فيها عندما تتحرف

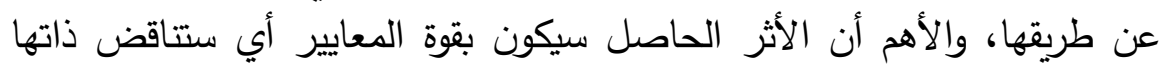

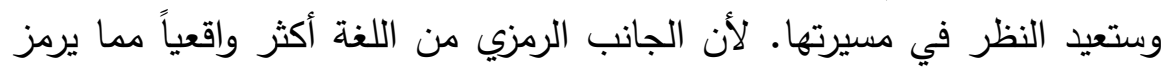

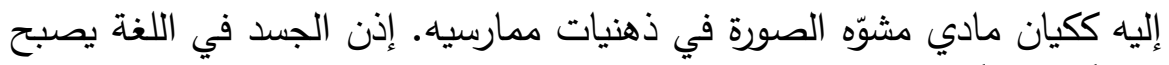
قانوناً، نظاماً من الدلالات، طاقات كامنة تحت الهو علامات، دهات، وكذلك يمكننا تفجير

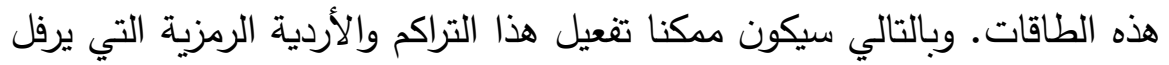

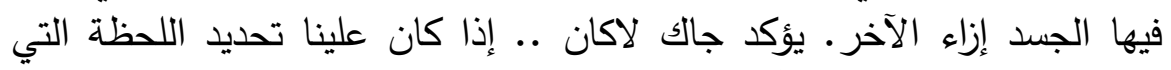

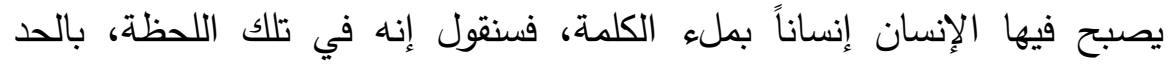
الأدنى الذي نريده، يدخل في علاقة رمزية، وستكون الاشكالية من ثم هي مفترق

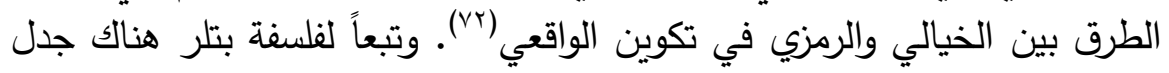

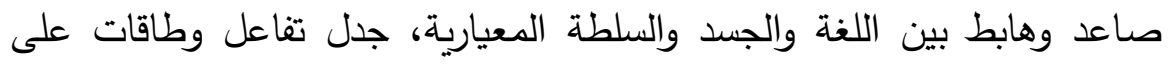
ممارسة الأصداء في مسرحة العلامات الجسدية كرموز لفكر وأساليب مختلفة في الحياة.

عندئذ تصبح اللغة كما ترى بتلر طاقة رمزية بمثابة الوسيط بين الجسد

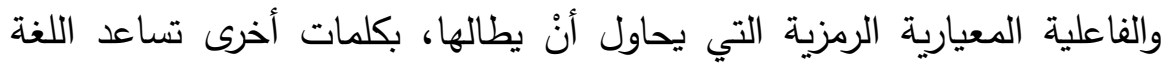
التي يخرج خلالها الجسد على تثكيل ذلك الجسد وتثبيته في قابلية معرفته لـانه knowability

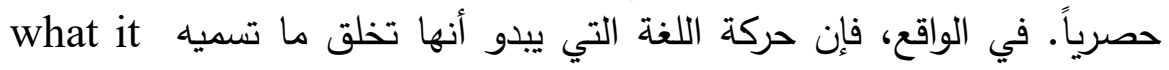

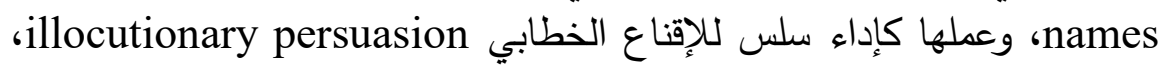
تغطي أو تبطل الاستبدالات substitution والمجازات trope التي تظهر بهاء اللغة كعمل متعدٍ transitive، والتي من خلالها تحتشد أية لغة بطابع أدائي

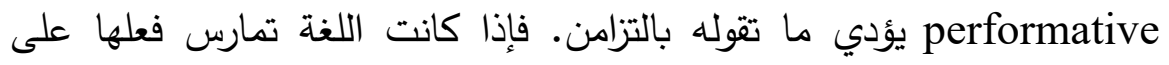

(72) - Jacques Lacan, The Seminar of Jacques Lacan, Book I: Freud's Papers on Technique 1953-54, Edited by Jacques-Alain Miller, Translated With Notes by John Forrester, W. W. Norton \& Company, Cambridge University Press, New York, 1988, p74.

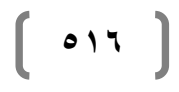




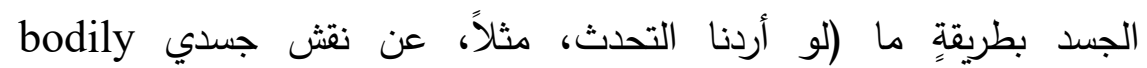

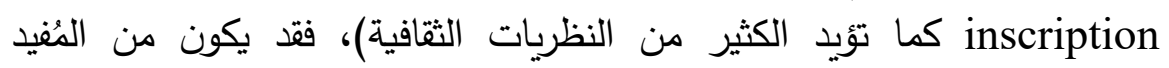

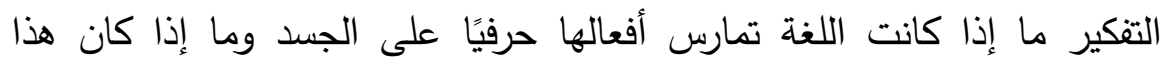

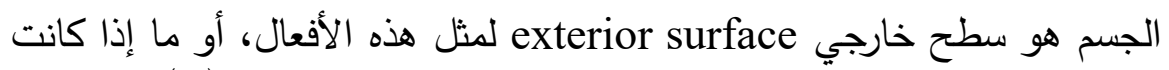

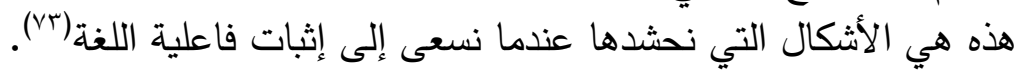

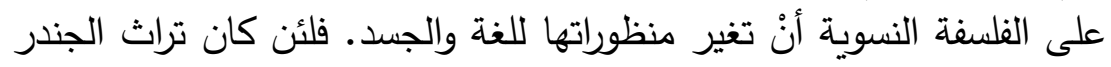

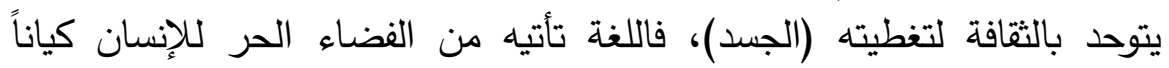

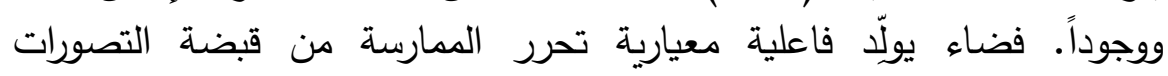
الجندرية. وإذا كان صعباً التخلص منها، فعلى الأقل يكون الأداء كاشفاً لتكرار

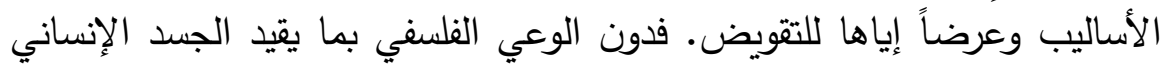

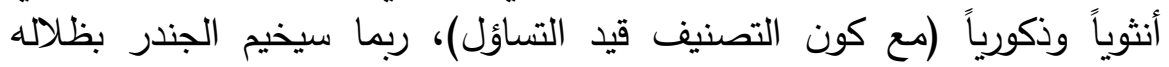

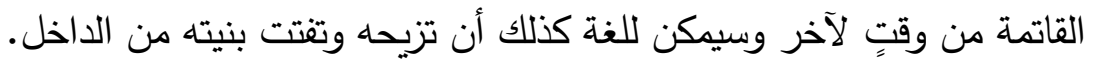

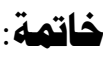

فلسفة اللغة النسوية feminist philosophy of language منظور (مختلف) للغة والفلسفة. أقول منظوراً مختلفاً وليس جديداً تمام الجدة، لأن الاتجاهات النسوية (تعيد توظيف) فلسفات ما بعد الحداثة والتنكيك والتحليل النفسي ودراسات اللغة في تتظيراتها. وربما لم تكُن مذاهب الفلسفات التهات التقليدية

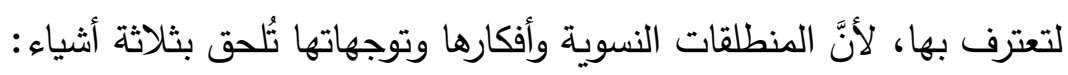

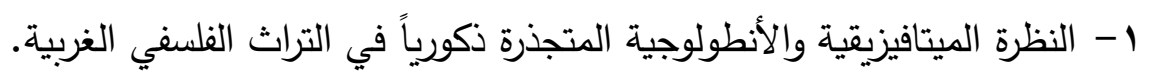
r- الفلسفة الذكورية التي تهمل النساء، وهي في أغلبها اتجاهات مسيَّسة ومؤدلجة حول الحقوق والمرأة والجسد. r-غياب القضايا النسوية لا بجندرها، بل باختلافاتها النوعية وقدرتها على انتاج مفاهيم وأساليب فلسفية جديدة.

(73) - Judith Butler, Senses of the Subject, P21.

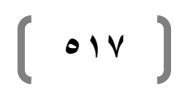


إذن بحب تحديد عدة نقاط:

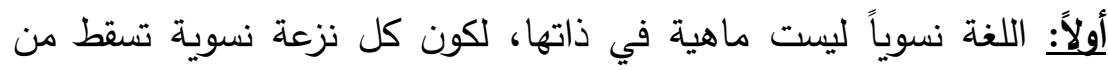

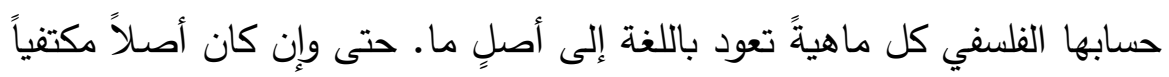

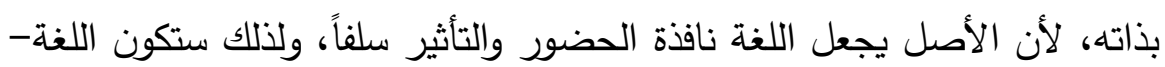

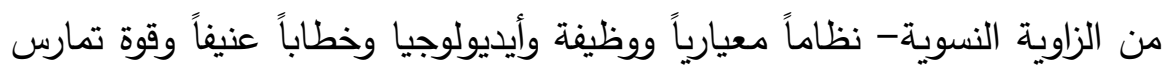
سلطةً ونظاماً رمزياً. ولأنَّ الأنثى تخشى ضئَ ضياع حريتها، بل تعتبر كلَّ كيانها

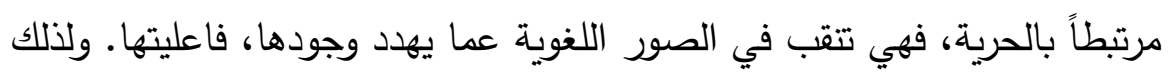

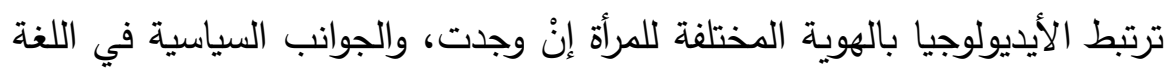
تصطنع مقولات تقلل من شأن المرأة. ثانياً: استراتيجيات اللغة، حيث تخلات تفلع الفلسفة النسوية معالم اللغة على قضايا تعالجها كما فعلت جوديث بتلر بصدد الجندر، ولذلك كانت تعتبر الجندر غير

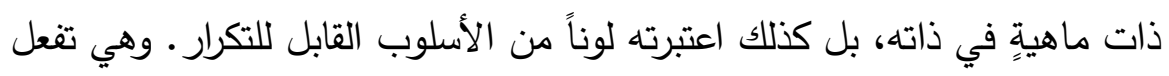

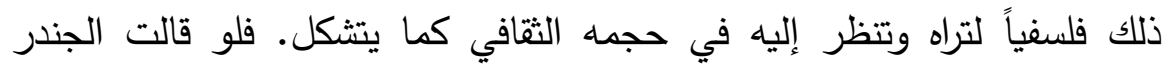
ماهية لكانت قد خلقت "وحشاً تاريخياً" يريد أن يلتهم كل أنثى تقابله. إنَّ فلسفة لتهل

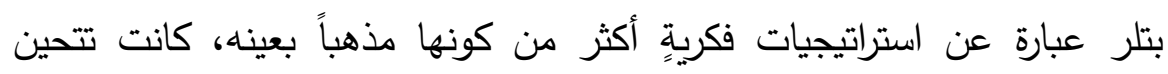

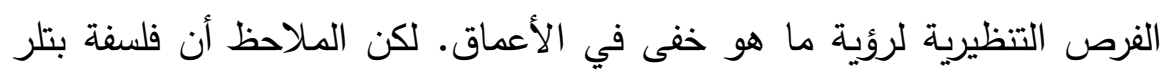

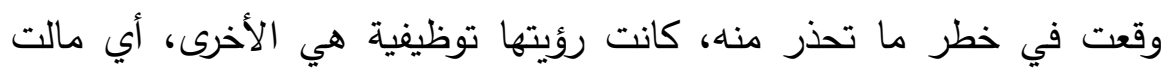

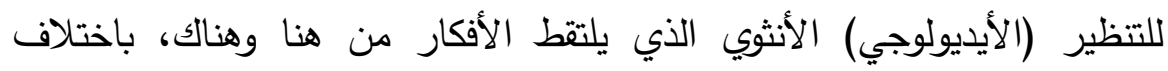

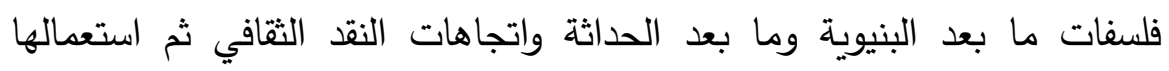
للدفاع عن قضايا المرأة. وذلك لكون معالجة هذه القضايا لا تبتكر مفاهيم وأدوات فلسفية أصيلة.

ثالثاً: بلاغة الجسد، وهي الصور والعلامات التي يبرزها الجسد الأنثوي بفضل الحضور الثقافي له، وهي بلاغة ليست بمعناه التقليدي كالمجازات 
والاستعارات اللغوية، بل بالجوانب السيميائية ورموز الثقافة التي تحدد أطره. وربما

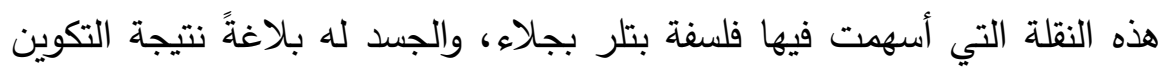

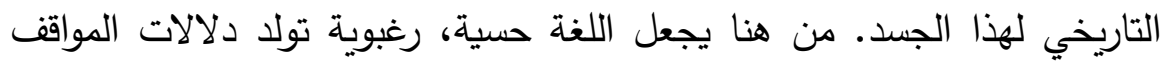
الحسية. ولذلك كانت الفلسفة النسوية أقرب الفلسفات لفهم تراث الجسد، نظراً لكونه يجسد روح الحياة وطبيعتها، إن الانثى هي التجلي الثري لتنوع الطبيعة في لئه ذاتها. وكانت بتلر دقيقة في اعتبار الجسد وسيطاً كاشفاً لطبيعة الممارسات

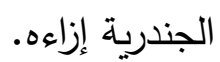

رليعاً: الفاعلية المعيارية للدلالة، وهي فكرة تعيد الفلسفة إلى المشهد النسوي

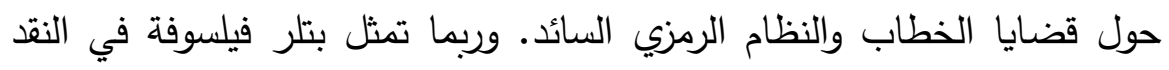

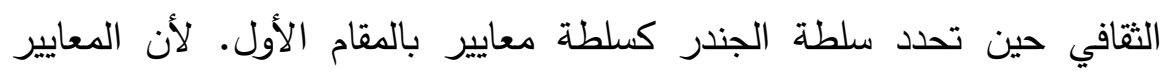

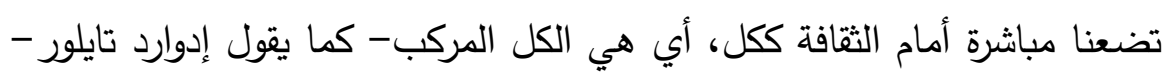
من عناصر أخرى تستدعي أوصالها لإعادة تدوير الأفكار لصالح مركزيتها.

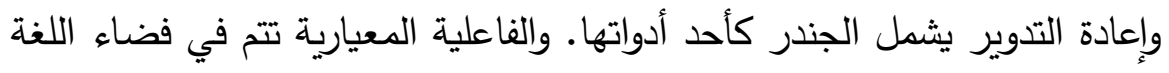

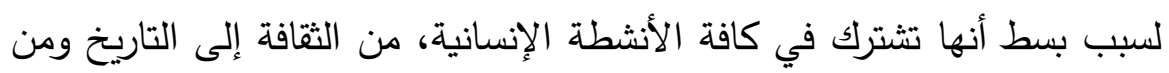

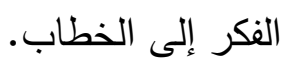

خامساً: مسرّحة اللغة، وهو مفهوم فلسفي بالمقام الأول. لأن كل متعلقات

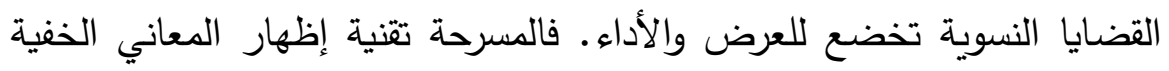

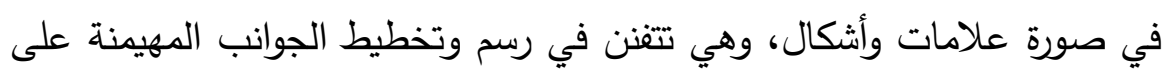
الجسد الأنثوي من حيث المبدأ. وكأننا لابد أن نترك المجال واسعاً وتهاً لتقول اللغة ما تتقله بإجراءات الدلالة وقوة المعنى. هناك تيمة تمثيلية بارزة في فلسفات اللغة التهات النسوية وهي إظهار إيقاع الممارسات الجندرية بثكل دراماتيكي، ولذلك تهتم كثيراً بما يسمى بالكتابة النسوية في الأدب والفلسفة والدراما. ولعل خاصية السخرية 
التي تراها بتلر في أفعال المرأة تجاه السلطة الذكورية أبرز الجوانب في فكر بتلر ، لأنها تلتقي بالمفارقات في السياسي واللغوي.

سادساً: الأداء إيقاع فلسفي يخترق كافة الدجالات الثقافية والاجتماعية، إنه

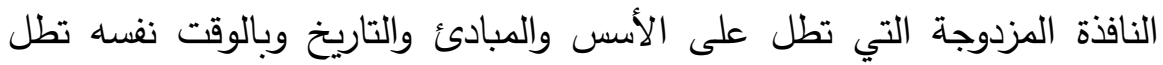

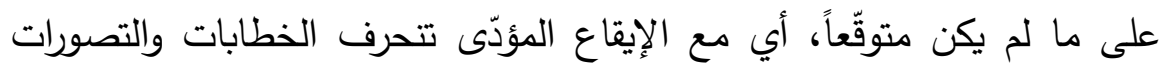

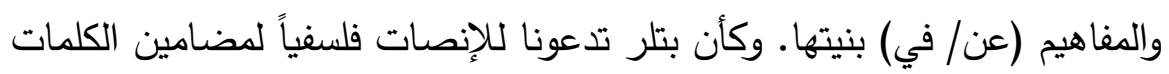
والخطاب والأفعال. ويلتقي الأداء مع المسرَّحة اللغوية كفعل فلسفي يعرض إنهان أفكاراً مختلفة، بالأحرى يطفو وينوّع بنيتها.

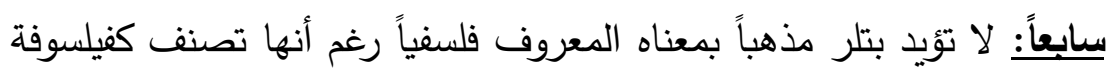

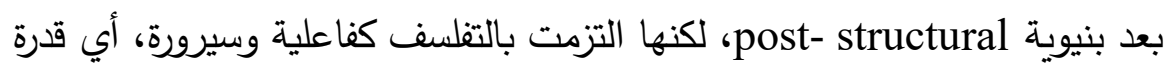

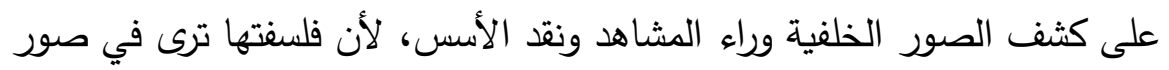

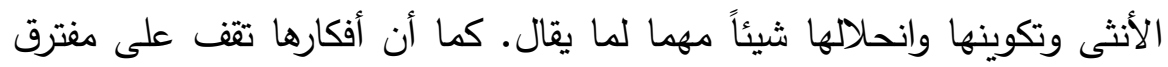

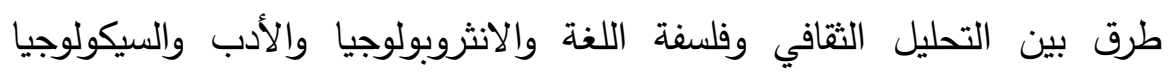

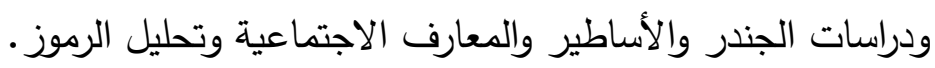

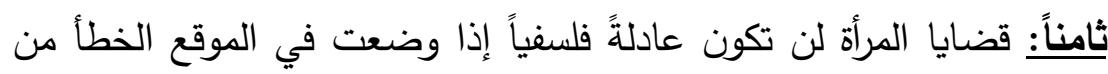

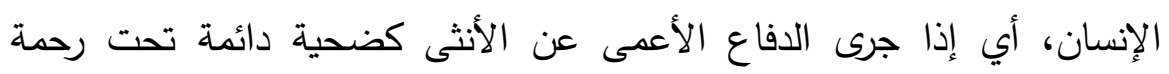

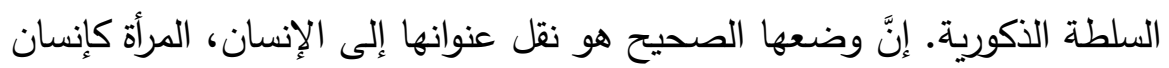
لها كامل الحقوق والقدرات لا كأنثى وحسب. والفلسفة تعرف الإنسان داخلنا نحن

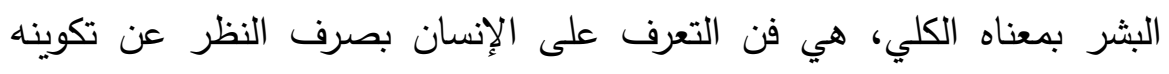

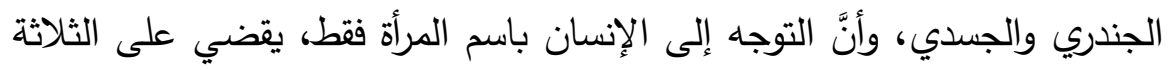
معاً: الأنثى والإنسان والفلسفة. 


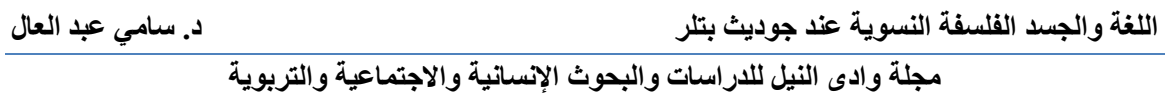

\section{المادر والمراجع}

- Judith Butler, Excitable Speech, A Politics of the Performative, Routledge, New York \& London, 1997.

- Judith Butler, Gender Trouble: Feminism and the Subversion of Identity, Routledge, New York, London, 2007.

- Judith Butler, Bodies That Matter, On the of "Discursive Limits Sex", Roudedge, New York, 1993.

- Judith Butler, Undoing gender, Routledge, New York and London, 2004.

- Judith Butler, Contingent Foundations: Feminism and the Question of "Postmodernism", In: Seyla Benhabib, Judith Butler, Drucilla Cornell, Nancy Fraser(Editors), Feminist Contentions: A Philosophical Exchange, Introduction by Linda Nicholson, Routledge, New York and London, 1995.

- Judith Butler, Is Judaism Zionism?, In: Judith Butler, Jurgen Habermas, Charles Taylor and Cornel West, The Power of Religion in the Public Sphere, Edited with an Introduction by Eduardo Mendieta and Jonathan Van Antwerpen; with an Afterword by Craig Calhoun,(Columbia- SSRC Book), Columbia University Press, New York, 2011.

- Judith Butler, Merely Cultural, In: Social Text 52 / 53: Entitled by Queer Transexions of Race, Nation, and Gender, Magazine is published quarterly (Volume 15, Number 3 and 4, Fall / Winter 1997), Duke University Press, Durham, 1997.

- Judith Butler, Performative Acts and Gender Constitution: An Essay in Phenomenology and Feminist Theory, Theatre Journal, Volume, 40, Number 4 (December, 1988), The Johns Hopkins University Press, 1988.

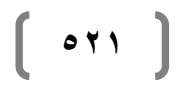




\section{مجلة وادي النيل للاراسات والبحوث الإنسانية والاجتماعية ـ مجلة علمية محكمة}

(ISSN: 2536 - 9555)

- Judith Butler, from "Critically Queer", GLQ: A Journal in Gay and Lesbian Studies, 1: 1, 1993, pp 17-32.

- Judith Butler, Senses of the Subject, Fordham University Press, New York, 2015.

- Judith Butler, the Psychic Life of Power: Theories in Subjection, Stanford University Press, Stanford, California, 1997.

- Judith Butler, When Gesture Becomes Event, In: Anna Street, Julien Alliot and Magnolia Pauker (Editors), Inter Views in Performance Philosophy: Crossings and Conversations, (series: Performance Philosophy, Edited by Laura Cull Ó Maoilearca, Alice Lagaay and Will Daddario), Palgrave Macmillan, London, 2017.

- Judith Butler and Elizabeth Weed, (Introduction), In: The Question of Gender, Joan W. Scott's Critical Feminism, Edited by Judith Butler and Elizabeth Weed, Indiana University Press, Bloomington and Indianapolis, 2011.

- David Gauntlett, Media, Gender and Identity; An introduction, Routledge, London and New York, 2002.

- Eric Pederson and Jurgen Bohnemeyer, On Representing Events- An Introduction, In: Jurgen Bohnemeyer, Eric Pederson (Editors), Event Representation in Language and Cognition,(Series: Language, culture and cognition, Edited by Stephen C. Levinson) Cambridge University Press, New York, 2011.

- Ferdinand De Saussure, Course In General Linguistics, Edited by Charles Bally and Albert Sechehaye, In collaboration with Albert Reidlinger, Translated from the French by Wade Baskin, Philosophical library, New York, 1959.

- Gilles Deleuze, Difference and Repetition. Translated by Paul Patton. Columbia University Press, New York, 1994.

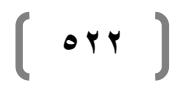




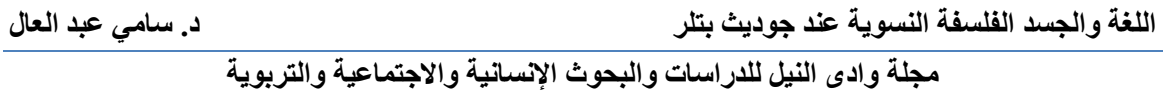

- Gilles Deleuze, Negotiations, Translated by Martin Joughin, Columbia University Press, New York, 1990.

- Goran Sonesson, From the Meaning of Embodiment to the Embodiment of Meaning: A study in Phenomenological Semiotics, In: Tom Ziemke, Jordan Zlatev and Roslyn M. Frank (Editors), Body, Language and Mind Volume 1: Embodiment, Mouton de Gruyter, Berlin- New York, 2007.

- H. W. Fowler, Dictionary of Modern English usage, Revised by Sir Ernest Gowers, Oxford University Press, OxfordNew York, First Edition, 1926.

- Jacques Derrida, "Structure, Sign, and Play in the Discourse of the Human Sciences", In: Writing and Difference, Translated by Alan Bass, Routledge, London, New York, 2003.

- Jacques Lacan, Écrits, A Selection, translated by Alan Sheridan (W. W. Norton, New York, 1977.

- Jacques Lacan, The Psychoses 1955-1956) The Seminar of Jacques Lacan 3, Translated by Russell Grigg, Norton, New York, 1993.

- Jacques Lacan, The Seminar of Jacques Lacan, Book I: Freud's Papers on Technique 1953-54, Edited by JacquesAlain Miller, Translated With Notes by John Forrester, W. W. Norton \& Company, Cambridge University Press, New York, 1988.

- Jurgen Habermas, The Structural Transformation of the Public Sphere :An Inquiry into a Category of Bourgeois Society, Translated by Thomas Burger with the Assistance of Frederick Lawrence, The MIT Press, Cambridge, Massachusetts, 1991.

- Jurgen Habermas, The Theory of Communicative Action (Volume 2), Lifeworld and System: A Critique of Functionalist Reason, Translated by Thomas McCarthy, Beacon Press, Boston, Massachusetts, 1987.

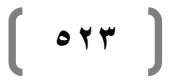


- Kenneth King, Writing in Motion: Body- LanguageTechnology, with a Foreword by Deborah Jowitt, Wesleyan University Press, Middletown, Connecticut, 2003.

- Marcel Danesi, Semiotics of Emoji, The Rise of Visual Language in the Age of the Internet, Series: Bloomsbury Advances in Semiotics, Bloomsbury Academic, Bloomsbury Publishing Plc, London- New York, 2017.

- Marina Sbisà, Austin on Language and Action, In: Brian Garvey (Editor), J.L. Austin on Language, Palgrave Macmillan, New York, 2014.

- Moya Lloyd, Judith Butler, From Norms to Politics, polity Press, Cambridge, 2007.

- Noam Chomsky, Knowledge of Language: Its Nature, Origin, and Use (Series of Convergence Edited by Ruth Nanda Anshen), Praeger, Westport Connecticut, New York, London, 1986.

- Paula Paron, In the Name of the Father: The Paternal Function, Sexuality, Law and Citizenship, Article in Victoria University of Wellington Law Review, July 2006.

- Seyla Benhabib, Feminism and Postmodernism, In: Seyla Benhabib, Judith Butler, Drucilla Cornell, Nancy Fraser (Editors), Feminist Contentions: A Philosophical Exchange, Introduction by Linda Nicholson, Routledge, New York and London, 1995.

- Seyla Benhabib, Sexual Difference and Collective Identities: The New Global Constellation, Signs, Volume 24, Number 2 (Winter, 1999), The University of Chicago Press, pp 335-361 . On this link: http://www.jstor.org/stable/3175645

- Thomas J. Csordas, Body/ Meaning/ Healing,( Series; Contemporary Anthropology of Religion Edited by Robert Hefner), Palgrave Macmillan, New York, 2002.

- Webster's dictionary of English usage, by Merriam-Webster Inc, Publishers Springfield, Massachusetts, 1989.

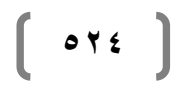

